\title{
Silk: A Promising Biomaterial Opening New Vistas Towards Affordable Healthcare Solutions
}

\author{
Ashutosh Bandyopadhyay ${ }^{1+}$ (D), Suvro Kanti Chowdhury ${ }^{1+}$ (i), Souradeep Dey ${ }^{2+}$ (i), \\ Joseph Christakiran Moses ${ }^{1+}$ and Biman B. Mandal ${ }^{1,2^{*}}$ [D
}

\begin{abstract}
Substantial progress in biomaterial research over the years has culminated in revolutionary technological advancements in the healthcare domain. This has triggered the quest for affordable healthcare solutions with focus on sustainable biomaterials with versatile applications endowed with green fabrication strategies. Silk as a biopolymer has garnered special attention which can largely be attributed to the excellent material properties of silk in addition to its affordability and resource ability. Silk fibroin from various silkworm and spider species and sericin from various silkworm species have been researched for their potential applications in the healthcare industry such as tissueengineered grafts, cancer therapeutics, high-throughput tissue-on-chip models, food preservatives, biomedical imaging, biosensing, biomedical textiles, implants, cosmetics and bioremediation products. The present review mainly focusses on the various sources of silk fibroin and its relevant properties that have been conferred to it by nature. Moreover, recent developments, progress and prevalent modalities of healthcare industry that involve the application of silk fibroin and sericin have been outlined in the present review.
\end{abstract}

Keywords: Silkworm silk, Spider silk, Biomedical research, Biomaterials, Silk sericin, Silk fibroin, Spidroin

\section{Introduction}

Biomaterial by definition is any material that is intended for use in the fabrication of medical device or implant/graft to replace function of defective body tissue in a safe, economic and reliable manner ${ }^{1}$. An ideal biomaterial endowed with biocompatibility, bioactivity, biodegradability, immuno-compatibility and mechanical resilience determines its suitability for use in various biomedical applications. In addition, the biomaterial must also possess appropriate material processing attributes to yield it into different formats. Advances in the field of material science have led to the discovery of novel biomaterials in the past few decades to fuel the revolutionary concept of bringing an ideal biomaterial to clinical reality. Among the various biomaterials, polymers have been in the forefront in biomaterial innovations $^{2}$, owing to their processing flexibility, superior physico-chemical attributes and bioactivity. However, not all shelved synthetic polymers are biocompatible and only handful of synthetic polymers have been approved for their application in various products by the Food and Drug Administration (FDA, USA) ${ }^{3}$. Moreover, the increasing mass volume usage of these polymeric-based composites for various biomedical applications has instigated concerns over the manufacturing processes and disposal issues after intended use of these polymeric biomaterials ${ }^{4}$. Hence, emphasis on greener synthesis and fabrication procedures for polymers and their alternatives is on the rise.
† Ashutosh Bandyopadhyay, Suvro Kanti Chowdhury, Souradeep Dey and Joseph Christakiran Moses equally contributed to this work.

${ }^{1}$ Biomaterial and Tissue Engineering Laboratory, Department of Biosciences and Bioengineering, Indian Institute of Technology Guwahati, Guwahati 781039. Assam India.

${ }^{2}$ Centre

for Nanotechnology, Indian Institute of Technology Guwahati, Guwahati 781039, Assam, India.

*biman.mandal@iitg.ac.in mandal.biman@gmail. 
Immunogenic: A commonly used term for describing the ability of a particular substance such as an antigen or epitope to provoke an immune response in the body.

Proteolytic: It refers to enzymes that are capable of breaking the protein chains into shorter fragments (peptides) and/or amino acids.

Bioremediation: It is the process of purification of contaminated water or soil using plant, microbial or natural enzymes and products.
Silk, a structural protein represents a distinct class of biocompatible and green polymers. It has been focussed upon in biomedical research pertaining to its biodegradability, low immunogenic response and easier processability ${ }^{5}$. Silk can be credited as one of the most ancient materials known to man which has been documented for its use as a medical suture, as early as 131-211 A.D by Greek physician Aelius Galenus ${ }^{6}$. The US pharmacopoeia (USP) classifies the conventional silk sutures which are still in practice today as nondegradable and non-adsorbent, primarily because of the wax coating which protects the silk fibroin (SF) from proteolytic digestion in vivo ${ }^{7}$. In addition to silk being a prime candidate for medical applications such as tissue engineering and drug delivery applications, silk has also been gaining prominence in new frontiers. The mild processing of silk fibres to obtain aqueous-derived regenerated silk fibroin aids in the feasibility of fabricating SF-based photonic devices or biosensors for various biomedical applications ${ }^{8,9}$. Silk has also been proven to be an effective stabilizing agent extending the shelf life of fruits ${ }^{10}$ and bio-pharmaceutical agents like vaccines and antibiotics ${ }^{11}$. For any material to be termed as bioresorbable, it must be physiologically acceptable by the body and broken down to get assimilated or safely eliminated from the body without eliciting any adverse reaction. Silk meets these criteria owing to its biocompatibility and biodegradability traits. Moreover, the greener approaches utilised to process the silk protein from the cocoon and silk glands further endow it as an ideal candidate for various biomedical applications. The present review of silk fibroinbased healthcare materials focusses on the diversity and sources of silk fibroin as well as on the components of silk fibroin that elicit the necessary properties for hitherto utilisation of silk as an ideal biomedical material. Following the exploration of silk as a biomedical material, the present review emphasizes on the real-world, potential, futuristic as well as the prototype technologies that comprise silk as a major component. These healthcare applications of silk have been broadly spanned into tissue engineering, cancer therapeutics, tissue-on-chip models, food technology, biomedical sensors, imaging and electronics, cosmetics, biomedical textiles and bioremediation.

\section{Diversity and Components of Silk 2.1 Silkworm Silk}

Lepidopterans larvae belonging to Bombycidae (mulberry silk) and Saturniidae (non-mulberry silk) have been exploited for commercial silk production, and their classification is based on the feeding habitat. The diversity of different types of silk, their lifecycle and feeding habitats have been exhaustively reviewed elsewhere ${ }^{12,13}$. Silkworm silk protein biopolymer is made up of two components-silk fibroin (SF) and silk sericin (SS) $)^{13}$. In silk, SF forms the central core which imparts the toughness and load-bearing attributes, while SS acts a gumming agent. SS, a group of water-soluble glycoproteins accounts for $25-30 \%(w / w)$ of total silk worm cocoon ${ }^{5}$. The functional diversity observed among the different silks spun by silkworms depends upon the feeding habitat, nutritional indices and environmental factors such as temperature and humidity ${ }^{14}$. These determining factors play a crucial role in the compositional difference of amino acids of SF and differential presence of flavonoids or carotenoid in SS.

To understand the toughness and high strength exhibited by silk fibres, we need to explore the processing of these two proteins in the silk glands (Fig. 1A i-iii). SF is secreted by cells lining the lumen of posterior silk glands, particularly by fifth larval instar silkworms ${ }^{15}$. The SF secreted here exists as a complex a-helixdominated structure referred to as silk-I form ${ }^{16}$. The secreted SF is pushed through the middle silk glands, where heterogeneous SS molecules are added, and the mixture passes through the anterior silk gland from where it is drawn through the spinnerets. The shear force and ionic gradient $/ \mathrm{pH}$ differences experienced at the spinneret (Fig. 1A iv-v) causes the SF to attain antiparallel $B$-sheet crystal conformation, referred to as silk-II form, rendering it as insoluble filament. This semi-crystalline nature of silk-II has been attributed to the toughness of silk, which is due to the unique crystal spinning process exhibited by the silkworms ${ }^{17}$. Silkworms (euarthropods) have evolved this process of folding and crystallization of SF for efficient fibre production and the spinning apparatus between Bombycidae and Saturniidae family has largely remained conserved ${ }^{18}$. However, the variability in between the different silks arises only due to, (i) differential presence and assembly of heavy chain (H-chain), light chain (L-chain) and glycoprotein; (ii) presence of repetitive polypeptide sequences which confer the unique bioactive, physico-chemical characteristics to the silk and (iii) divergent sericin fractions present in different silk varieties. The molecular weight of SF, SS and the repetitive sequence of most commercially important silk varieties are presented in Table 2. These include mulberry silk (Bombyx mori, Bombyx mandarina) and non-mulberry 


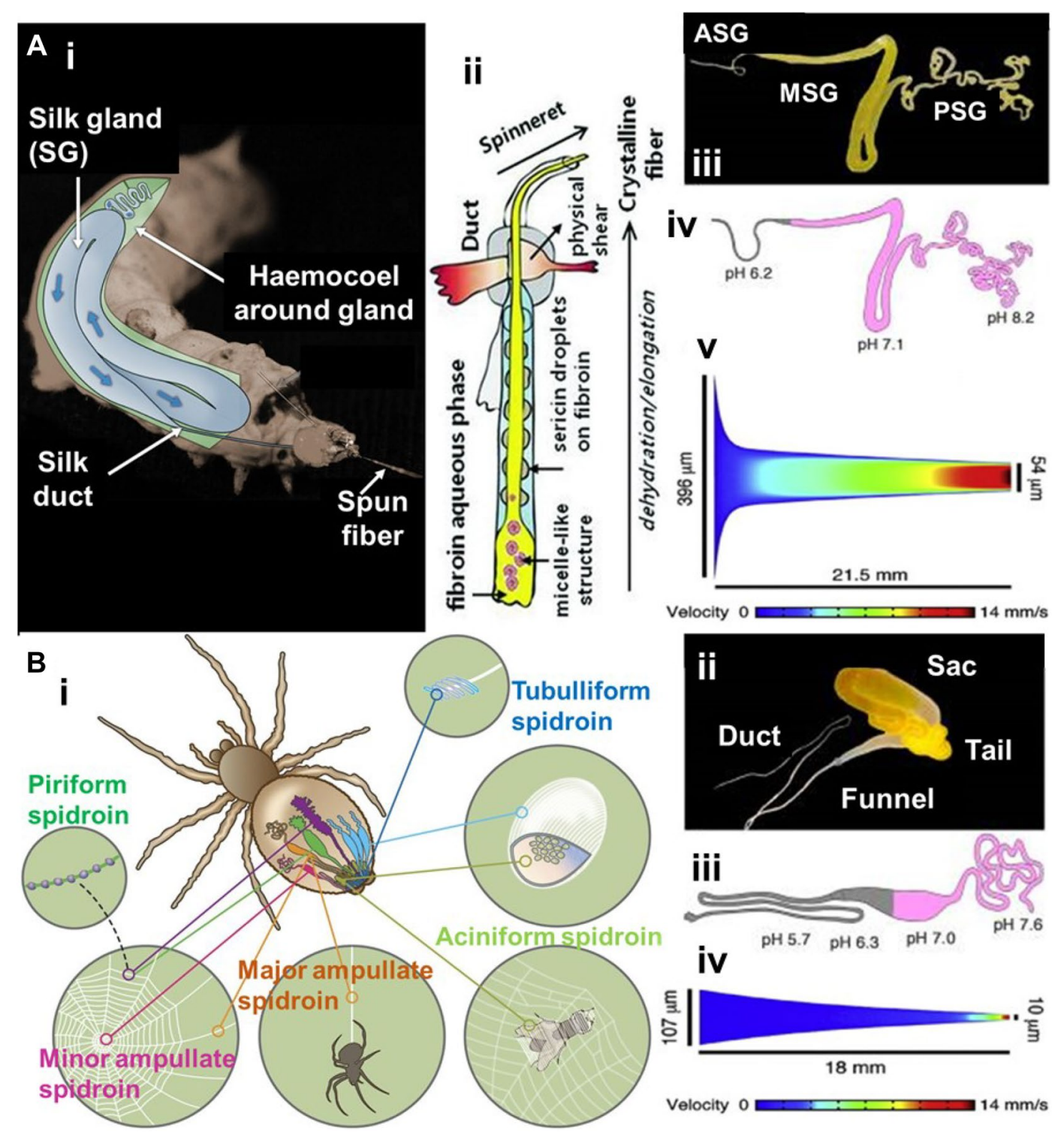

Figure 1: Spinning apparatus of A (i) B. mori silk gland (Copyright 2017, reproduced with permission from Springer Nature publication under creative common license CC-BY) ${ }^{195}$ (ii) spinning duct (Copyright 2016, reproduced with permission from Elsevier) ${ }^{194}$; (iii) anterior silk gland (ASG), middle silk gland (MSG), posterior silk gland (PSG), (iv) different pH conditions seen in B. mori silk gland (Copyright 2016, reproduced with permission from MDPI publication under creative common license CC-BY), (v) velocity vector as seen in B. mori silk gland (Copyright 2016, reproduced with permission from Elsevier) ${ }^{194}$ B spider, (i) depicting seven silk glands each producing its distinct spidroin (Copyright 2015, reproduced with permission from Springer Nature) ${ }^{196}$; (ii) major ampullate silk gland, (iii) different $\mathrm{pH}$ conditions (Copyright 2016, reproduced with permission from MDPI publication under creative common license CC-BY) ${ }^{197}$; (iv) velocity vector found along major ampullate silk gland (Copyright 2016, reproduced with permission from Elsevier)

silk (Antheraea assama-Indian muga, Antheraea mylitta-Indian tropical tasar, Antheraea pernyi-Chinese temperate oak tasar, Antheraea yamamai-Japanese oak silk and Philosamia ricini-Indian eri silk).

\subsubsection{Silk Fibroin}

The Lepidoptera larvae of Bombycidae family spins twin delicate filaments of SF enwreathed by SS exhibiting a triangular smooth cross-section as observed at the microscopic level ${ }^{19}$. The mulberry SF consists of an H-chain, an L-chain and a glycoprotein (fibrohexamerin fhx/P25), assembled 
Glycosylation: It refers to the reaction of a carbohydrate, a glycosyl donor, and hydroxyl or other functional groups of another molecule, a glycosyl acceptor. In biological sciences, it is commonly used to refer to the enzymatic reaction that leads to the attachment of glycans to proteins and other organic molecules

Anticoagulant: Anticoagulants refer to the group of compounds or molecules that prevent or reduce coagulation of blood thereby prolonging the clotting time. They are also known as blood thinners.

Antioxidant: Antioxidants are compounds that prevent oxidation, especially of stored organic and food products, thereby limiting their spoilage. Some examples include Vitamins $\mathrm{C}$ and E, thiols, etc. in the molar ratio of $6: 6: 1$. The H-chain and L-chain are linked by disulphide linkage and six such hetero-dimers get associated with a single P25 at the H-chain moiety through hydrophobic interactions ${ }^{20}$. The $\mathrm{N}$-terminal has glycosylation containing mannose and glucosamine residues ${ }^{21}$. Poly-(glycine-alanine) repeats (GAGAGS, GAG AGY) forms the primary repeat sequences which accounts for the $ß$-sheet crystallite regions observed in the silk. The crystallite regions are embedded between amorphous a-helical regions, and these crystallite regions exhibit strong interchain interactions through hydrogen bonding, contributing to the silk's superior strength ${ }^{22}$.

The silk spun by Lepidoptera larvae belonging to the Saturniidae family is very much distinct from the mulberry silk. The fibroin L-chain (flc) and fhx/P25 are absent in the non-mulberry silk varieties. Evolutionarily the gene encoding for fhx/P25 is thought to represent a paralog of gene(s) which might have adopted new functions other than the fibre formation as noticed in Bombycidae family ${ }^{23}$. Hence, the genes encoding for flc and fhx/P25 have been lost in the ancestors of Saturniidae family. The $\mathrm{H}$-chain forms homodimers which constitutes the fibroin core in the silk fibre. Unlike the poly-(glycine-alanine) repeats which constitute the crystalline domains of mulberry silk, the non-mulberry silk possesses poly-(alanine) repeats. The silk fibroin arising from the Saturniidae larvae spinneret also consist of two fibroin monofilaments enveloped by SS, similar to $B . m^{18} i^{18}$. However, the monofilaments of non-mulberry silk disorient during fibre formation, due to the inability of $\mathrm{H}$-chains to pack closely owing to the higher percentage of bulky side chains present in the $\mathrm{SF}^{24}$. Thus, the nonmulberry cocoons appear more fibrous (flattened cross-section of SF) in nature which is evident from the density difference between the mulberry and non-mulberry silk fibres.

\subsubsection{Silk Sericin}

Silk sericin, an amorphous glycoprotein is produced in the middle silk gland and constituted primarily by serine (32-34\%), aspartic acid (14$16 \%)^{25}$ and other amino acids such as histidine, threonine, tyrosine and glutamic acid ${ }^{26}$. Sericin exists as random coil conformation and the molecular weight of sericin varies between 10 and $350 \mathrm{kDa}$. The fraction of sericin obtained solely depends upon the extraction protocol ${ }^{26,27}$. For instance, hydrolysates of sericin obtained through plain water boiling are mostly low molecular weight (10-20 kDa), while other methods [usage of alkali or high temperature, high pressure) HTHP)] yields high-molecular-weight fractions ${ }^{28}$. Five different fractions of sericin from $B$. mori have been reported, namely ser- 1 , ser- 2 , ser3 , ser- 4 and ser-5 ranging between 24 and $400 \mathrm{kDa}^{25}$. The non-mulberry silk sericin varies from the mulberry silk varieties, for instance, the glycine content is lower in A. mylitta when compared to B. mori. Several sericin fractions have been reported from non-mulberry silk which is listed in Table 1. Though sericin is considered as a by-product and deemed as waste in sericulture industry, it has attracted immense interest from the cosmetic and pharmaceutical applications owing to its antibacterial, antioxidant, anticoagulant and wound healing properties ${ }^{25,28,29}$.

\subsection{Spider Silk}

Unlike the euarthropods, spiders (order Araneae) rely on silk for the entire life span and their total dependence on it for their evolutionary success ${ }^{30}$. Based on the web weaving type, spiders could be classified as either orb web weavers or nonorb web weavers. Orb weavers capture their prey on the surface of the web, whereas the non-orb weavers entrap their prey inside intricate maze. Much of the current day research is focussed on orb-weaving spiders and interestingly these spiders use up to six different types of silks and a silk-like glue produced in seven distinct organs (Fig. 1Bi) to weave a single intact orb ${ }^{31}$. Each of these six types of structural silk protein is composed of repetitive monomers called spidroins comprised of a variable central core distinct for each silk flanked by non-repetitive amino and carboxy terminals ${ }^{32}$. The variable central core has modular repeat units which confer the variation in mechanical strength. The dragline silk secreted by major ampullate silk gland has a toughness of $180 \mathrm{MJ} / \mathrm{m}^{3}$, whereas the auxiliary spiral thread secreted by minor ampullate silk gland has a toughness of $150 \mathrm{MJ} / \mathrm{m}^{331}$. The aciniform silk secreted by aciniform silk gland responsible for soft inner egg case wrapping has a toughness of $250 \mathrm{MJ} / \mathrm{m}^{331}$.

Much similar to silkworm sericin, spiders too coat their capture silk with a special glue-like substance secreted from the aggregate gland ${ }^{33}$. This adhesive coating is primarily comprised of lipids, phosphorylated glycoproteins and organic low-molecular-weight components such as $\gamma$-aminobutyramide, choline, betaine and isethionic acid $^{34}$. Listed in Table 1 are the different structural silks secreted by orb-weaving spider's abdominal glands namely major and minor 


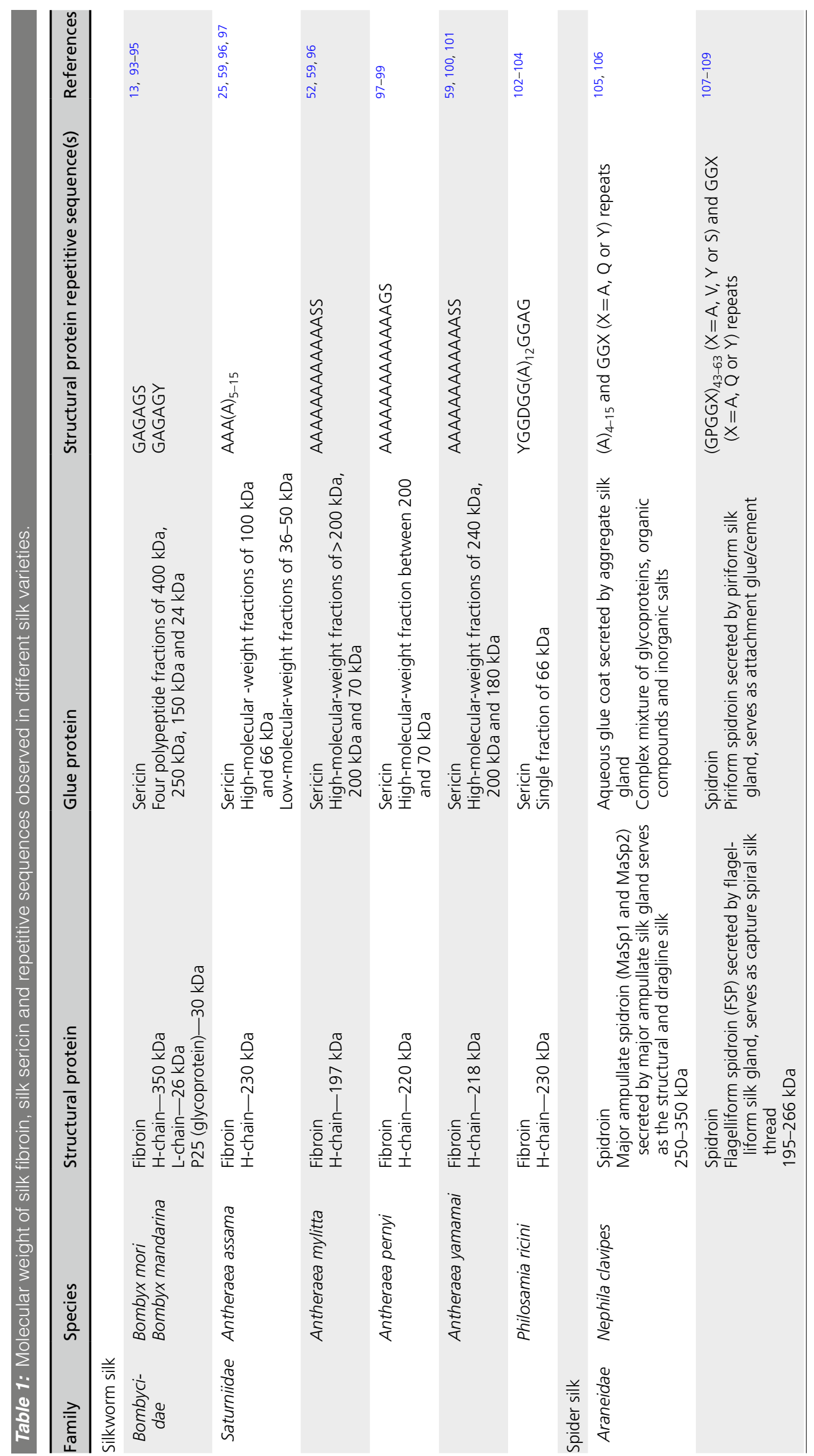




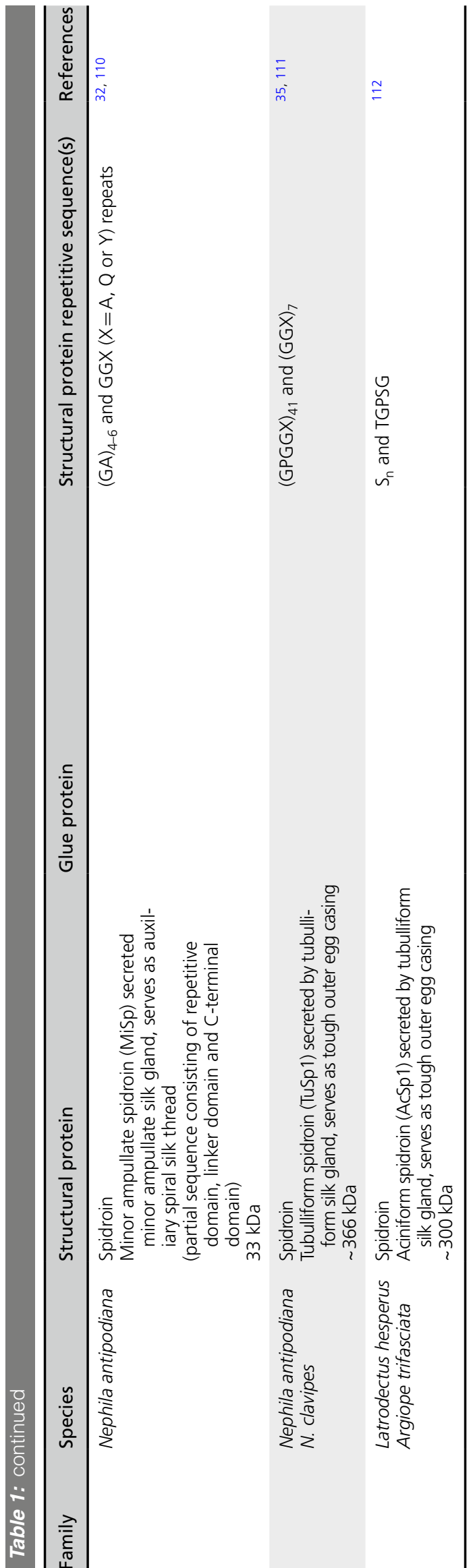

ampullate, tubuliform, flagelliform, aciniform, piriform and aggregate silk glands. Major research focus has been attributed to the major ampullate spidroins (MAS) which constitute the dragline silk of orb weavers (Fig. 1B ii-iv). The MAS complex is majorly constituted by two proteins namely, major ampullate dragline silk proteins 1 (MaSp1) and $2(\mathrm{MaSp} 2)^{35}$. Both MaSp1 and MaSp2 proteins comprise poly-alanine domains and poly-glycine rich domains, but the main difference is that MaSp2 accounts for $15 \%$ proline in the total amino acid content, while MaSp1 is proline free ${ }^{36}$. Each orb weaver spider's silk varies based on the ratio of MaSp1 and MaSp2 content, for instance, Nephila clavipes has $81 \%$ MaSp1 and 19\% MaSp2, while Argiope aurantia has 41\% MaSp1 and 59\% MaSp2.

\section{Features of Silk Befitting for Biomedical Research 3.1 Silkworm Silk}

The amino acid compositional diversity and differential presence of repetitive units [poly(alanine) or poly-(glycine-alanine)] govern the distinct physico-chemical properties noticed in the different silk varieties which are listed in Table 2. The relationship between the physical properties and chemical constituency of fourteen types of silk, inclusive of the commercially important mulberry and non-mulberry silk highlighted in the current section, has been reported elsewhere ${ }^{19}$. As stated earlier, the fibre packing density of mulberry silk $\left(1.35-1.37 \mathrm{~g} / \mathrm{cm}^{3}\right)$ is higher in comparison to the non-mulberry silk $\left(1.30-1.31 \mathrm{~g} / \mathrm{cm}^{3}\right)^{37}$. This high order of packing may be attributed to the compact assembly of fibroin H-chain, L-chain and fhx/P25 in the ratio 6:6:1, contributing to the mulberry silk's high tensile strength in comparison to non-mulberry silk, as noticed in Table 2. However, the lack of orientation in $\mathrm{H}$-chain homodimers and the inability to form a close association due to presence of bulky side chains of hydrophobic amino acids, contributes to higher yield rates (higher extension percent while breaking). The disoriented entangled $\mathrm{H}$-chains open up resulting in higher breaking extension ${ }^{24}$. Additionally, the poly-(glycine-alanine) repeats namely GAGAGS and GAGAGY are responsible for forming the crystalline regions in the $B$-sheet domains confer heterogeneity along the SF peptide. On the contrary, the homogenous poly-alanine repeats in the non-mulberry silk result in uniform transitions during tensile deformations, thus contributing to the mechanical resilience of non-mulberry silk. 


\begin{tabular}{|c|c|c|c|c|c|c|}
\hline Family & Species & Extension (\%) & $\begin{array}{l}\text { Tensile strength } \\
(\mathrm{GPa})\end{array}$ & $\begin{array}{l}\text { Toughness (GJ/ } \\
\mathrm{m}^{3} \text { ) }\end{array}$ & $\begin{array}{l}\text { Crystallinity } \\
(\%)\end{array}$ & References \\
\hline \multicolumn{7}{|l|}{ Silkworm silk } \\
\hline $\begin{array}{l}\text { Bombyci- } \\
\text { dae }\end{array}$ & $\begin{array}{l}\text { Bombyx mori } \\
\text { Bombyx manda- } \\
\text { rina }\end{array}$ & $24.5 \pm 10.1$ & $0.57 \pm 0.12$ & $0.103 \pm 0.057$ & $30.5-33.7$ & $19,41,113$ \\
\hline \multirow[t]{5}{*}{ Saturniidae } & $\begin{array}{c}\text { Antheraea } \\
\text { assama }\end{array}$ & $29.2 \pm 10.7$ & $0.36 \pm 0.10$ & $0.068 \pm 0.031$ & 34.7 & 19,113 \\
\hline & $\begin{array}{c}\text { Antheraea } \\
\text { mylitta }\end{array}$ & $26-39$ & $0.25-0.45$ & 0.13 & 39.5 & $24,114,115$ \\
\hline & Antheraea pernyi & $29.6 \pm 10$ & $0.43 \pm 0.08$ & $0.079 \pm 0.027$ & 30.9 & $19,114,116$ \\
\hline & $\begin{array}{c}\text { Antheraea } \\
\text { yamamai }\end{array}$ & $35.6 \pm 13.7$ & $0.39 \pm 0.07$ & $0.092 \pm 0.043$ & 32.5 & 19,117 \\
\hline & Philosamia ricini & $29.4 \pm 8.0$ & $0.47 \pm 0.11$ & $0.086 \pm 0.030$ & 25.8 & $19,41,113$ \\
\hline \multicolumn{7}{|c|}{ Spider silk (orb weavers) } \\
\hline \multirow[t]{3}{*}{ Araneidae } & $\begin{array}{l}\text { Araneus diade- } \\
\text { matus } \\
\text { Dragline spidroin }\end{array}$ & 27 & 1.1 & 0.180 & $\sim$ & 31 \\
\hline & $\begin{array}{l}\text { Argiope trifas- } \\
\text { ciata } \\
\text { Dragline spidroin }\end{array}$ & $\sim 30$ & $6.9 \pm 0.4$ & $\sim 0.09$ & $17-29$ & 118,119 \\
\hline & $\begin{array}{l}\text { Nephila clavipes } \\
\text { Dragline spidroin }\end{array}$ & $12-37$ & $6.9-11$ & 0.08 & $10-15$ & 120,121 \\
\hline
\end{tabular}

Silk films and scaffolds fabricated from the regenerated non-mulberry silk fibroin also exhibited similar strain hardening behaviour ${ }^{38}$. Moreover, silk possesses a strength-to-density ratio that is ten times more than that of the steel ${ }^{39}$, affirming their suitability for load-bearing applications.

As discussed earlier, SF's main structural component is the H-chain which is amphiphilic, consisting of hydrophobic crystallite domains (made up of $B$-sheets) interspaced between hydrophilic amorphous domains (made up of a-helices). Hence, SF can be considered a co-block polymer, which exists in an anionic $(\mathrm{pI}=4)$ form in neutral solution ${ }^{40}$. The basic/acidic amino acid ratio of the non-mulberry silk is slightly higher than the mulberry counterpart. This in turn contributes to the SF's varied surface property in terms of hydrophilicity and hydrophobicity and subsequently plays a crucial role in surface wettability of biomaterials derived from the regenerated silk solution. Adding to the notion, it was found that the grand average of hydropathicity (GRAVY) indices of mulberry silk is higher than the nonmulberry silk ${ }^{41}$. Crystallinity in silk-II conformation is conferred by the B-sheet structure that is packed in an asymmetrical fashion. If the crystallinity of the crystallite domains is considered, the non-mulberry silk varieties are more crystalline than the mulberry silk (as seen in Table 2). This is attributed to the poly-alanine repeats found in the crystallite domains of non-mulberry silk which constitute tight $B$-sheet crystals in comparison to the poly-(glycine-alanine) repeats found in the mulberry silk. Crystallinity also remains to be a crucial factor for biodegradation of regenerated SF-based materials in vivo. By controlling the degree of crystallinity of $B$-sheets through various physical and chemical treatments, the biodegradation rate and the water stability of the SF-based materials can be modulated ${ }^{16,42}$. Owing to the extraordinary physico-chemical properties and high thermal stability (for fibres, $T_{\mathrm{g}}=190$ $200{ }^{\circ} \mathrm{C}^{40}$; for films obtained from regenerated SF from mulberry and non-mulberry silks, $T_{\mathrm{g}}=224-290{ }^{\circ} \mathrm{C}^{43}$ ), silk-based biomaterials are compatible to most of the sterilization methods. This is very advantageous, as in most polymerbased matrices sterilization through autoclaving or any heat-based method, denatures the polymer network, however, silk overcomes this drawback.

\subsection{Spider Silk}

Spider silk unlike silkworm silk has not been explored to a great extent largely due to the difficulty in rearing and collection in large quantities for commercial upscaling. Though instances
Sterilization: It is the process of elimination, removal, killing or deactivation of life forms and biological agents (e.g., fundi, bacteria, viruses, spores, and prions) in a specified surface or volume. Some commons methods used include heat, chemicals, irradiation, high pressure and filtration. 
of spider silk being used for wound healing by the ancient Greek ${ }^{44}$ and as fishing nets by the Australian aborigines ${ }^{45}$ have been found, but it was not until the recently that a full-scale spider silk has been materialized ${ }^{44}$. Howbeit, the mechanical superiority of spider silk has been documented to match the strength of Kevlar $\left(4 \times 10^{9} \mathrm{~N} / \mathrm{m}^{2}\right)$ while being six times more flexible than Kevlar. This uniqueness of the spidroin has pushed it to be recombinantly engineered and produced in bacterial systems for biomedical applications, particularly MaSp1 and MaSp2 which have been well studied ${ }^{30}$. Interestingly, the elasticity of spider silk has been attributed to the phenomenon of 'supercontraction' when hydrated or under humid conditions, causing it to contract to half of its dry length. This could be attributed to the entropy-driven rearrangement of GPGGX motifs of MaSp spidroins giving rise to a recoiling effect of dragline silk ${ }^{46,47}$. The mechanical properties bestowed by spider silk may deem it to be an ideal candidate for biomedical textile or biosensing applications. Additionally, the recent reports of its applications in tissue engineering owing to its biodegradability, presence of inherent cell adhesion motifs and possibility to tailor new properties have given a new lease of life for this ancient material $^{48}$.

\subsection{Affordability and Resourceability}

One of the utmost advantageous features of silk fibroin as a biopolymer over other biopolymers is the sheer commercial scale in which silkworm silk is produced (Fig. 2A) in tonnes per annum. Notably, more than $70 \%$ of world silk production is from the Asian subcontinent with China and India being the major players. Mulberry silk ( $B$. mori) accounts for $90 \%$ of global silk production $^{12}$. Sericulture is mainly concentrated in the tropical and sub-tropical regions, with the prevalence of bivoltinism (two generations per year) and multivoltinism (multiple generations per year) in silkworms, there is year round availability of silk ${ }^{49}$. On the other hand, biopolymers like collagen-I are primarily extracted from animal sources (porcine, bovine skin, bovine tendon) and human cadavers. The major drawbacks associated with animal-sourced collagen are contamination with pathogens, disease transmission through prions, immunogenicity and antigenicity related with telopeptides ${ }^{50}$. To overcome these drawbacks, there is very critical and stringent quality control associated with downstream processing of collagen deemed for biomedical use. This ultimately results in increase of production cost. The extraction of silk fibroin from cocoons or from silk glands is relatively easy and the greener aqueous processing has rendered US FDA approval of silk fibroin for drug delivery, surgical suture and applications pertaining to tissue engineering ${ }^{51}$. The facile processing and purification strategies have resulted in cost effectiveness in production of silk fibroin solution ${ }^{5,52}$. For instance, $1 \mathrm{~mL}$ of $0.3 \%(\mathrm{w} / \mathrm{v})$ collagen-I (from bovine skin) costs $\sim \$ 12$ (USD), while a $\mathrm{mL}$ of $0.3 \%(\mathrm{w} / \mathrm{v})$ silk fibroin solution (mulberry $B$. mori) costs just $\sim$ \$ (USD) (Sigma, USA, cell culture reagent grade; information retrieved from https://www.sigmaaldrich.com). Though synthetic polymers, for instance, poly(D,L-lactic acid) (PLA), polycaprolactone (PCL) and poly(D,L-lactic-co-glycolic acid) (PLGA) are relatively inexpensive than biopolymers, they are plagued with drawbacks of little or no bioactivity and biodegradability, toxic degradation products and non-resorbability. Moreover, these synthetic polymers do not meet the requirements of natural polymers (Fig. 2B).

\subsection{Processing Feasibility and Ease in Modification}

Mulberry silk cocoons can be subjected to aqueous processing which is a major advantage when compared to other biopolymers. For instance, biopolymers such as collagen, chitosan need to be processed in acidic conditions, which is a major concern when dealing with delivery of bioactive molecules or cells for therapeutic applications. On the contrary, regeneration of silk fibroin from mulberry silk cocoons involves two steps. (i) degumming or process of removal of silk sericin from raw silk using $0.02 \mathrm{M}$ sodium carbonate, (ii) dissolution of obtained silk fibroin fibres in $9.3 \mathrm{M}$ lithium bromide (chaotropic agent) to obtain regenerated silk fibroin solution after thorough dialysis in water to remove $\mathrm{LiBr}^{5}$. Few protocols also use a ternary system, namely Ajisawa's method (ethanol/water/ $\mathrm{CaCl}_{2}$ in $92 / 144 / 111 \mathrm{w} / \mathrm{w}$ ratio) for dissolution of degummed silk fibres, but the yield of the regenerated silk fibroin is relatively less than the former protocol ${ }^{53,54}$. The obtained aqueous regenerated silk fibroin solution can be concentrated and stored in liquid form in cold storage ( 1 month or lesser) and in lyophilized powder form at $25^{\circ} \mathrm{C}$ for longer durations. Non-mulberry degummed silk fibres dissolution with the help of chaotropic reagents such as lithium bromide, lithium thiocyanate do not result in good yield of the protein ${ }^{12,13}$. This is partly because of the amino acid composition, 
A

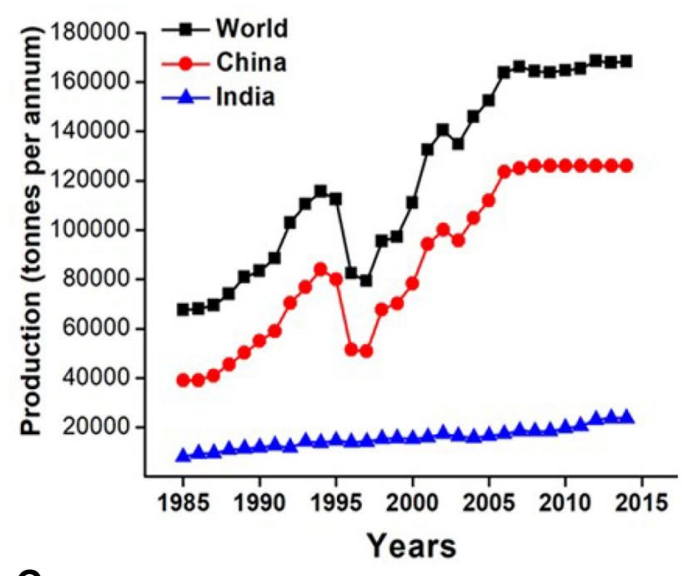

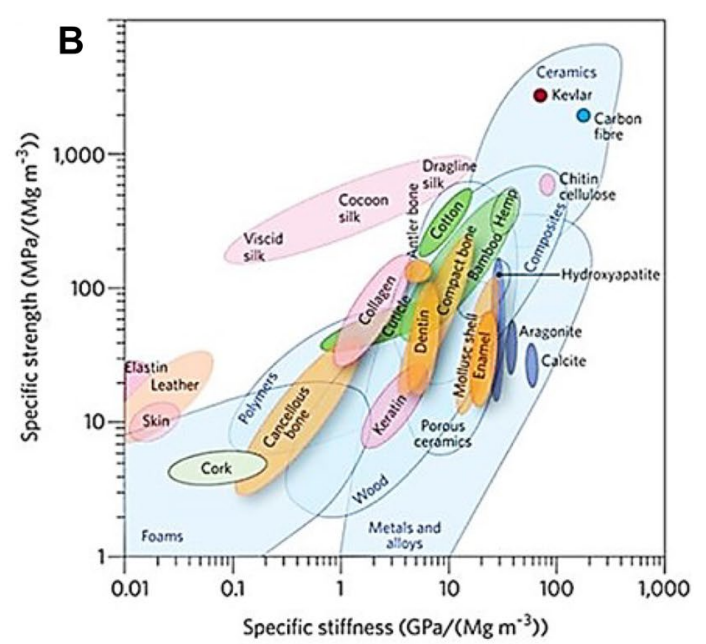

$\mathbf{v}$
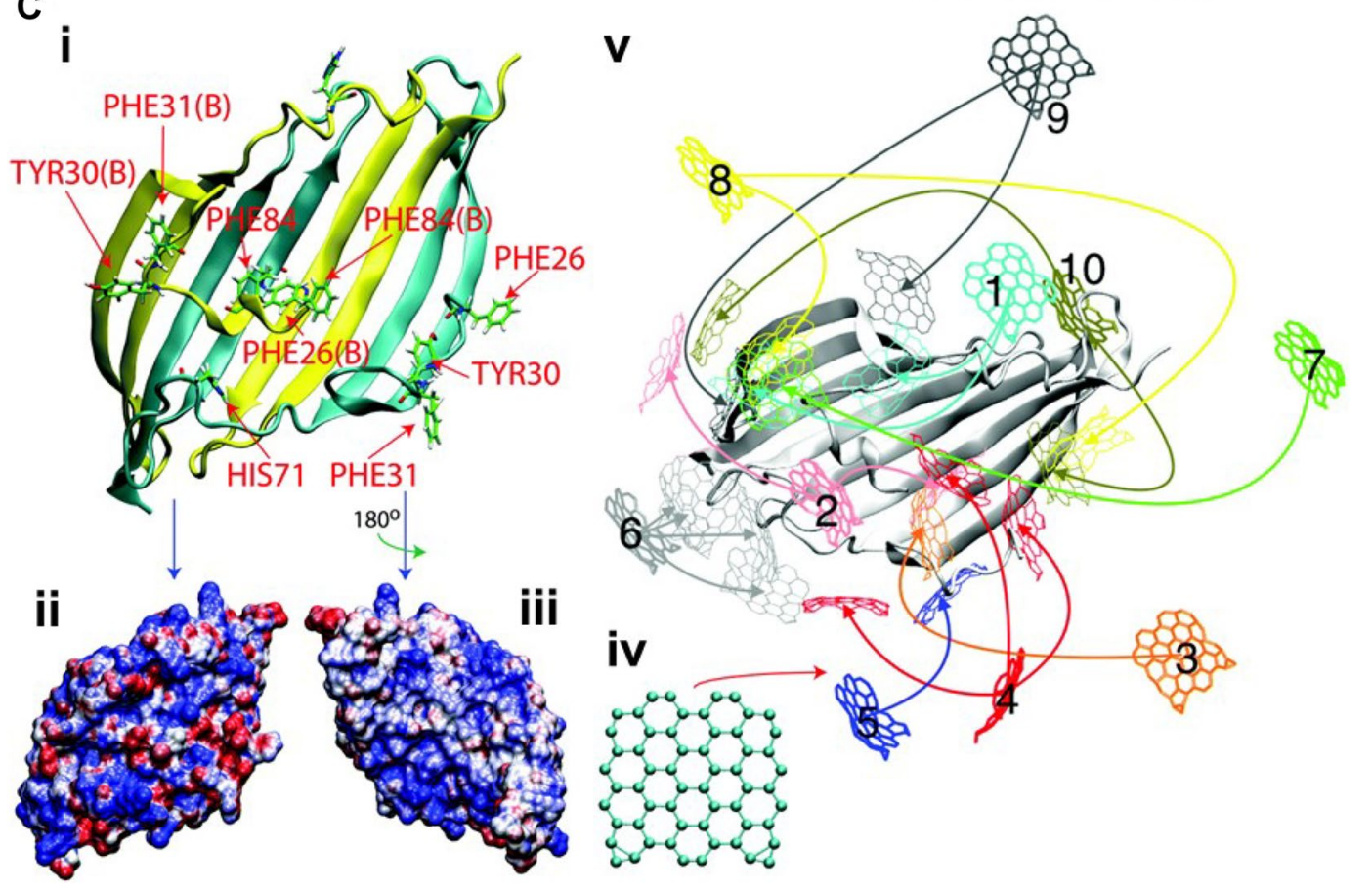

Figure 2: A Production quantity in tonnes per annum for raw silk. (data obtained from FAOSTAT-Food and Agriculture Organization of the United Nations Statistics Division h

QP, Assessed on 20th March 2019); B Ashby chart for strength vs. stiffness performance of natural and synthetic materials, silk outperforming some of the most commonly used synthetic polymers (Copyright 2014, reproduced with permission from Springer Nature $)^{198}$; C simulated visualization of (i) B. mori heavy chain N-terminal domain whose electrostatic charge distributions are seen in ii, iif for docking (iv) graphene at (v) various docking positions (Copyright 2018, reproduced with permission from RSC) ${ }^{80}$ for fabrication of composites with predictive physical properties.

where non-mulberry silk fibroin is constituted $\sim 47 \%$ by alanine, which tend to take up a-helical conformation in aqueous solution ${ }^{55,56,}$ getting packed closely thereby preventing chaotropic agents from disassociating the hydrogen bonding between chains. These non-mulberry silk fibroins, however, are endowed with unique physico-chemical properties such as the presence of poly(A) stretches which confer superior mechanical resilience ${ }^{57,58}$ and presence of RGD tripeptide which confer cell adhesion features ${ }^{59}$ and thus exploiting it for tissue engineering applications is advantageous. To overcome this, silk fibroin from the silk glands of fifth instar silk worms (A. mylitta ${ }^{52,60,61,}$ A. assama ${ }^{57,58,62-64}, P$. ricin $i^{65-67}$ ) was directly dissolved in anionic surfactant, sodium dodecyl sulphate (SDS) $(1 \% \mathrm{w} / \mathrm{v})$ to disrupt the hydrogen bonding in the native silk 

refers to the loss of quaternary or tertiary or secondary structure of biological molecules such as proteins and nucleic acids produced as a result of external stress (heat and pressure) or chemical (strong acid or base, organic/inorganic salts) treatment.

Electrospun: It refers to the product formed by electrospinning. Electrospinning is a method of nano-fibre production using an electric force to draw out charged threads of polymeric solutions or melts.

Transgenic: It refers to the production of genetically modified organisms that have been produced by the transfer of gene/genetic material from one organism to another by natural means or genetic engineering techniques. It brings about a change in the phenotype of the targeted organism.
Denature: Denaturation

fibroin, and dialysed to remove SDS to obtain the aqueous regenerated silk fibroin solution. The protein thus obtained maintains the biomechanical properties of SF (unlike chaotropic agents which shear the protein during isolation) and feasible to get high yields (1-1.5 g protein per silk gland), thus making the process amenable for scaling up in biomedical research ${ }^{52}$. Other harsher approaches for dissolving silk have been reported recently which mainly involve the application of ionic liquids such as 1-butyl-3-methyl imidazolium acetate (BMIAc) (A. mylitta ${ }^{68,69}$ and A. assama $^{70}$ ), 1-butyl-3-methylimidazolium chloride (BMIMCl) (B. mori ${ }^{71}$ ). However, these harsher chemical agents irreversibly denature the isolated SF and the structural integrity of formed scaffolds or matrices is questionable ${ }^{72}$.

The regenerated aqueous SF solution is amenable to be processed and formed into various formats such as 2D films, 3D silk sponges, electrospun membranes, microparticles, nanoparticles, hydrogels, 3D printed constructs, micropatterned surfaces, microfluidic and micromolded devices. Listed in Table 3 are few of the interesting instances of silk being used in different formats for myriad of applications in healthcare and other allied endeavours. In addition to the processing feasibility, silk structure is well explored and offers the opportunity to chemically modify it for more precise applications ${ }^{73}$. For instance, addition of another polymer chain such as polyethylene glycol or oligosaccharides or specific peptide chains (RGD tripeptide) could be done through coupling reactions (cyanuric chloride activated or carbodiimide $)^{74,75}$. Similarly, grafting of chemical moieties could also be done in silk fibroin. To achieve UV photo-crosslinking, poly-methacrylate grafting has been reported ${ }^{76}$ for $3 \mathrm{D}$ printing applications. The versatility of silk matrices is also endowed with thermal stability, which allows them to be autoclaved to sterilize them post-fabrication ( $\beta$-sheet-induced matrices $)^{77}$. Silk matrices unlike other polymers such as PCL, PLGA which are thermosensitive, can withstand many sterilization techniques such as ethylene oxide treatment, $70 \%$ ethanol disinfection, $\gamma$-irradiation, UV irradiation and the mechanical properties are not drastically altered ${ }^{78}$.

Inflammatory cytokines: These are signalling molecules produced by immune cells (helper T cells and macrophages) that are involved in the promotion (proinflammatory) or suppression (anti-inflammatory) of inflammatory response.

\subsection{In Silico and Recombinant Engineering Strategies}

With the age of machine-learning seeping into all aspects of study, biomaterial design is no exception. Silk as a biomaterial has been investigated at large in the last few decades and utilising predictive biomaterial design strategies enables material scientists to tailor the material more precisely to suit the need. In a pioneering study, Wong et al. describe an iterative material design process involving computation simulation, genetic engineering and mechanical characterization to obtain silk fibres with predictive mechanical properties ${ }^{79}$. Similarly, understanding the precise position of docking a molecule for composite fabrication would desirably help in improving its physico-chemical properties. In these lines, molecular dynamics simulation was utilised to determine the binding position of graphene in B. mori silk fibroin (Fig. 2C) ${ }^{80,81}$. Multiscale modelling approaches also enables us to predict the structure-function properties in bottom-up approach ${ }^{82}$. For instance, silk hydrogels made through binary solvent-induced conformation transition approach rely solely on hydrogen bonding and atomistic modelling enabled to modulate the degree of bonding thus tailoring the hydrogel properties ${ }^{83}$.

Spider silk, despite its phenomenal properties is difficult to obtain in large quantities, because rearing spiders is difficult owing to their cannibalistic nature. This has been overcome using recombinant engineering, where partial or full sequences of spider silk have been expressed in bacterial, yeast, mammalian, insect, transgenic plants and animal hosts ${ }^{84}$. Knowing the structural information of spider silk through sequencing has enabled it to be engineered with other useful domains such as for cell adhesion (fibronectin) or anti-microbial peptides, to obtain fusion spidroin peptides for tissue engineering applications ${ }^{85,86}$.

\subsection{Biocompatibility of Silk Implants}

The antigenicity and cytocompatibility of SFbased scaffolds (in different forms such as $3 \mathrm{D}$ porous matrices, $2 \mathrm{D}$ electrospun mats and films, gels, micro/nanoparticles) have been extensively studied over the years ${ }^{38,40}$. The studies have affirmed the materials' compatibility for the intended use under in vitro conditions as well as in animal models. Implanted 3D SF scaffolds in a rat model showed lower expression of TNF-a IFN- $\gamma$, IL-4, IL-6 and IL-13 (M1 macrophagespecific genes) immune response genes ${ }^{87}$ suggesting that SF activates the humoral-mediated immune response without C3 compliment activation. The host reaction post-implantation of the biomaterial determines the fate of the implant. The initial immune recognition, followed by subsidence of M1-specific inflammatory cytokines and finally the switch over to M2 


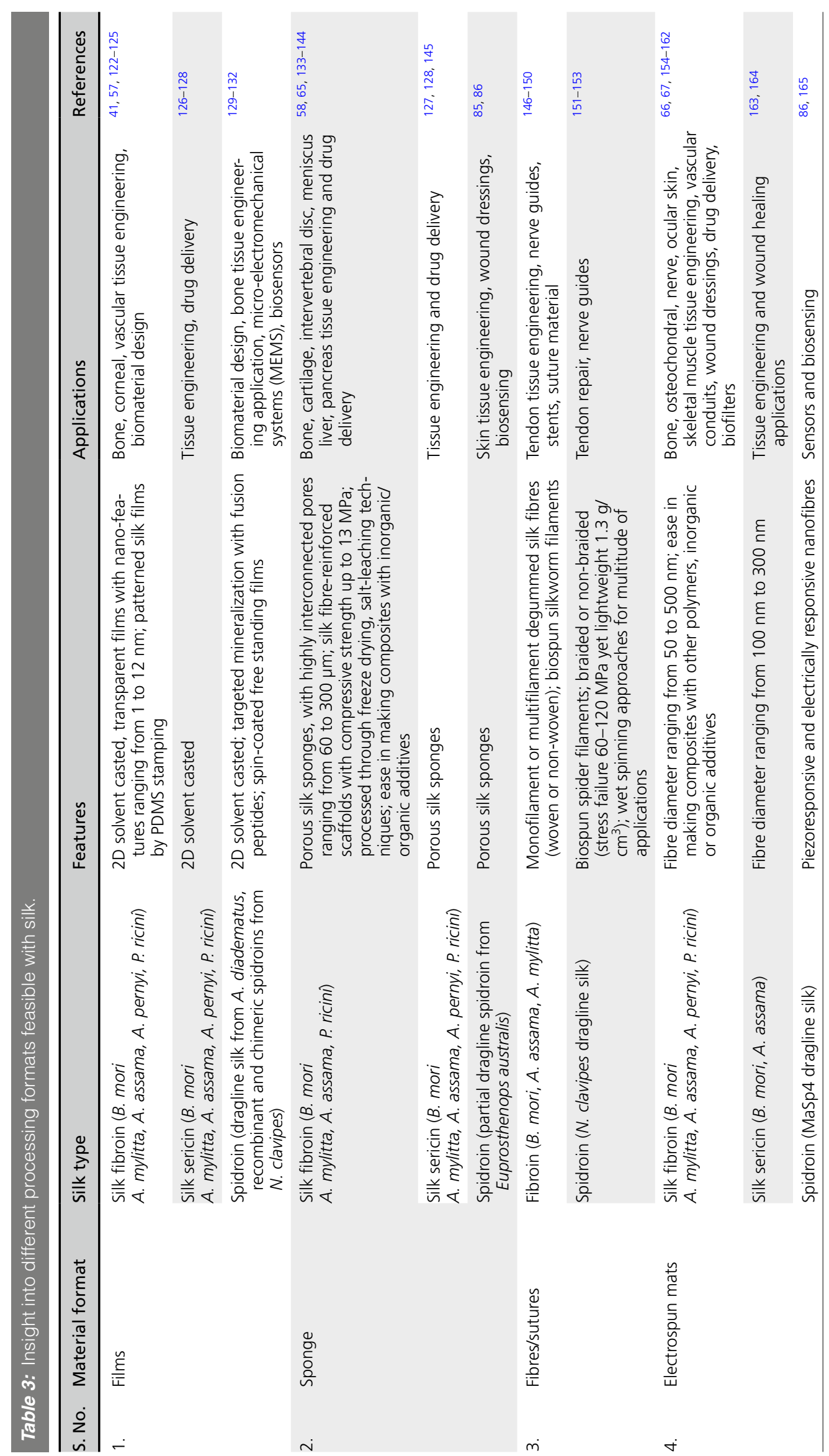




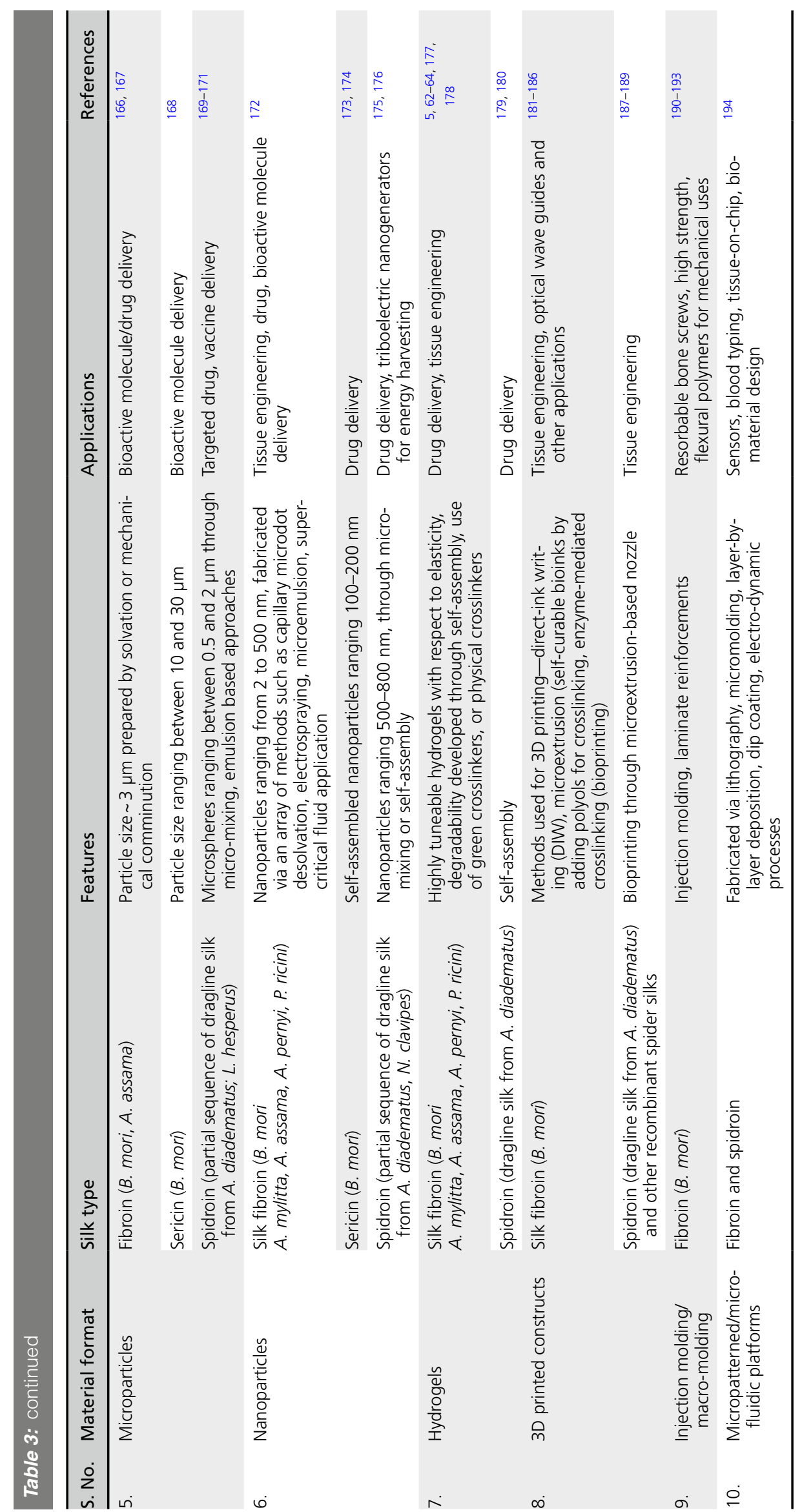


macrophage commitment is crucial for the biomaterial to be accepted. Assessing reports of the past 15 years, it has been found that, for the alkali heat purified SF-based materials exhibited promising biocompatibility mainly due to their cytocompatibility and lower immunogenic potential as compared to collagen, PLGA and many more other polymers ${ }^{40}$. However, careful removal of sericin from silk is essential to completely eliminate the chances of provoking immune response, as SF and SS when presented individually are relatively less immunogenic than when they are associated with each other ${ }^{88}$. The non-mulberry SF silk additionally benefits from the intrinsic presence of arginine-glycine-aspartate, i.e., RGD tripeptide in the $\mathrm{N}$ and $\mathrm{C}$ termini of $\mathrm{G}_{\mathrm{C}}$ motifs of $\mathrm{H}$-chain ${ }^{59}$. These tripeptides enhance the cell adhesion and proliferation via integrin-mediated pathway ${ }^{43}$ and hence find immense potential in designing smart biomaterials for tissue engineering and varied biomedical applications.

\subsection{Biodegradability of Silk Implants}

Silk being a protein polymer is prone to undergo proteolytic digestion owing to the presence of proteolytic cleavage sites ${ }^{89}$. The intrinsic physicochemical attributes possessed by the SF such as B-crystal polymorphism, strong intermolecular and hydrophobic interactions governs the rate of degradation of silk ${ }^{40}$. The self-assembled regenerated SF-based matrices also exhibit similar biodegradation kinetics. The degraded products include soluble amino acids and shorter peptide fragments which are resorbed into the system. Unlike other FDA-approved synthetic polymers such as PLGA, PLA which undergo rapid dissolution in vivo and whose degraded products increases local $\mathrm{pH}$, silk as a polymeric matrix mitigates these drawbacks. Moreover, depending upon the degree of crystallinity conferred on the regenerated SF-based matrices, the degradation rate can be fine tuned to meet the requirement. A high content of B-sheet content results in slow degradation and vice versa ${ }^{90}$. The mechanism of degradation studied in vitro studied using a model enzyme protease XIV, revealed that the enzyme acted upon the amorphous regions reducing the a-helical and random coil structures. The $B$-sheet crystallite remained largely non-degraded, nevertheless the breakage of random coils linking the $ß$-sheet led to the progressive but slow removal of sheets from the structure ${ }^{91}$. Also, the rate of degradation of regenerated SF-based matrices was found to be dependent on the concentration of SF and molecular weight of SF used in the fabrication procedure ${ }^{40}$. The rate of degradation under in vivo conditions mirrored the results obtained under in vitro conditions. 3D scaffolds prepared from regenerated SF when implanted inside Lewis rats, started to get remodelled within few weeks and totally got resorbed by the system after 1 year ${ }^{92}$. These results are promising, as any biomaterial used for tissue engineering must be resorbed shunning the need for another secondary correctional surgery to remove the graft from the site of application.

\section{Applications of Silk in Healthcare Industry \\ 4.1 Silk-Based Tissue Engineering}

Tissue engineering involves the in vitro formation of a functional three-dimensional natural tissue by utilising cells, scaffold and biomolecules to improve the damaged tissue and organs. The choice of biomaterial and formulation strategy decides whether a scaffold will be functional or not. The slower rates of degradation of silk fibroin and low inflammatory response render it useful for biodegradable scaffolds where slow tissue growth is imperative ${ }^{199}$. However, the sericin protein present in the silk is responsible for eliciting immune response and thus should be separated properly from the silk fibroin before the processing of scaffolds ${ }^{61}$. Mulberry silk fibroin from B. mori has been used predominantly in tissue engineering applications followed by the nonmulberry ones such as A. mylitta, A. pernyi, A. assama and P. ricini silk fibroin ${ }^{13,64,133,137,200 .}$ With the rapid advancement in tissue engineering, various scaffold formulation strategies are available (Fig. 3).

\subsubsection{Fabrication Strategies for Tissue Engineering Scaffolds and Constructs}

A three-dimensional tissue-engineered scaffold should support cell recruitment, adhesion, proliferation and differentiation as under in vivo conditions ${ }^{61,133}$. These scaffolds can be fabricated using conventional techniques such as freeze drying, fibre bonding, self-assembly, solvent casting, gas foaming, electrospinning and porogen leaching ${ }^{133,199,201}$ as listed in Table 4.

Though in practice, traditional scaffold fabrication techniques possess drawbacks such as uncontrolled pore size, pore distribution and non-uniform seeding and proliferation of cells and other biologics. This can be overcome by rapid prototyping (RP) techniques. These are advanced computer-aided scaffold fabrication
Scaffolds: These refer to temporary structures that are used to support the proliferation, retention and growth of cells. These may fabricated using natural or artificial polymers and materials that are biocompatible in nature.

Differentiation: Differentiation generally refers to the change of one cell type to another cell type that is more specialized in terms of function. This process allows the progenitor cells to mature into various terminally differentiated cell types exhibiting different phenotypes and specialized function despite possessing the same genome. 

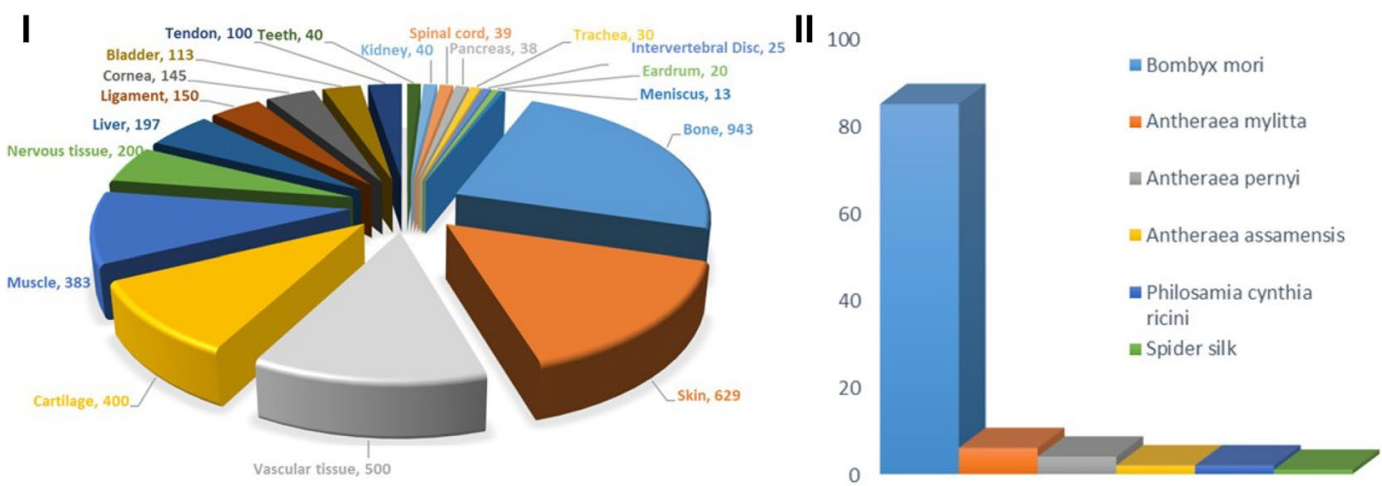

Figure 3: I Reports published on various tissue engineering applications by utilising silk fibroin. (Source: An extensive PubMed search till April 2019). II Percentage of reports published exhibiting the application of various silk types in tissue engineering. (Source: PubMed).

Microextrusion: It is the process of extrusion of polymers and other substances through a micrometre size orifice to microform structures during additive manufacturing.

Autograft: Autografts are tissue grafts that are taken from one part and grafted to another part of the same individual's body.

Allograft: Allografts are tissue grafts that are taken from one donor and grafted to recipient that are different organisms and genetically unidentical but hail to the same species.

Osteoinductive: Any biomaterial or molecule which induces the formation of osteoprogenitor cells. techniques used to construct three-dimensional structures in a layer-by-layer fashion ${ }^{202}$. RP involves designing of a 3D model from a scanned target tissue by computer-aided design (CAD) software and biomedical imaging modalities for rapid reconstruction of the native tissue structure. Thereafter, the 3D model is replicated using techniques such as selective lase sintering (SLS $^{203}$, fused deposition modelling ${ }^{204}$, pressureassisted micro-syringe ${ }^{205}$ and 3D bioprinting. Bioprinting has gained immense prominence in tissue/organ engineering and can be performed using several types of printers like Inkjet-based, microextrusion-based and laser-based bioprint$\mathrm{ers}^{206}$. Some of the multitude of tissue constructs that have been fabricated by bioprinting technology are listed below in Table 5 .

4.1.1.1 Bone Grafts The field of bone tissue engineering has gained immense interest ever since people tried to find alternatives for autograft and allograft in repairing bone defects ${ }^{221}$. Autografts are currently the gold standard as they are histocompatible, but are expensive and difficult to procure, while allografts may lead to immune rejection ${ }^{221,222}$. Currently, a number of biomaterials are available for scaffold-based bone tissue engineering ${ }^{223}$, but silk fibroin acts as an appropriate biomaterial for constructing osteoinductive functional bone grafts on account of its remarkable physico-chemical and biological properties while possessing a close resemblance collagen $\mathrm{I}^{58}$. Porous scaffolds of A. mylitta silk fibroin have been shown to mimic native bone tissue using bone marrow mesenchymal stromal cells (BMSCs $)^{60}$. B. mori has been extensively used to make functional bone grafts ${ }^{224}$ by inducing osteogenic differentiation of human mesenchymal stromal cells. Apatite overlayed silk fibroin scaffolds have successfully repaired mandibular border defects by means of BMSCs. Premineralization of these scaffolds aided in closely mimicking the native extracellular matrix, thereby leading to rapid formation of new bone tissue from the $\mathrm{BMSCs}^{225}$. A combination of $B$. mori silk fibroin and hydroxyapatite (HA) has also been explored widely for treating bone defects ${ }^{226,227}$. Such scaffolds made of silk fibroin/ HA completely repaired segmental bone defects in Sprague-Dawley rats after 12 weeks of implantation $^{228}$. Recombinant human bone morphogenetic protein-2 (rBMP2)-laden silk fibroin scaffolds induced faster osteoblast differentiation as compared to the non-loaded silk fibroin scaffolds ${ }^{229}$. Tricomposite scaffolds made by blending hydroxyapatite (HA), A. assama silk fibroin fibres and its solution revealed high osteogenic potential along with enhanced proliferation rates of hBMSCs and MG63 cell line ${ }^{135}$. Incorporation of HA into the silk scaffold enhances the compressive modulus to a greater extent as compared to pure silk scaffold ${ }^{230}$. Another study demonstrates that a blend of 70 S bioactive glass, B. mori and $A$. assama silk fibroin made by electrospinning provides a good scaffold matrix for repairing osteochondral tissue defects ${ }^{208}$. Repairing large volume bone defects was exhibited by copper-doped bioactive glass silk composite matrices ${ }^{58}$. Such porous composite matrices enhanced the resorption, maturation of stem cells and endothelial cells within the scaffold, thereby exhibiting its potential for clinical translation as seen in Fig. 4I.

4.1.1.2 Skin Grafts and Wound Dressings Tissue engineering strategies for skin have been widely explored due to its high susceptibility to damage 


\begin{tabular}{|c|c|c|c|c|c|}
\hline $\begin{array}{l}\text { Fabrication tech- } \\
\text { nique }\end{array}$ & Tissue & Scaffold material & Cell tested & Conclusion & References \\
\hline Electrospinning & Skin & $\begin{array}{l}\text { Mats (B. mori/A. } \\
\text { assama + PVA) coated } \\
\text { with 4RepCT spider silk }\end{array}$ & HDF, $\mathrm{HaCaT}$ & $\begin{array}{l}\text { Improved cell adhe- } \\
\text { sion, antimicro- } \\
\text { bial activity }\end{array}$ & 85 \\
\hline Electrospinning & Skin & Mats (silk sericin + PVA) & $\begin{array}{l}\text { Murine fibroblasts, } \\
\text { HaCaT }\end{array}$ & $\begin{array}{l}\text { No inflammatory } \\
\text { response; better } \\
\text { healing rates }\end{array}$ & 164 \\
\hline Electrospinning & Skin & $\begin{array}{l}\text { Mats }(A \text {. assama }+P \text {. } \\
\text { ricini) with } E G F \text {, cipro- } \\
\text { floxacin } \mathrm{HCl}\end{array}$ & HDF, $\mathrm{HaCaT}$ & $\begin{array}{l}\text { Scar-less wound } \\
\text { healing }\end{array}$ & 66 \\
\hline Electrospinning & Skin & $\begin{array}{l}\text { Silk }+ \text { collagen solu- } \\
\text { tion }+1,1,1,3,3,3 \text {-hex- } \\
\text { afluoro-2-propanol }\end{array}$ & HEK, HEF & $\begin{array}{l}\text { Functional wound } \\
\text { dressing matrix }\end{array}$ & 207 \\
\hline Electrospinning & Bone & $\begin{array}{l}\text { Biphasic scaffold (bioac- } \\
\text { tive glass + silk) }\end{array}$ & MG63 & $\begin{array}{l}\text { Increased ALP, OPN, } \\
\text { SGAG and colla- } \\
\text { gen deposition }\end{array}$ & 208 \\
\hline Freeze drying & Skin & $\begin{array}{l}\text { Sponge (silk + alginate } \\
\text { sol.) }\end{array}$ & $\begin{array}{l}\text { Used in rat wound } \\
\text { model }\end{array}$ & $\begin{array}{l}\text { Increased wound } \\
\text { healing rate }\end{array}$ & 209 \\
\hline Freeze drying & Bone & $\begin{array}{l}\text { Scaffold (silk solu- } \\
\text { tion + fibres + HA) }\end{array}$ & MG63, hBMSCs & $\begin{array}{l}\text { Functional bone } \\
\text { graft substitute }\end{array}$ & 135 \\
\hline Freeze drying & Bone & $\begin{array}{l}\text { Scaffold (Cu-doped } \\
\text { bioactive glass + silk } \\
\text { fibres + silk sol.) }\end{array}$ & hMSCs & $\begin{array}{l}\text { Enhanced vascular } \\
\text { and fibrous tissue } \\
\text { growth in scaf- } \\
\text { folds }\end{array}$ & 58 \\
\hline Freeze drying & Bone & $\begin{array}{l}\text { Scaffold (Si/Zn-doped } \\
\text { brushite cement + silk } \\
\text { sol.) }\end{array}$ & MG63, THP1, pECs & $\begin{array}{l}\text { Affordable and } \\
\text { viable bone graft } \\
\text { substitute }\end{array}$ & 144 \\
\hline Freeze drying & Liver & $\begin{array}{l}\text { Scaffold (B. mori }+ \text { A. } \\
\text { assama silk sol.) }\end{array}$ & $\begin{array}{l}\text { HepG2, rat hepato- } \\
\text { cytes }\end{array}$ & $\begin{array}{l}\text { Functional bioartifi- } \\
\text { cial liver }\end{array}$ & 137 \\
\hline Freeze drying & IVD & $\begin{array}{l}\text { Lamellar scaffold (B. } \\
\text { mori silk sol.) }\end{array}$ & pAF, hMSCs & $\begin{array}{l}\text { AF cell alignment, } \\
\text { proliferation, } \\
\text { ECM deposition }\end{array}$ & 200 \\
\hline Solvent casting & Vascular tissue & $\begin{array}{l}\text { Films (silk fibroin } \\
\text { sol. + water vapour } \\
\text { annealing) }\end{array}$ & $\begin{array}{l}\text { pECs, SMCs, Fibro- } \\
\text { blasts }\end{array}$ & $\begin{array}{c}\text { Closely mimics } \\
\text { native vessel }\end{array}$ & 57 \\
\hline Solvent casting & Vascular tissue & Patterned films (silk sol.) & $\mathrm{pECs}, \mathrm{SMCs}$ & $\begin{array}{l}\text { Functional due to } \\
\text { aligned vascular } \\
\text { cells }\end{array}$ & 125 \\
\hline Solvent casting & Vascular tissue & $\begin{array}{l}\text { Films (silk fibroin + pec- } \\
\text { tin + glycerol) }\end{array}$ & ADSCs & $\begin{array}{l}\text { Useful for cutane- } \\
\text { ous wound } \\
\text { healing }\end{array}$ & 210 \\
\hline Solvent casting & Muscle & Films (silk sol. + melanin) & C2C12 myoblasts & $\begin{array}{l}\text { Promoted myogen- } \\
\text { esis }\end{array}$ & 161 \\
\hline Self-assembly & Pancreas & $\begin{array}{l}\text { Hydrogel (B. mori }+A \text {. } \\
\text { assama silk sol.) }\end{array}$ & RIN-5, rat islet cells & $\begin{array}{l}\text { Functional hydrogel } \\
\text { encapsulating } \\
\text { islets }\end{array}$ & 64 \\
\hline Self-assembly & Cartilage & $\begin{array}{l}\text { Hydrogel (DMEM pow- } \\
\text { der + silk fibroin sol.) }\end{array}$ & Chondrocytes & $\begin{array}{l}\text { Completely degra- } \\
\text { dable construct }\end{array}$ & 211 \\
\hline Self-assembly & Cartilage & $\begin{array}{l}\text { Hydrogel (silk sol. + silk } \\
\text { fibres) }\end{array}$ & $\begin{array}{l}\text { Bovine chondro- } \\
\text { cytes }\end{array}$ & $\begin{array}{l}\text { Functional cartilage } \\
\text { constructs }\end{array}$ & 212 \\
\hline
\end{tabular}

and wear 6 6, 232, 233. Various biomaterials such as chitosan, collagen, cellulose, alginate, silk fibroin, dextran, polylactic acid (PLA), elastin, polyethylene glycol(PEG), polycaprolactone (PCL), and silicone have been utilised to make acellular scaffolds for wound healing till date $234-236$. Amongst them, B. mori silk fibroin has been extensively accepted as a wound dressing material owing to its remarkable properties such as biodegradability, biocompatibility, cost-effective and low immune response ${ }^{199}$. Recent studies demonstrated the use of electrospun silk fibroin ( $A$. assama and $P$. 
Table 4: continued

\begin{tabular}{|c|c|c|c|c|c|}
\hline $\begin{array}{l}\text { Fabrication tech- } \\
\text { nique }\end{array}$ & Tissue & Scaffold material & Cell tested & Conclusion & References \\
\hline Self-assembly & Bone & $\begin{array}{l}\text { Hydrogel (Silk sol. + nano } \\
\text { HA) }\end{array}$ & MG63 & $\begin{array}{l}\text { Properties identical } \\
\text { to native tissue }\end{array}$ & 213 \\
\hline Self-assembly & Skin & $\begin{array}{l}\text { Hydrogel (B. mori+A. } \\
\text { assama silk sols.) }\end{array}$ & $\mathrm{HDF}, \mathrm{HaCaT}$ & $\begin{array}{l}\text { Enhanced healing } \\
\text { in full thickness } \\
\text { burn wounds }\end{array}$ & 63 \\
\hline Salt leaching & Bone & $\begin{array}{l}\text { Scaffold (silk } \\
\text { sol. + HFIP }+\mathrm{NaCl} \text { ) }\end{array}$ & HMSCS & $\begin{array}{l}\text { Enhanced minerali- } \\
\text { zation }\end{array}$ & 214 \\
\hline
\end{tabular}

HFIP 1,1,1,3,3,3,-hexafluoroisopropanol, HDF human dermal fibroblast, HaCaT human keratinocyte, EGF epidermal growth factor, HEK human embryonic kidney, HEF human esophageal fibroblast, MG63 osteosarcoma cells, THP1 human monocytic cells, HepG2 human hepatocellular carcinoma cell, $p E C s$ porcine endothelial cells, SMCs smooth muscle cells, ADSCs adipose-derived stem cells, RIN-5 rat insulin-producing cells

Table 5: Reports of tissue constructs 3D bioprinted using silk as a biomaterial.

\begin{tabular}{|c|c|c|c|c|}
\hline Bioprinting technique & Bioink & Engineered Tissue & Features & References \\
\hline Microextrusion & Silk fibroin-gelatin & $\begin{array}{l}\text { MSCs differentiated to } \\
\text { chondrocytes, osteo- } \\
\text { cytes }\end{array}$ & $\begin{array}{l}\text { Successful differentiation } \\
\text { of encapsulated cells }\end{array}$ & 215 \\
\hline Microextrusion & Silk fibroin-gelatin & Cartilage & $\begin{array}{l}\text { Chondrogenic differ- } \\
\text { entiation leading to } \\
\text { hypertrophy }\end{array}$ & 183 \\
\hline Microextrusion & Silk fibroin-gelatin & Soft tissue reconstruction & $\begin{array}{l}\text { Promoted cellular infiltra- } \\
\text { tion }\end{array}$ & 216 \\
\hline Microextrusion & Silk fibroin-collagen & Knee cartilage & Cell growth supported & 217 \\
\hline Microextrusion & Silk fibroin + cells + PEG & hMSC & $\begin{array}{c}\text { Functional construct } \\
\text { post-implantation }\end{array}$ & 184 \\
\hline Microextrusion & Silk fibroin + chitosan & BMSC & Cell growth supported & 217 \\
\hline Microextrusion & $\begin{array}{l}\text { Silk + gelatin + sulfonic } \\
\text { acid + FGF }\end{array}$ & Skin & Visible skin regeneration & 218 \\
\hline Inkjet & Silk fibroin-alginate & 3Т3 fibroblast & Rapid cell proliferation & 219 \\
\hline Inkjet & Silk fibroin + PEG & Cartilage & High shape fidelity & 220 \\
\hline Digital light processing & $\begin{array}{l}\text { Silk fibroin-glycidyl meth- } \\
\text { acrylate }\end{array}$ & Bone & Cell growth maintained & 76 \\
\hline
\end{tabular}

Chondrogenesis: It is a process of cartilage formation which results from the condensation of mesenchymal cells and differentiation of chondroprogenitor cells. ricini) mats as a potential wound dressing material ${ }^{66}$. Similarly, electrospun blends of polyvinyl alcohol (PVA) and silk nanofibrous mats promoted faster wound healing via granulation tissue formation when activated by combining growth factors $^{67}$. An amalgamation of recombinant spider silk along with silkworm silk fibroin has also shown to do wonders as wound dressing ${ }^{85}$ as shown in Fig. 4III.

4.1.1.3 Repair Strategies for Cartilage Tissue Chondroblasts and chondrocytes form an integral part of the cartilage tissue and hence should be able to proliferate, differentiate and mature over the engineered tissue constructs that are meant to mimic the native cartilage. Various biomaterials have been evaluated to construct artificial cartilage tissue ${ }^{237}$. Silk fibroin scaffolds have been shown to enhance the maturation of cartilage cells when used in conjunction with dexamethasone and transforming growth factor (TGF- $\beta 3)^{238}$. Other silk blends have also been shown to positively influence chondrogenesis ${ }^{239,240}$. Silk fibroin sponge scaffolds provided mechanical stimulation to the chondrocytes when cultured inside a bioreactor $^{241}$ and such cartilage grafts could repair knee joint defects. Agarose-silk fibroin blended hydrogels have been evaluated for cartilage regeneration and found to support chondrogenesis and cartilage-like native extracellular matrix deposition ${ }^{242}$. Moreover, the non-mulberry hydrogel blends exhibited higher sulphated glycosaminoglycans (sGAGs) and collagen content as compared to the mulberry ones. Porous scaffolds made from nonmulberry A. assama silk fibroin have also been 


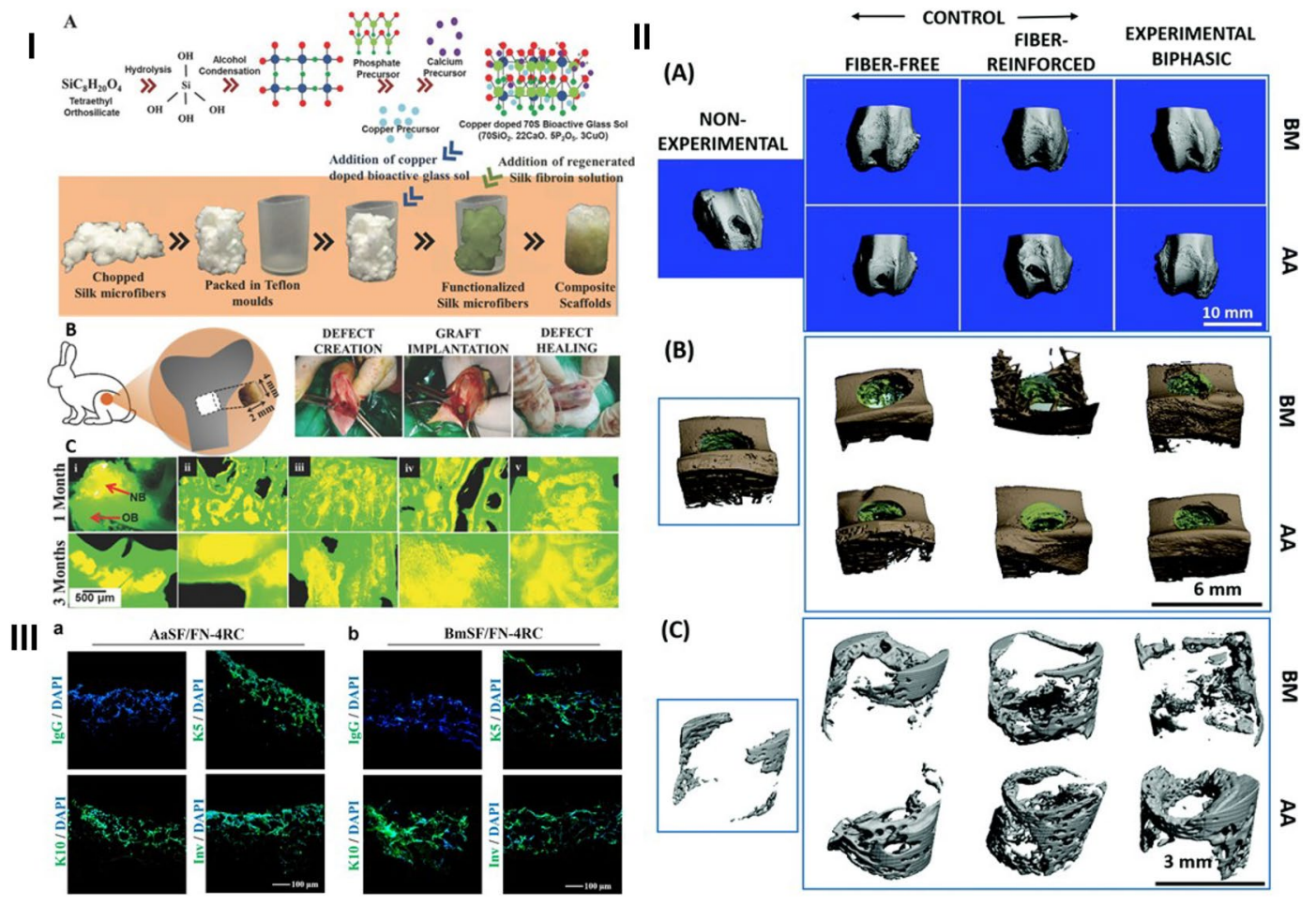

Figure 4: I (A) Fabrication of bioactive glass silk composite scaffolds by sol-gel coating of the silk microfibres. (B) In vivo studies using the matrices to treat volumetric bone defect created in rabbit. (C) Fluorochrome (oxytetracycline) labelling after 1-3 months of implantation showing a bright yellow new bone (NB) formation region and a green old bone (OB) region. (adapted with permission from ${ }^{58}$ (c) 2018 WILEYVCH Verlag GmbH \& Co. KGaA, Weinheim) II Micro-CT images showing formation of subchondral bone after 8 weeks of implantation. (A) Morphological analysis of the implant site; (B) 3D reconstructed images depicting the volume of interest (VOI); (C) CT images showing the actual bone volume formed. (Adapted from $^{231}$ with permission from The Royal Society of Chemistry). III SF scaffolds cross-sections coated with FN-4RC peptide and co-cultured along with HDF and HDMEC before seeding HaCaTs on top, followed by culturing at air-liquid interface conditions. (a) FN-4RC-peptide-coated A. assamensis SF (AaSF) scaffolds showed better keratinization in contrast to, (b) the B. mori SF (BmSF) counterpart. Cytokeratin markers: $\mathrm{K} 5, \mathrm{~K} 10$, and Inv (in green) in the FN-4RC coated AaSF scaffolds. IgG depicts isotype control. DAPI was used for counterstaining of nuclei (in blue). Scale bar $=100 \mu \mathrm{m}$. (Adapted with permission from ${ }^{85}$, Copyright (c) 2016 American Chemical Society)

reported to support cartilage tissue growth ${ }^{136}$. Silkbased biphasic osteochondral interface tissue constructs showed excellent regeneration of knee osteochondral joints in rabbits ${ }^{231}$.

4.1.1.4 Vascular Grafts Vascularization and endothelialisation are two important factors determining the long-term functionality of any bioengineered tissue to be used an substitute for autologous grafts ${ }^{243}$. Most of the biomaterials used earlier faced the drawback of mechanical stability and incomplete vascularization ${ }^{243}$. Nonwoven silk fibroin mesh showed incomplete endothelialisation when human endothelial cells were cultured on them ${ }^{244}$, but coating the meshwork with extracellular matrix components improvised the endothelial cellular response. Gelspinning technique has been used by Lovett et al. to fabricate silk fibroin microtubes ${ }^{245}$, which exhibited rapid endothelialisation. Tri-layered vascular grafts have been made using silk, elastin, collagen and polycaprolactone (PCL) to replace the traditional autografts ${ }^{246}$. B. mori silk fibroin has been comprehensively explored in vascular tissue engineering ${ }^{247}$. Multi-layered vascular grafts made by rolling patterned mulberry and non-mulberry silk films ${ }^{57}$ mimicked the native vessels as shown in Fig. 5I.

4.1.1.5 Cardiac Tissue Patches The biggest challenge in cardiac tissue engineering is to efficiently mimic the native extracellular matrix so that it can be used to replace damaged heart muscles. Silk can be used as an effective natural biomaterial for such purposes, as its matrix stiffness can be tuned accurately to match the native
Vascularization: It is a process of capillary tube formation by the assembly of differentiated de novo endothelial progenitor cells (EPCs).

Endothelialisation: It refers to the process of endothelial tissue formation. 
Myocardial infarction: It is defined as the necrosis of cardiac myocytes due to prolonged ischemia.

Cirrhosis: It is defined as a late stage of liver fibrosis indicated by regenerative nodules formation that are separated and enclosed by fibrotic septa. muscle rigidity ${ }^{199,249}$. The prime focus of the moment is proper vascularization and maturation of the cardiac cell-laden constructs. Both B. mori and A. mylitta silk fibroin scaffolds have been shown to treat myocardial infarction ${ }^{250}$, 251 with the latter demonstrating better maturation of myocytes. Three-dimensional cardiac constructs fabricated by stacking of cell-laden patterned silk films have been pitched as an excellent platform for cardiac tissue regeneration ${ }^{248}$ as depicted in Fig. 5II.

4.1.1.6 Liver Modules In recent times, hepatic disorders especially liver cirrhosis has posed a grave danger to the population due to their adoption of abnormal lifestyle and unhealthy eating habits. Several bioartificial liver
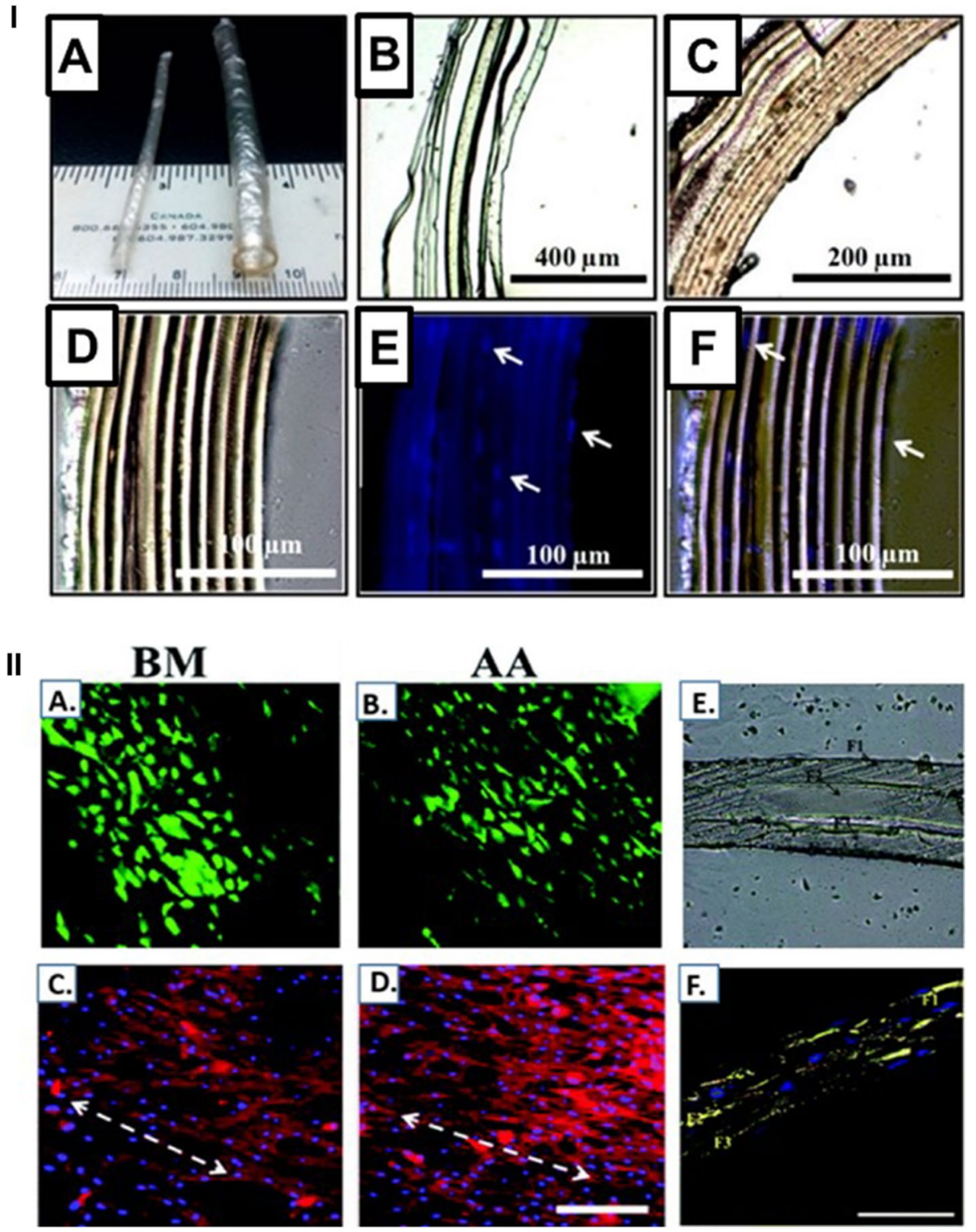

Figure 5: I Evaluation of the small diameter vascular grafts fabricated by rolling vascular cell sheets grown on patterned silk films. (A) Appearance of the graft. Cross-section of the graft after (B) 1 day of cell seeding, (C) 14 days of cell seeding showing enhanced structural integrity. Hoechst 33,342 (blue) staining of the constructs to show presence of vascular cells: (D) Unstained, (E) stained and (F) merged constructs. (Adapted with permission from ${ }^{57}$. Copyright @ 2016 American Chemical Society). II Live/dead assay of primary rat cardiomyocytes on patterned (A) Bombyx mori, (B) Antheraea assama silk films. (C), (D) Rhodamine phalloidin staining was done for the same. (E) Cross-section of the cardiac tissue construct made by stacking of cell-laden patterned silk films. (F) Cell distribution analysis using Hoechst 33,342 dye (scale

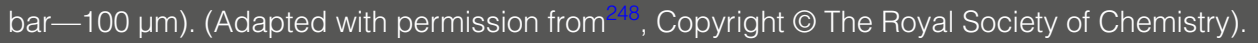


devices $^{252}$ and cell therapies ${ }^{253,254}$ have been developed in the past several years to treat liver disorders. Implantable hepatic tissues have been developed by loading hepatocytes on 3D scaffolds made up of polymers like polylactide-co-glycolide, polycaprolactone, polyethylene glycol, polyethylene, alginates and cellulose ${ }^{255}, 256$. Silk fibroin-collagen blended films have been successfully demonstrated to enhance proliferation of rat hepatocytes ${ }^{257}$. Silk fibroin-chitosan-heparin blended scaffolds also exhibited hepatocyte regeneration ${ }^{258}$. PLA-silk fibroin scaffolds were shown to increase hepatocyte attachment, proliferation and differentiation compared to only PLA scaffolds ${ }^{259}$. Janani et al. demonstrated the fabrication of functional liver scaffolds by blending mulberry (B. mori) and non-mulberry (A. assama) silk fibroin ${ }^{137}$.

4.1.1.7 Muscle Tissue Repair Strategies Tissue engineering of muscle requires robust biomaterials with desired mechanical strength. Scaffolds seeded with satellite cells have been used widely for skeletal muscle tissue engineering (SMTE) ${ }^{260-}$ ${ }^{262}$. Manchineella et al. demonstrated that electrospun silk fibroin/melanin composite films promoted myogenesis and myotube formation of $\mathrm{C} 2 \mathrm{C} 12$ cells $^{161}$. Recently, conducting polymers have been in focus as they can influence the electrical activity of the muscles. Silk fibroin and a conducting polymer, poly (aniline-co- $\mathrm{N}$-(4-sulfophenyl) aniline) (PASA) have been blended together to devise functional muscle constructs $^{263}$. These scaffolds illustrated the rapid proliferation of $\mathrm{C} 2 \mathrm{C} 12$ cells in vitro. Moreover, electrospun nanofibrous scaffolds made using a blend of silk fibroin/PLA/collagen revealed enhanced adherence, proliferation and maturation of myoblasts ${ }^{264}$.

4.1.1.8 Tendon and Ligament Grafts Tendon and ligament tissue damage becomes more prevalent during sports injury leading to hindrance in movement. Tissue engineering is much needed for restoring the function of such tissues as they have poor regeneration capacity ${ }^{265}$. The tensile strength of silk makes it an ideal candidate for tendon/ligament tissue engineering scaffolds ${ }^{199,} 266$. A silk fibroin matrix has been braided to resemble the human anterior cruciate ligaments (ACL) $)^{267}$. It had mechanical strength similar to the native ACL and supported the proliferation of human bone marrow mesenchymal stromal cells. Hennecke et al. demonstrated that spider silk bundle sutures possess the appropriate tensile strength and elastic modulus to restore tendons ${ }^{152}$. A three-dimensional composite scaffold was made by electrospinning a mixture of polyurethane and collagen on knitted silk to mimic the native tendon tissue ${ }^{268}$. A hybrid knitted silk-collagen sponge scaffold seeded with human embryonic stem cell-derived mesenchymal stem cells restored tendon regeneration when in vitro mechanical stimulation was given ${ }^{269}$. The alignment of tenocytes was mimicking the native tissue due to the stimulation. Scleraxis overexpressed hESC-MSCs were seeded onto the composite sponge scaffolds in the next consecutive study ${ }^{270}$. Several other silk fibroin scaffolds have been designed to mimic the natural medial collateral ligament, rotator cuff and Achilles tendon ${ }^{271}$.

4.1.1.9 Engineered Intervertebral Disc Intervertebral disc (IVD) degeneration in the form of lower back pain, spinal stenosis and radiculopathy ${ }^{272,273}$ affects posture and stability of the backbone. None of the current therapies available can restore the function of the IVD ${ }^{274}$. An ideal biomaterial for IVD scaffold should have biocompatibility, high tensile strength and mimic the native extracellular matrix ${ }^{275}$. Silk fibroin owing to its wondrous properties ${ }^{199}$ have been used in this regard. The successful tissue-engineered IVD should resemble the morphology and function of both the components of IVD: nucleus pulposus (NP) and annulus fibrosus (AF). A biphasic hybrid scaffold was made using silk fibroin/fibrin/hyaluronic acid to mimic both the $\mathrm{NP}$ and $\mathrm{AF}^{276}$. The lamellar silk fibroin scaffold part seeded with porcine AF cells resembled the native $\mathrm{AF}$, whereas the fibrin/hyaluronic acid scaffold part seeded with porcine chondrocytes resembled the native NP. Another 3D biphasic silk fibroin scaffold has been fabricated by paraffin sphere-leaching technique to resemble the $\mathrm{AF}$ phase and phase separation technique for the NP phase ${ }^{277}$. Rabbit AF and NP cells were shown to adhere and proliferate on these porous scaffolds. Bhunia et al. fabricated a bioartificial AF construct comprising of concentric rings of lamellar silk scaffold made utilising directional freezing technique ${ }^{200}$ and demonstrated the proliferation of primary porcine AF cells and hMSCs over it as depicted in Fig. 6I. Furthermore, this angle-ply construct was designed using a gradient of two different silk combinations-mulberry (B. mori) and non-mulberry (A. assama, P. ricini) ${ }^{65}$. This aided in successful cellular alignment, maturation and extracellular matrix deposition.

4.1.1.10 Repair and Replacement of Meniscus Tissue The main function of the meniscus is shock $a^{a b s o r p t i o n}{ }^{279}$ and providing mechanical stability
Spinal stenosis: It is a condition described by the osteoarthritis of the intervertebral discs and facet joints.

Radiculopathy: It is a condition characterized by pain, weakness, motor loss and sensory changes in a specific nerve root distribution.

Satellite cells: These are adult muscle stem cells that are lineage committed and are localized between the muscle sarcolemma and the basal lamina.

Sutures: Materials used to stitch body tissues together after an injury or surgery. 


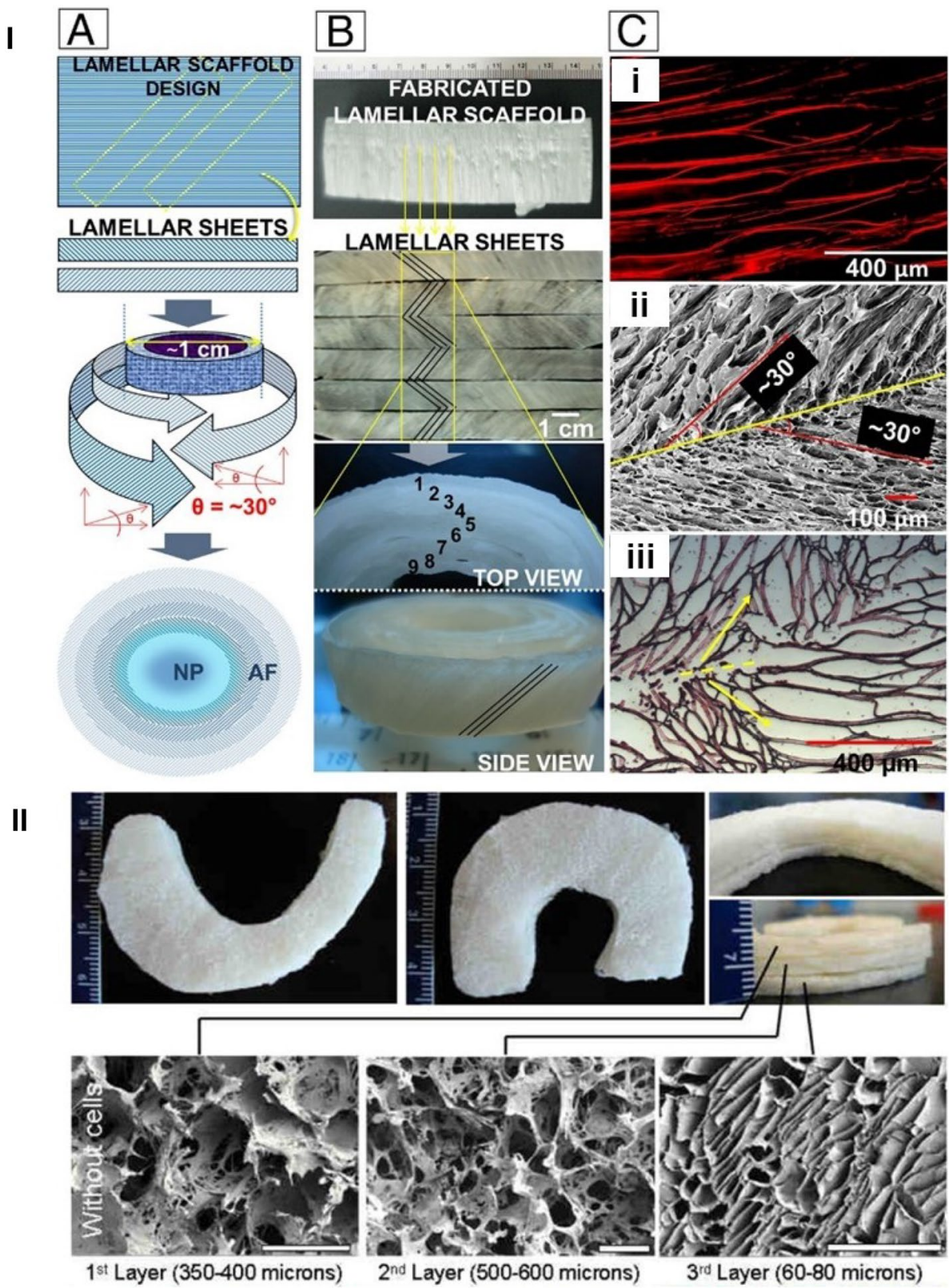

Figure 6: I (A) Fabrication plan of the silk fibroin angle-ply construct. (B) Step-wise construction of the scaffold. (C) (i) Lamellar pattern is seen in the fluorescent image. (ii) SEM and (iii) histology of the crossaligned section. (Reproduced with permission from Proceedings of the National Academy of Sciences of the United States of America under creative common license CC-BY ${ }^{200}$ ) II Triple layered scaffold resembling meniscus. SEM images representing porosity of each layer. (Adapted with permission ${ }^{278}$, Copyright (c) Elsevier).

to the knee for aiding in locomotion. A damaged meniscus due to any traumatic injury or degeneration has been repaired using different implants like the collagen meniscus implant (Menaflex) ${ }^{280}$. Several biomaterials like collagen ${ }^{281}$, polyurethane ${ }^{282}$, polycaprolactone ${ }^{283}$, polyvinyl alcohol ${ }^{284}$ and silk ${ }^{285}$ have been explored for meniscal tissue engineering. Mandal et al. designed a multilamel- lar silk fibroin scaffold and seeded it with human BMSCs to closely mimic a functional meniscus ${ }^{285}$. A three-layered silk fibroin scaffold seeded with fibroblasts on the outside and chondrocytes on the inside resembled the meniscus both structurally and functionally ${ }^{278}$ as shown in Fig. 6II. 
4.1.1.11 Neural Conduits Large nerve injuries are difficult to treat completely without utilising neural grafts $^{286}$. The only tentative solution to treat spinal cord injury is via neural tissue engineering. Silkbased scaffolds have been proved to be a boon in this context ${ }^{287,288}$. Electrospun silk fibroin-nerve guidance conduits have been shown to be effective for peripheral nerve repair ${ }^{289}$ by Wang et al. Mulberry and non-mulberry silk fibroin scaffolds seeded with human neural progenitor cells were evaluated for neural tissue regeneration and the non-mulberry ones demonstrated an increase in cell proliferation and deposition of extracellular matrix $^{288}$. Conducting polymers like polypyrrole have been blended with silk fibroin to form functional neural tissue scaffolds ${ }^{290}$. In a different study, silk fibroin/polycaprolactone scaffolds fabricated by electrospinning were found suitable for peripheral nerve regeneration ${ }^{291}$.

4.1.1.12 Bioartificial Pancreas With the rapid increase in patients suffering from diabetes, there is an increasing need to focus on new treatment strategies other than the traditional insulin therapy, drug therapy and islet transplantation ${ }^{292}$. Several hydrogels, nanoparticles and microspheres have been fabricated for ensuring sustained release of insulin $^{293}$. Encapsulation of islets with biomaterials before transplantation ensures minimal immune response and controlled insulin release ${ }^{294}$. Pancreatic islets encapsulated in silk hydrogel along with laminin, collagen and mesenchymal stromal cells exhibited enhanced graft survival rate ${ }^{295}$. Encapsulation of islets in silk hydrogel along with MSCs improvised the in vivo function of the islets post-transplantation ${ }^{296}$. In another study, Kumar et al. fabricated bioartificial pancreas by encapsulating insulin-secreting cells in silk alginate/agarose scaffolds ${ }^{138}$.

\subsection{Cancer Therapeutics and Models for Drug Screening}

Silk serves as an excellent biomaterial for cancer therapy due to its biocompatibility, biodegradability and no immune rejection ${ }^{199}$. The biggest obstacle an anti-cancer drug faces is sustained release leading to its target destination, which can be overcome using silk formulations like films, hydrogels, capsules, silk-coated liposomes and nanoparticles as the drug carrier ${ }^{297}$. B. mori silk films have been shown to deliver doxorubicin when administered intratumorally in a human orthotopic breast cancer model ${ }^{298}$. Moreover, the drug delivery rate could be controlled by altering the crystallinity of the films. These silk films also exhibited sustained release of doxorubicin in a neuroblastoma mouse model ${ }^{299}$. Sieb et al. reported that $B$. mori silk hydrogels can be fine tuned for controlled release of doxorubicin and the metastatic spread was reduced to a great extent in mice breast cancer model ${ }^{300}$. Wu et al. demonstrated that silk fibroin nanoparticles encapsulated with the drug paclitaxel were noncytotoxic and potential drug carriers in gastric

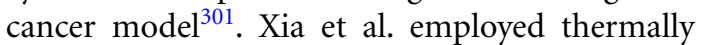
induced silk elastin-like protein polymers (SELPs) to form nanoparticles for the efficient delivery of doxorubicin in cervical cancers ${ }^{302}$. Silk fibroincoated liposomes have lately been used to coat emodin, a receptor tyrosine kinase inhibitor for its efficient delivery to breast cancer cells ${ }^{303}$. These coated liposomes could easily target the specific cancer cells via enhanced drug diffusion rates. Gupta et al. showed that curcumin-loaded silkchitosan nanoparticles act as biodegradable delivery systems to target breast cancer cells ${ }^{304}$. In another study, a hybrid injectable hydrogel comprising silk fibroin blend (B. mori and A. assama) and folic acid functionalized single-walled carbon nanotubes was used for targeted delivery of doxorubicin $^{62}$ to the folic acid receptor-positive cancer cells.

Silk fibroin can also be used for making $3 \mathrm{D}$ cancer models to mimic the in vivo conditions much better than in a 2D culture dish and for drug discovery applications. Ewelina et al. designed a 3D heterotypic breast cancer model using silk scaffolds made by salt leaching ${ }^{305}$. These scaffolds showed successful EMT6 and NIH3T3 cellular proliferation and expression of cancer cell markers. An osteosarcoma model made by Tan et al. using freeze-dried Bombyx mori scaffolds ${ }^{306}$ closely resembled the in vivo expression profile and behaviour of the cancer cells. Similarly, mammary adenocarcinoma and hepatocarcinoma models were also made by freeze drying nonmulberry A. mylitta silk fibroin scaffolds ${ }^{307,308}$ with the latter clearly amplifying the mechanism of hyaluronan synthase inhibitor (4-MU). Reagan et al. developed B. mori silk fibroin scaffolds to effectively target breast cancer cells using tumour necrosis factor-related apoptosis-inducing ligand (TRAIL) expressing mesenchymal stem cells ${ }^{309}$. These models helped in a better understanding of the cellular behaviour in vivo.

\subsection{Tissue-On-Chip for High-Throughput Screening}

The growing need for newer technologies to reduce failures in pre-clinical trials of drug
Neuroblastoma: Neuroblastoma refers to the cancer of sympathetic nervous system which originates from neural precursor cells (neuroblasts) and affects the infants mostly.

Liposomes: They are small spherical vesicles containing lipid bilayers of phospholipids mostly. Due to their size, hydrophilicity and hydrophobicity, liposomes are preferred for enhanced drug delivery.

Intratumorally: It is an adverb which refers to an activity directed inside the tumour.

Orthotopic: Orthotopic describes the occurrence of anything in its original place. In medical science, it refers to the restoration or implantation of a tissue or organ to its original position within the body. 
Waveguides: They are the structures that transport electromagnetic waves from one point to another by limiting loss of energy. discovery have resulted in the birth of a state-ofthe-art technique called tissue-on-chip or organon-chip (TOC/OOC), which is an innovative approach towards three-dimensional microfluidic devices that mimic a functional tissue/organ and can replace animal models for drug screening and drug development applications $s^{310}$. Several such chips have already been devised to engineer heart ${ }^{311}$, skin ${ }^{312}$, lung ${ }^{313}$, kidney ${ }^{314}$ and arteries $^{315}$. Advancements in technology have even lead to development of human-on-chip model ${ }^{316}$. Recently, silk hydrogel microfluidics has been in the limelight for exhibiting enhanced biological activities resulting in replication of human tissues $^{317}$. Silk bypasses the limitations of polydimethylsiloxane (PDMS) and other traditional materials used to make microfluidic devices owing to its amazing properties of biocompatibility, biodegradability and enhanced cell proliferation support ${ }^{199,317}$. A silk-based microfluidic device was fabricated utilising gelatin sacrificial molding and construction of three-dimensional microchannel networks within horseradish peroxidase-hydrogen peroxide $\left(\mathrm{HRP}-\mathrm{H}_{2} \mathrm{O}_{2}\right)$ crosslinked silk hydrogel ${ }^{317}$. Such devices can be easily functionalized for regenerative medicine applications. In another instance, silk fibroinbased microfluidic device was designed to replicate a functional liver ${ }^{51}$. The hepatocytes cultured on this device exhibited morphology and functions similar to in vivo conditions. These microengineered devices have been the latest paradigm in the field of biomedical science leading to a better understanding of cell physiology, behaviour and function (Fig. 7).

\subsection{Advances in Silk-Based Biosensing and Biomedical Imaging}

Silk fibroin has been subjected to different fabrication techniques that controllably influence its property as a biomaterial, to reconfigure its purpose for different end uses. Silk fibroin has been used in formulations to develop bioinks that can be doped with components to develop inkjet printable functional devices for sensing, therapeutics and regenerative medicine. Silk-based Au NP-doped inks can be applied for photonics and thermal sensing applications, while those doped with enzymes can be used for extending their lifetime as opposed to traditional loading techniques. Similarly, silk-based inks can be doped with therapeutically active molecules such as antibiotics and topographically deposited onto anti-microbial assay kits ${ }^{318}$. Silk fibroin has also been employed in the fabrication of conventional biosensors for amperometric detection of pesticides $^{319,}{ }^{320}$. Moreover, silk fibroin-based edible food sensors were created to detect their spoilage $^{321}$. Development of silk-based optical waveguides $^{322,}, 323$ and diffractive elements ${ }^{324}$ has opened new avenues towards development of optical sensing devices. Moreover, silk has shown improved resonance at terahertz frequencies and paved a promising path towards the fabrication of hybrid metamaterial-inspired bioelectric and

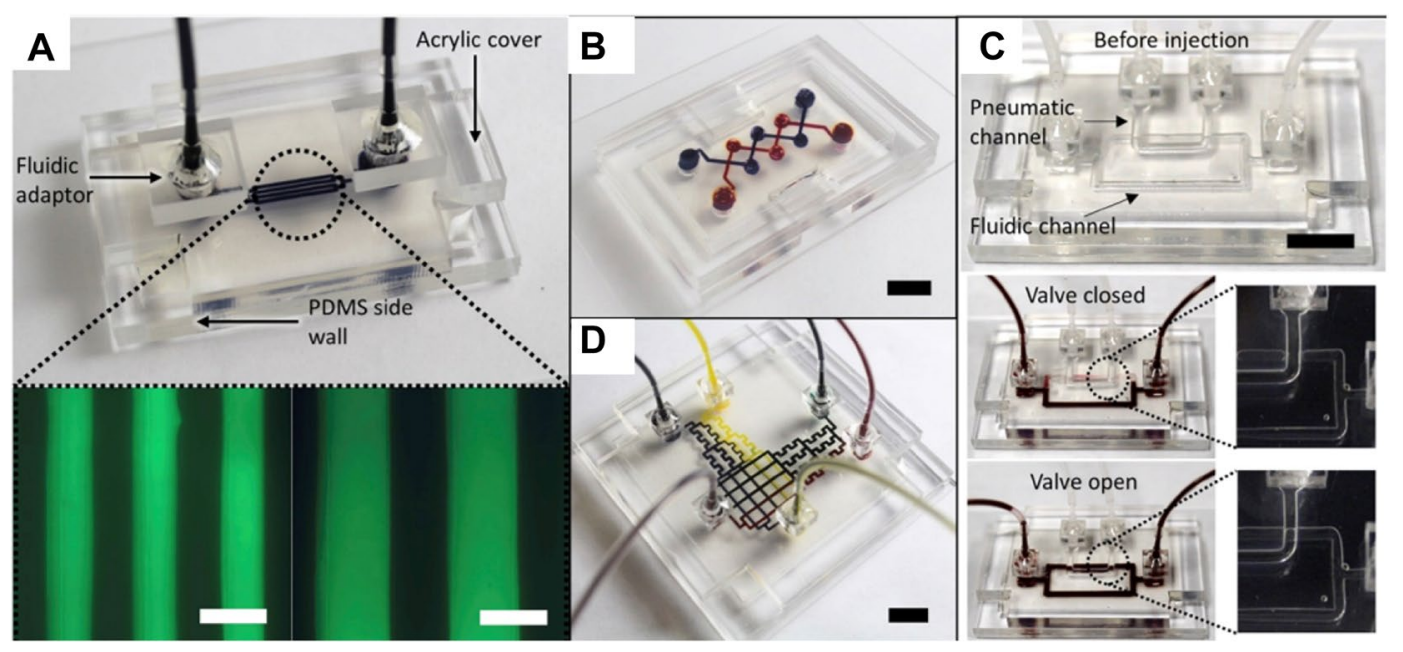

Figure 7: a Silk hydrogel microfluidic device showing the minimum fluid channel thickness. (scale: $200 \mu \mathrm{m})$, b A bi-layered microfluidic system exhibiting serpentine channels. c Silk hydrogel microfluidic system attached to a pneumatic valve. d 2D bi-layered chemical gradient generator chip. (scale: $1 \mathrm{~cm})$. (Adapted with permission from ${ }^{317}$. Copyright (C) 2019 Elsevier). 

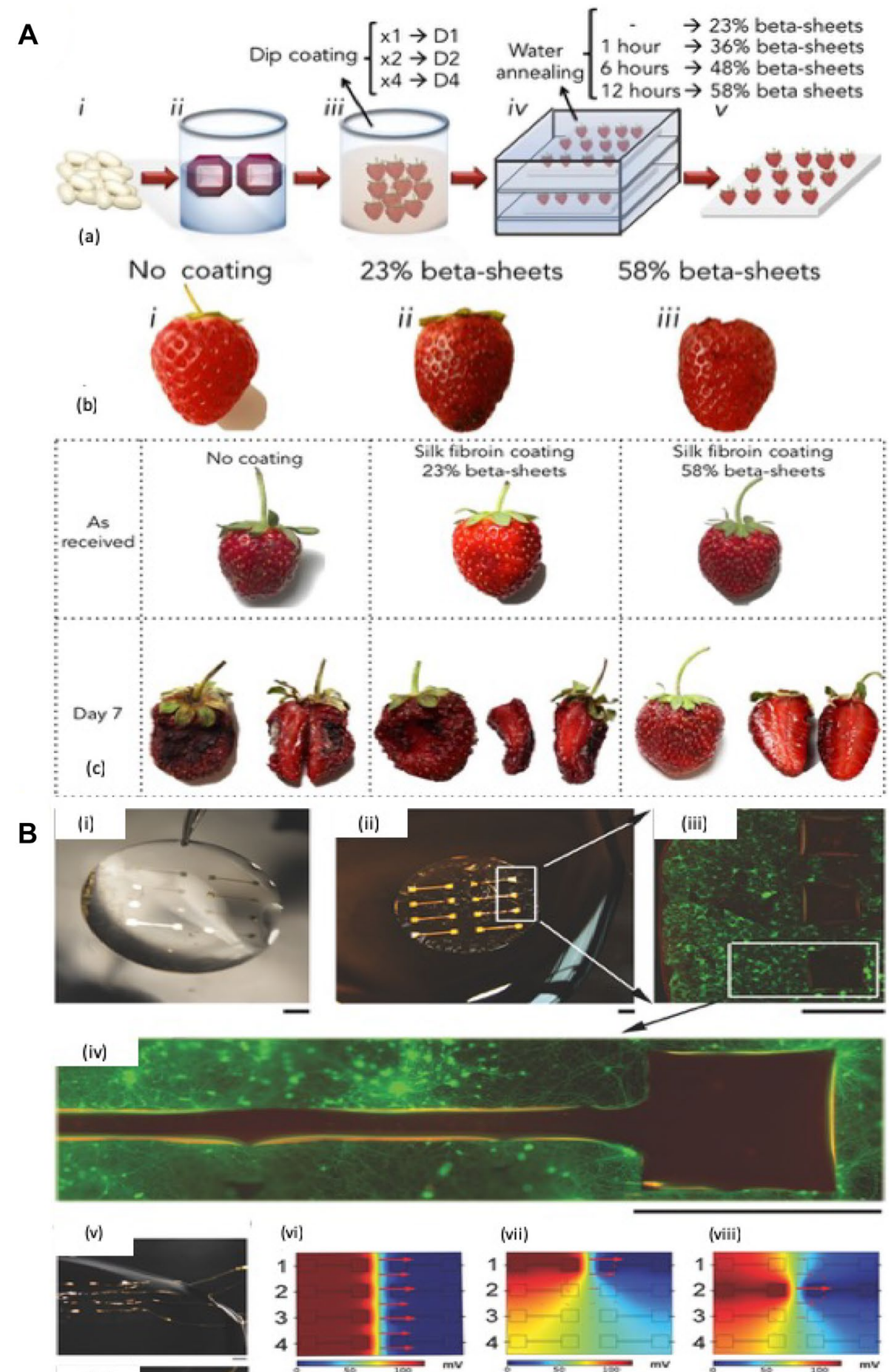

(viii)
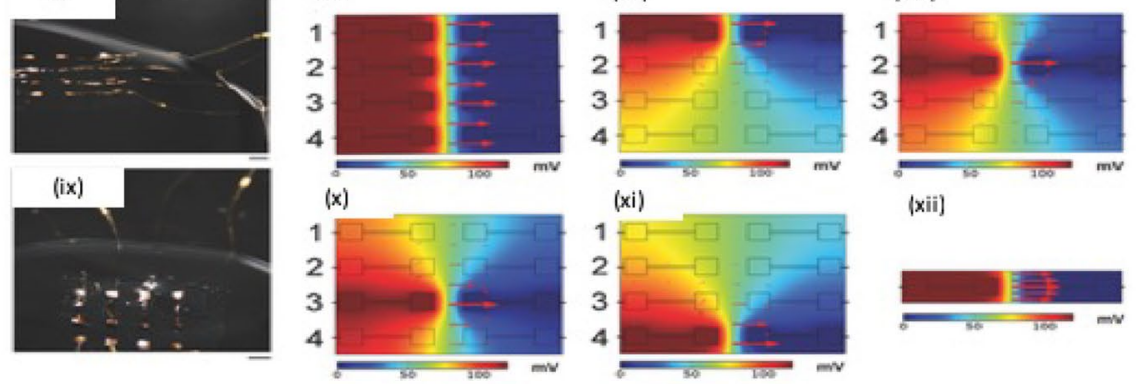

(xii)

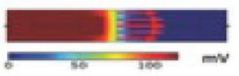


Figure 8: Silk in food technology and electronic devices. A Investigation on the effect of silk fibroin coating on freshly picked strawberries. (a) Isolation of B. mori silk fibroin and coating of strawberries. (i) Bombyx mori silk fibroin extraction from cocoon fibres by $\mathrm{LiBr}$ dissolution and (ii) dialysis in deionized water. (iii) 1 wt\% silk fibroin suspension used for coating of strawberries by dip coating process. (iv) Modulation of beta-sheet content in edible SF coatings by water annealing method. Beta-sheet content of the protein increased with longer exposure to water vapour (up to $12 \mathrm{~h}$ ). (v) Investigation of the impact of SF coating on the quality of fruit left at room conditions. Staining of silk fibroin coating with crystal violet dye. (b) Images represent the stained strawberries that are (i) freshly picked, (ii) silk fibroin edible coated by four dip coating processes having $23 \%$ beta-sheet and (iii) silk fibroin coated by four dip coating processes having $58 \%$ beta-sheet. (c) Time lapse of strawberries ripening. At day 7 , the stored strawberries coated with silk fibroin showed improved quality. (Copyright 2016, reproduced with permission from Nature publication under creative common license CC-BY) ${ }^{335}$. B Integrated neuron-electrode interfaces based on silk films (i) Dried silk films with electrode patterning, supported by a glass coverslip. (iii) Electrode patterning on detached silk films. (iii) and (iv) Representative fluorescence images show electrode-patterned silk film with a mature (DIV 21) calcein AM-stained (green) neural cell culture. Scale bar, $2 \mathrm{~mm}$. (v) and (vi) Water droplets consisting of patterned silk films with built-in gold wire connections (100 $\mu \mathrm{m}$ dia.). Scale bar, $2 \mathrm{~mm}$. (vii), (viii), (ix) and (x) represent electric modelling of silk films having patterned electrode. (xi). Colours represent the electric potentials in $\mathrm{mV}$. Red arrows depict the electric field strength and directions. Arrow size is proportional to electric field strength. (Adapted with permission from ${ }^{356}$, Copyright (02013 Wiley-VCH, Germany)

Biophotonic: Biophotonics is the application of photonics in the field of biology. It involves the development of novel imaging techniques to visualize biological materials like cells and tissues.

Microresonators: They are the microcavities formed by the two reflecting surfaces of an optical medium.

Fluorophore: It is a fluorescent substance that can re-emit light upon excitation by an external light source. It helps in the imaging of various biological components like cellular vesicles. biophotonic devices ${ }^{325}$. Also, silk-based microresonators have been developed for the biophotonic devices ${ }^{326}$. Silk-based bioimaging modalities have been advanced by research in the area of fabrication of fluorescent silk fibroin nanospheres ${ }^{327}$, luminescent silk-based carbon $\operatorname{dots}^{328,329}$ and silk-derived graphene oxide magnetic fluorophore $^{330}$.

\section{Applications of Silk in Allied Healthcare Applications \\ 5.1 Food Technology}

Food and Agricultural Organization (FAO) of the United Nations estimated that a lot of (approximately one-third) food produced annually for human consumption worldwide is lost or wasted ${ }^{331}$. It has been reported that wastage of food not only has an impact on food quality and safety but also is a loss of both economic value and resources. Silk fibroin as a biomaterial has been extensively investigated in textiles, biomedical, photonic, electronic applications and in food technology, 62, 323, 332 . It has been used as edible sensors to monitor cheese ageing as well as fruit ripening ${ }^{323}$. Silk cocoon materials have been reported to have gas diffusion properties. Tailoring of these materials into regenerated protein can be regulated by silk fibroin polymorphism ${ }^{333}$, 334.

Marelli et al. has developed a water-based silk fibroin protein suspension. These suspensions coat on the surface of the food when dipped in it. It has self-assembling property and helps to enhance the shelf life of the food at room conditions by decreasing cellular respiration rate and moisture loss. As reported, protein polymorphism and post-processing are the key parameters in maintaining food freshness by enabling it to modulate the diffusion of gases through the thin membrane of silk fibroin. Dip coating of bananas and strawberries have been used in the study as a proof of principle to depict that a silk fibroin membrane of micrometer thickness around the fruit helps in maintaining the physiology after harvesting (Fig. 8A) ${ }^{335}$.

Pritchard et al. reported silk micro- and macro-particles (diameter ranging from $300 \mu \mathrm{m}$ to $4 \mathrm{~mm}$ ) that have potential applications in food, nutritional and medicinal products ${ }^{336}$. Flavourless and odourless are some of the characteristics of silk fibroin, which are the key parameters for food coating and packaging applications ${ }^{335}$. Veletini et al. developed a living hybrid composite of a single cell fungi and regenerated silk (RS) nanofibrils based on yeast fermentation. The activated metabolic activity of microorganisms with regenerated silk has been reported to not only reduce water permeability but also increases the shelf life of the food over a period of 7 days. Another method of smart food packaging which transfer prints a free standing RS and RS/yeast layer onto an adherent parafilm substrate has been reported. This method can potentially be used to manage food storage conditions by its temperature-sensing mechanism ${ }^{337}$. 
Baycin et al. explored the adsorbent property of silk fibroin. It was used to adsorb olive leaf antioxidants, which increased the antioxidant property of silk and showed antimicrobial activity against $S$. aureus and $K$. pneumonia. Silk fibroin adsorbed with olive leaf antioxidants has been proposed as a biopolymer to produce antioxidant and antimicrobial functional food and dietary supplements ${ }^{338}$. Bombyx mori silk sericin in food is reported to relieve constipation, suppress development of bowel cancer and also increase absorption of minerals ${ }^{339}$. There are several advantages, reported, of using silk sericin in food industry which include its ready availability, non-toxicity, excellent moisture-retaining capacity, antioxidant and good emulsifying and antifrosting agent ${ }^{340-344}$. Silk sericin added in calculated amount in bread is reported to be an ideal processed food that affects digestion and absorption ${ }^{345}$. Silk protein has also been used for the production of baby food which is claimed to prevent and reduce skin disease such as atopic asthma and atopy ${ }^{346}$. Silk protein has also been used for producing health functional food that is claimed to prevent or treat Parkinson's disease ${ }^{347}$.

\subsection{Electronics}

Flexible, stretchable and wearable have been some of the key features of next-generation electronics. Recently, implantable medical devices having electronic components are being developed for therapeutics or functions like cardiovascular regulation, delivery of drugs as well as for biological structure enhancement ${ }^{348}$. Beside these functions, electronic components also increase the sophistication of the medical devices ${ }^{349}$. These electronic devices have been developed to operate while inserted in the living tissue, that might lead to several complications and restrictions on the constituents of the material. Implantable devices should have regulated degradation while functioning reliably and integrate into the biological milieu without inflammation or rejection. Several natural and synthetic polymers such as silk, collagen, gelatin, thermoplastic polyesters have been used to fabricate biodegradable and biocompatible electronic devices ${ }^{350-354}$. Silk due to its unique structure and properties have exhibited several advantages which include robust mechanical properties, tunable degradation and fabrication into several forms. Food and Drug Administration (FDA) approval has made silk suitable for electronic devices with implantable biomedical and healthcare applications (Fig. 8B) ) $^{350,355-358}$.
Tao et al. recently developed a silk-based fully degradable, remote controlled implantable therapeutic device that can counter Staphylococcus aureus infection and be fully resorbed once its function is complete. The device consisted of a serpentine resistor and a coil for receiving power, on a silk substrate. Both the serpentine resistor and the coils were made of magnesium. The device was developed for thermal treatment in infection $\operatorname{area}^{355}$. Kim et al. fabricated thin polyimide films, embedded with PDMS stamp and silicon-based transistors, onto free standing silk fibroin films which showed good mechanical property and bendability without adhesive failure $^{351}$. Silk fibroin-based electrodes have been fabricated for application in supercapacitors composed of carbon-based microporous nanoplates containing heteroatoms- $\mathrm{N}^{359}$. Silk fibroin has also been used as a dielectric material for organic field-effect transistors (OFET), because of its dielectric properties, favourable mechanical flexibility and processability. Wang et al. has developed a flexible pentacene OFET on poly (ethylene terephthalate) by utilising silk fibroin thin films as the gate dielectric ${ }^{360}$.

Silk has also been used for biosensing application. For instance, a flexible and biocompatible graphene field emission effect transistor have been developed by applying silk fibroin as both gate dielectric and substrate for glucose sensing applications ${ }^{361}$. Silk sensors have also been developed for monitoring food quality. A radiofrequency identification (RFID) like silk sensor was developed, for monitoring food quality, by integrating silk substrates with wireless antennas $^{362}$. Despite the evolution, these silk-based sensor platforms are still in a rudimentary stage and more research is needed to address technical challenges.

\subsection{Biomedical Textiles}

For nearly 5 decades, biomedical textiles have been manufactured and used for first aid, clinical and hygiene needs. Synthetic and natural materials are used for engineering fibrous textile structures which are utilised as medical devices to improve the quality of life of the patients ${ }^{363-365}$. Non-implantable fibrous textile structures include wound dressings while implantable ones include vascular grafts, heart valves, polymer sensors and sutures used for medical implants. Advancement in biomedical textiles has given solution for several clinical applications which include tissue engineering, bariatric surgery,
Antimicrobial: Antimicrobials are the chemical compounds that kills (microbicidal) or prevents the growth of microbes (biostatic).

Inflammation: Inflammation is the body's natural protective response arising due to damaging stimuli like pathogenic attack or cellular damage. It can be acute (instant response) or chronic (prolonged response).

Thermoplastic: Thermoplastics are those polymers which gains plasticity (softening) on heating to a high temperature and solidifies (hardens) on reducing the temperature.

Bariatric: Bariatric relates to the pathology or treatment of adipose (fat) tissue-related disorders, majorly obesity. 
Recombinant: It is the use of exogenous DNA engineered into host genome (the complete genetic material in an organism) at very specific sites.

Extracorporeal: It refers to any procedure or biomaterial performing bodily or physiological function outside the host.

Peritoneal: Peritoneal is the abdominal cavity where organs such as stomach, intestines are housed.

Prosthetic: Prosthetic refers to any artificial implant to augment the function of a lost body part.
Atopic dermatitis: Also known as eczema, atopic dermatitis is a chronic skin disease which is characterized by dry and itchy skin, mainly occurring due to different allergies.

Lesions: Lesions are any abnormal damage to healthy tissue.

Thrombogenicity: It is the property of any material to form a blood clot when it comes into contact with blood. orthopaedic, cardiovascular and cosmetic surgeries and veterinary needs ${ }^{134,149,201,366-371}$.

Silk-based biomaterials are clinically employed for several years and are now being recognized as a potential alternative material for biomedical textiles. Silkworms have been domesticated by humans for centuries, while spider silk proteins are produced by recombinant DNA methods 372,373 . There are several other modifications that have been introduced into silk-based biomaterials to make it suitable for biomedical textile applications. The various silkbased biomaterials for biomedical textiles can be categorized into non-implantable materials, implantable materials, extracorporeal implants and healthcare materials.

\subsubsection{Silk-Based Non-Implantable Materials}

In biomedical textiles, non-implantable materials include wound dressings, pressure garments, orthopaedic bandages, prosthetic socks and many others. Silk fabrics have been used very often for wound dressings. It has been used for the fabrication of fibrous mats by non-weaving and electrospinning techniques ${ }^{374}$. It has been reported that silver nanoparticles when blended with silk fibroin gave rise to antibacterial wound dressings. Bacterial growth was inhibited by the combination of Bombyx mori fibroin films and titanium dioxide nanoparticles ${ }^{375}$.

In recent times, a two-layered wound dressing has been developed where wax-coated SF woven fabric was introduced along with a sericin sponge and a bioactive layer of glutaraldehyde crosslinked silk fibroin gelatin. Such wound dressings showed reduction in wound size, epithelialization and collagen formation ${ }^{376,377}$. Chouhan et al. (2018) fabricated nanofibrous mats with silkworm SF coated with recombinant spider silk peptide, cell binding antimicrobial peptides and growth factors showed enhanced cell adhesion as well as antimicrobial activity ${ }^{85}$.

\subsubsection{Silk-Based Implantable Materials}

Implantable materials in biomedical textiles are used for wound closures during surgeries of skin, vascular implants, artificial tendons/ligaments, artificial heart valves and several others. Sutures made out of natural silk fibres have been used for several years. Addition of $50 \mathrm{wt} \%$ PVA into silk fibroin enhanced the tenacity and elongation at break of the fibres as well as increased their knot strength, rendering the mats suitable for suturing ${ }^{378}$. Antimicrobial sutures have been developed by coating Bombyx mori fibres with silver or tetracycline $\mathrm{e}^{379,380}$. The other silk-based implantable materials for replacement of various tissues post-fabrication into various formats have already been thoroughly explored in the previous section dedicated to tissue engineering applications of silk.

\subsubsection{Silk-Based Extracorporeal Implants}

Artificial organs which are involved in the purification of blood are defined as extracorporeal organs. Artificial kidney, artificial liver and mechanical lung are referred to as extracorporeal organs. Silk-based wearable artificial kidney system has been developed recently using ureaseimmobilized SF membrane and polymer-based spherical carbonaceous adsorbent for peritoneal dialysis. In vivo results showed that the filtering system had good efficiency in toxins removal (Fig. 9A $)^{381}$. Janani et al. fabricated a functional liver construct that can potentially be used in an extracorporeal device, using a blend of mulberry and non-mulberry silk fibroin. These scaffolds not only enhanced biological activity but also influenced the spheroidal growth of hepatocytes $^{137}$.

\subsubsection{Other Silk-Based Healthcare Materials}

5.3.4.1 Silk-Based Healthcare/Hygiene Biomedical Textiles Silk-based healthcare/hygiene biomedical textiles have been in clinical applications in the operating theatre which include surgeon's gowns, masks, caps, patient drapes and cover cloths as well. The several advantages of these substances include mechanical property, softness and several antibacterial properties of the silk fabric. Special silk fibre (MICROAIR DermaSilk ${ }^{\circledR}$ ) has been evaluated for its effectivity in the treatment of atopic dermatitis with acute lesions in young children ${ }^{382}$. The results depicted a significant decrease in the severity of atopic dermatitis. Silk mask papers have also been developed by combining silk fibres and nano- $\mathrm{TiO}_{2}$ which has properties like degradation of volatile organic compounds ${ }^{383,384}$.

5.3.4.2 Physical and Chemical Modification of Silk for Biomedical Textiles The surface properties of a biomaterial are very important for its use in biomedical textiles. Surface properties such as topography, hydrophobicity and electrostatics are to be taken into consideration as these properties affect thrombogenicity, antimicrobial behaviour as well as biocompatibility ${ }^{385}$. Coating of $B$. mori silk on poly(propylene) and poly(amide) films has been reported to exhibit antibacterial properties and inhibit the 

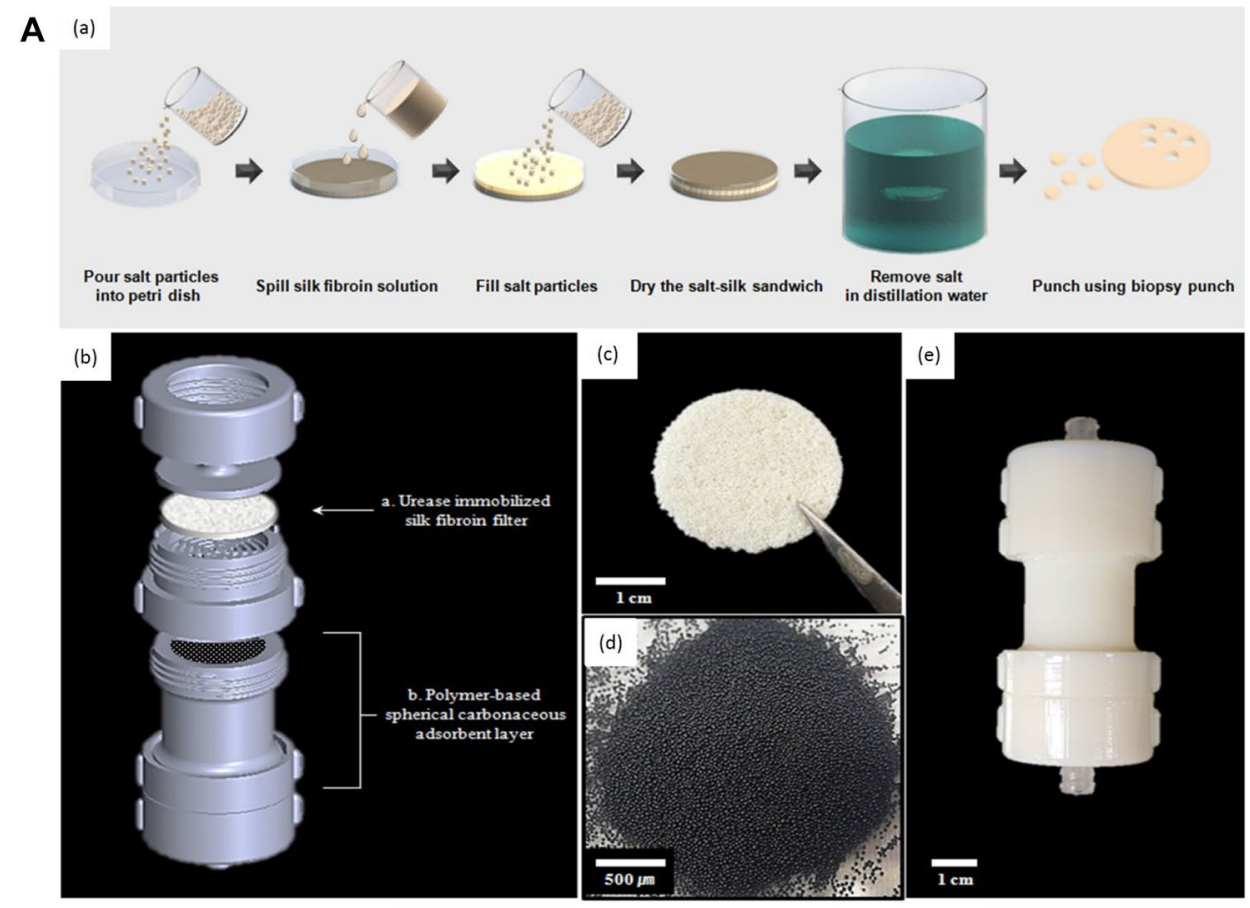

B
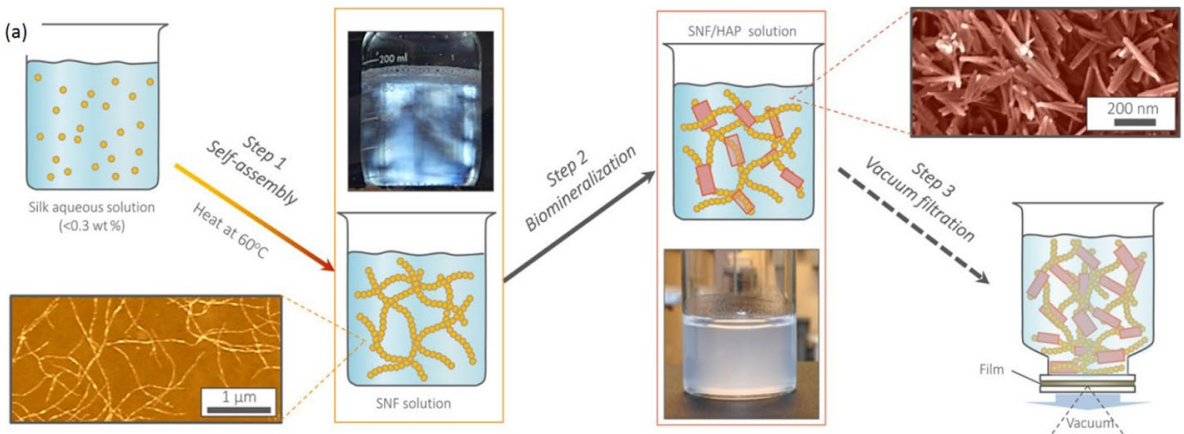

(b)
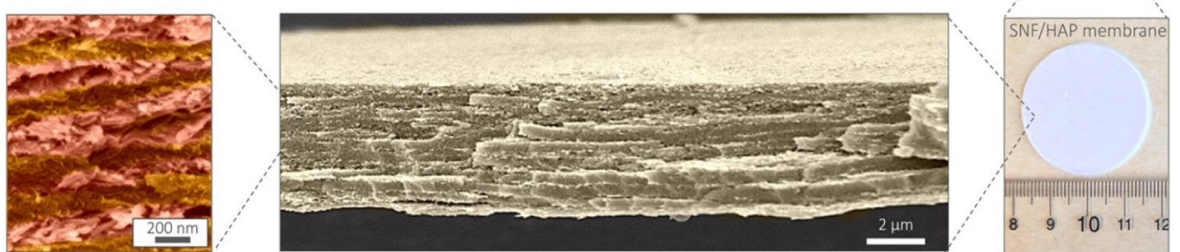

Figure 9: Silk in biomedical devices and bioremediation. A Schematic fabrication procedure of porous silk fibroin (SF) filters membrane and illustration of the filter used for wearable artificial kidney system. (a) Salt-leaching method for the preparation of three-dimensional porous SF membrane. (b) Image of the filter components, (c) Urease-immobilized silk fibroin filter membrane, (d) polymer-based spherical carbonaceous adsorbent and (e) illustration of the filter for wearable artificial kidney system. Figure reproduced with permission from (Sultan et al. 2019) ${ }^{381}$. C2019 Elsevier. B Fabrication procedure of the silk nanofibril (SNF)/hydroxyapatite (HAP) membranes and visualization of the structures formed. (a) Schematic process of the SNF/HAP membranes preparation. Step 1: Assembly of silk into SNFs in aqueous solution. The bottom image in the first row depicts SNFs in an atomic force microscopy (AFM); the top image in the second row indicates the presence of a nematic phase of SNFs, when the SNF solution was under polarized light. Step 2: HAP nanocrystals were grown on the SNFs. The bottom image in the third row is an image of SNF/HAP solution; the top image in the fourth row illustrates biomineralized HAP nanocrystals in scanning electron microscopy (SEM). Step 3: Vacuum filtration was used to assemble the SNF/HAP dispersions into membranes. (b) Illustration of the multilayer structures of the membrane. The first high-resolution crosssectional image depicts SEM image of SNF/HAP membrane. The second SEM image shows nacre-like, highly ordered multilayer structures of the SNF/HAP membrane. The third image is a 4- $\mu$ m-thick SNF/HAP membrane. False colour has been shown in AFM and SEM images. (Copyright 2019, Reproduced with permission from Science Advances under creative common license CC-BY) 
Antithrombic: Antithrombic agents are substances which prevent the formation of blood clots.
Anti-staticity: Anti-staticity is the property of a material or surface which helps in reducing the static charge build up. attachment of Staphylococcus epidermis in vitro ${ }^{386}$. There are several biomedical implants that require anticoagulant coatings. Antithrombic features have been reported by a blend of $B$. mori silk and tetramethylpyrazine or carboxymethyl keratin-modified poly(acrylic acid) ${ }^{387}$. Gogoi et al. studied the surface modification of muga silk fibres using argon plasma treatment. It enhanced the tensile strength and hydrophobicity of the muga silk fibres ${ }^{388}$. Several other studies have been conducted on radio-frequency plasma treatment of silk fibres to alter properties like wetting, flame resistance, antibacterial properties, hydrophobicity, hydrophilicity, shrinkage resistance and tensile properties ${ }^{389-393}$. Chemical modification on silk protein enables site-specific addition of unique chemical moieties. Vepari et al. demonstrated that $\mathrm{pH}$, hydrophobicity and pI influenced the attraction or repulsion of proteins by the silk surface ${ }^{394}$.

\subsection{Cosmetics}

Silk has been used in cosmetics for several years. Sericin and its combination with SF have been used for skin, hair and nail cosmetics. Lotion, cream and ointment have been developed based on silk sericin. These have been reported to show skin elasticity, antiwrinkle and antiaging effects $^{395-397}$. Sheng et al. showed that amino acid composition of sericin is responsible for its moisture absorption and retention capacity, which makes it an ideal substance for maintaining moisture content in the skin and make it more elastic, smooth and soft. It is also reported that sericin inhibits tyrosinase activity and melanochrome formation, which makes it a suitable component for skin whitening cosmetics. Through scanning electron microscopy (SEM), they also displayed that sericin provides excellent hair care and repair effect $^{398}$.

Padamwar et al. demonstrated the moisturizing property of sericin gel. It was reported to enhance hydroxyproline content in the stratum corneum and decrease skin impedance. SEM images revealed the decrease in skin cracking and flaking as compared to the normal skin repli$\operatorname{cas}^{399}$. Anti-staticity and moisture absorbability has been shown by a powder that contains $5-30 \%$ sericin (average molecular weight 7000-3,00000) and $70-95 \%$ SF when applied as films ${ }^{400}$. Miyashita reported that cosmetics containing cellulose fibres soaked with fibroin dispersion and aqueous sericin solution absorb sweat and sebum ${ }^{401}$. Moisturizing and conditioning lotions have been developed with $1 \% \mathrm{w} / \mathrm{w}$ sericin and $4 \% \mathrm{w} / \mathrm{w}$
D-glucose ${ }^{402}$. Creams have also been developed for enhanced cleansing property with less skin irritation, containing $0.001-30 \% \quad \mathrm{w} / \mathrm{w}$ of sericin $^{403}$. Foundation creams and eyeliners have been formulated by coating sericin hydrolysate on talc, titanic, mica, nylon and iron oxide ${ }^{404}$.

Sunscreen consisting of sericin has been reported to enhance the light screening effect of UV filter like triazines and cinnamic acids ester $^{405}$. It has been reported that nail cosmetics consisting of $0.02-20 \%$ sericin prevent nail from becoming brittle, chapping and imparts inherent gloss to nails ${ }^{406}$. Hoppe et al. reported reduction in hair surface damage by hair and bath preparations consisting of $0.02-2 \%$ sericin and $0.01-1 \%$ olive oil, fatty acid or their salts ${ }^{407}$. Conditioners for skin and hair have also been developed consisting of sericin hydrolysates (average molecular weight 300-3000) (08 $^{4}$. Shampoos suitable for care and cleaning of hair have been reported to consist of sericin and pelarogenic acid ${ }^{409}$.

\subsection{Bioremediation}

Remediation of polluted land, air and groundwater is a major environmental issue having worldwide significance ${ }^{410}$. Silk has been extensively used singly or in combination with other polymers for the removal of heavy metals from aqueous solution, purification of water, as an adsorbent for toxic dyes and in air filtration ${ }^{411-417}$. Xiao et al. developed ultrafine silk fibroin powder which could be used as low-cost adsorbents for the removal of dyes from printing wastewater ${ }^{418}$.

Gao et al. developed a modified SF membrane (water insoluble) by blending fibroin and silane coupling agent and used it for the adsorption of six metal ions, $\mathrm{Cu}(\mathrm{II}), \mathrm{Co}(\mathrm{II}), \mathrm{Ni}(\mathrm{II}), \mathrm{Cr}(\mathrm{III})$, $\mathrm{Pb}(\mathrm{II})$ and $\mathrm{Cd}(\mathrm{II})^{419}$. Ajitha et al. reported a practical and highly efficient method for treatment of water containing toxic heavy metals at a moderate concentration. A novel chitosan oligosaccharidegraft-maleic anhydride(COS-g-MAH)/polyvinyl alcohol (PVA)/silk fibroin (SF) composite was fabricated for removal of toxic heavy metal lead (II) ion from aqueous solution ${ }^{420}$. Pelit et al. reported the potential use of natural spider silk as a biosorbent for $\mathrm{Cu}(\mathrm{II})$ and $\mathrm{Pb}$ (II) ions from aqueous solutions ${ }^{410}$. Kwak et al. fabricated silk sericin beads modified by polyethylenimine (PEI) for potential $\mathrm{Cr}(\mathrm{VI})$ adsorption and detoxification of aqueous solutions ${ }^{421}$. Also, Kwak et al. fabricated sericin-derived activated carbon/alginate beads that served as economical adsorbents for the removal of contaminants from water ${ }^{422}$. 
Ling et al. fabricated a low-cost and highly efficient silk nanofibril and hydroxyapatite-based multilayer membrane with nanoporous features that can be used for purification of water for various applications (Fig. 9B) ${ }^{416}$. Min et al. developed a highly efficient and multifunctional silk nanofibrous air filter that not only has chemosensing functions but also air-filtering capacity. It can be used as a translucent window screen which provides viewability and controls room temperature ${ }^{423}$. Silk fibroin fibres have also been modified to prepare a superhydrophobic natural sorbent that can adsorb oil efficiently from water surfaces, while repelling water. The adsorbed oil can be removed from the fibres by squeezing and the fibres can be reused. This approach promotes silk fibres for repeated usage in oil spill clean-up applications ${ }^{424}$.

\section{Opportunities and Challenges}

With increase in the population size, there is an increase in the demand for biomedical and healthcare needs. Silk-based biomaterials are being used in conjunction with other polymeric materials for various healthcare and clinical applications. Owing to its biodegradability, biocompatibility, easy processability and immense tensile strength, silk has paved its way into the healthcare industry ${ }^{199}$. Low immunogenicity and high tunability also add up to its set of marvellous properties in tandem, thereby proving the importance of silk in healthcare applications such as tissue engineering, drug delivery, biomedical imaging and cancer therapeutics ${ }^{199,}{ }^{201}$. Many natural and synthetic polymers have been investigated in the past few years for tissue engineering, but the latter poses disadvantages in biocompatibility and immune rejection in the long run ${ }^{425}$. Silk is an ideal biomaterial for tissue engineering due to its tuneability to mimic the native extracellular matrix of various tissues ${ }^{201}$. Though some of the products have achieved clinical translation over the past few decades, but there are many avenues that are yet to be forwarded by regulatory authorities for application in the real world. Though silk-based healthcare products have shown tremendous potential as ideal healthcare materials in tissue engineering domain, yet the translation remains a demand of the future. Similarly, the field of silk-based biomedical imaging, sensing and electronics is at its nascent stage and is advancing exponentially to reach the efficacy of the conventional counterparts as silk is biocompatible and non-toxic. Also, the field of cosmetics and food technology is poised to benefit tremendously with the translation of silk-based modalities with little to no side effects of the same. Also, silk can offer cost-effective bioremediation solutions for areas where the drinking water is contaminated with heavy metals and other pollutants leading to health hazards.

\section{Conclusion}

Silk is one of the most promising biopolymers bestowed with excellent biocompatibility, low immunogenicity, tuneable mechanical strength and regulated degradability with non-toxic byproducts. It is one of the prime sources of livelihood for many families in the Asian countries and remains popular among researchers for its easy availability and marvellous processability. For instance, exploitation of endemic nonmulberry silk varieties would open avenues for utilisation of this bioresource for prospective biomedical research more extensively and in turn help the local dwindling sericulture industry by creating new job opportunities and help in preserving the biodiversity. The inherent characteristics confer silk with the potential to be employed in multitude of applications across the wide spectrum of healthcare products and modalities. Silk has been found its purpose in the facile fabrication of wound dressings, textiles and sutures since the olden days. It continues to fascinate researchers all over the globe with its immense potential for applications spanning cosmetics, cancer therapeutics, tissue-on-chip screening platforms, tissue-engineered artificial grafts and organs, food preservation and bioremediation. Though a few bottlenecks still exist in the regulatory aspects of the various silk-based technologies and products, the advantages of using silk-based solutions far outweigh the hurdles being faced in the development of finished marketable products for the future.

\section{Publisher's Note}

Springer Nature remains neutral with regard to jurisdictional claims in published maps and institutional affiliations.

\section{Acknowledgements}

BBM thankfully acknowledges funding support from Department of Biotechnology (DBT) and Department of Science and Technology (DST), Government of India. AB, SD and JCM express their gratitude to MHRD, Govt. of India for their research fellowship. 
Received: 30 June 2019 Accepted: 7 August 2019 Published online: 24 August 2019

\section{References}

1. Park J, Lakes RS (2007) Introduction to silk biomaterials. In: Biomaterials: an introduction, 3 edn. SpringerVerlag, New York, pp 1-16

2. Kohn J (2004) New approaches to biomaterials design. Nat Mater 3:745-747

3. Ramakrishna S, Mayer J, Wintermantel E, Leong KW (2001) Biomedical applications of polymer-composite materials: a review. Compos Sci Technol 61:1189-1224

4. Netravali AN, Chabba S (2003) Composites get greener. Mater Today 6:22-29

5. Rockwood DN et al (2011) Materials fabrication from Bombyx mori silk fibroin. Nat Protocols 6:1612

6. Goel A (2015) Surgical sutures-a review. Off Sci J Delhi Ophthalmol Soc 26:159-162

7. Omenetto FG, Kaplan DL (2010) New opportunities for an ancient material. Science 329:528-531

8. Kim S et al (2014) All-water-based electron-beam lithography using silk as a resist. Nat Nanotechnol 9:306-310

9. Tao H, Kaplan DL, Omenetto FG (2012) Silk materials-a road to sustainable high technology. Adv Mater 24:2824-2837

10. Marelli B, Brenckle M, Kaplan D, Omenetto F (2016) Silk Fibroin as edible coating for perishable food preservation. Sci Rep 6:25263

11. Zhang J et al (2012) Stabilization of vaccines and antibiotics in silk and eliminating the cold chain. Proc Natl Acad Sci 109:11981-11986

12. Konwarh R, Bhunia BK, Mandal BB (2017) Opportunities and challenges in exploring Indian non-mulberry silk for biomedical applications. Proc Indian Natl Sci Acad 83(1):85-101

13. Kundu $S$ et al (2012) Nonmulberry silk biopolymers. Biopolymers 97:455-467

14. Rahmathulla V (2012) Management of climatic factors for successful silkworm (Bombyx mori L.) crop and higher silk production: a review. Psyche J Entomol 2012

15. Consortium ISG (2008) The genome of a lepidopteran model insect, the silkworm Bombyx mori. Insect Biochem Mole Biol 38:1036-1045

16. Hu X et al (2011) Regulation of silk material structure by temperature-controlled water vapor annealing. Biomacromol 12:1686-1696

17. Jin H-J, Kaplan DL (2003) Mechanism of silk processing in insects and spiders. Nature 424:1057-1061

18. Asakura T, Yao J, Yang M, Zhu Z, Hirose H (2007) Structure of the spinning apparatus of a wild silkworm Samia cynthia ricini and molecular dynamics calculation on the structural change of the silk fibroin. Polymer 48:2064-2070
19. Malay AD et al (2016) Relationships between physical properties and sequence in silkworm silks. Sci Rep 6:27573

20. Inoue $S$ et al (2004) Assembly of the silk fibroin elementary unit in endoplasmic reticulum and a role of L-chain for protection of a 1, 2-mannose residues in N-linked oligosaccharide chains of fibrohexamerin/ P25. Eur J Biochem 271:356-366

21. Naskar D, Barua RR, Ghosh AK, Kundu SC (2014) Introduction to silk biomaterials. In: Kundu SC (ed) Silk biomaterials for tissue engineering and regenerative medicine. Woodhead Publishing, pp 3-40

22. Cheng $Y$ et al (2014) On the strength of $\beta$-sheet crystallites of Bombyx mori silk fibroin. J R Soc Interface 11:20140305

23. Yukuhiro K, Sezutsu H, Yonemura N (2014) Evolutionary divergence of Lepidopteran and Trichopteran fibroins. In: Asakura T, Miller T (eds) Biotechnology of silk. Springer, Dordrecht, pp 25-47

24. Chattopadhyay SDR, Gulrajani M, Sen K (2005) Study of property and structural variants of mulberry and tasar silk filaments. AUTEX Res J 5:81-86

25. Kundu SC, Dash BC, Dash R, Kaplan DL (2008) Natural protective glue protein, sericin bioengineered by silkworms: potential for biomedical and biotechnological applications. Prog Polym Sci 33:998-1012

26. Kumar JP, Mandal BB (2017) Antioxidant potential of mulberry and non-mulberry silk sericin and its implications in biomedicine. Free Radic Biol Med 108:803-818

27. Kumar JP, Alam S, Jain AK, Ansari KM, Mandal BB (2018) Protective activity of silk sericin against UV radiation-induced skin damage by downregulating oxidative stress. ACS Appl Bio Mater 1:2120-2132

28. Javali UC, Padaki NV, Das B, Malali KB (2015) Developments in the use of silk by-products and silk waste. In: Basu A (ed) Advances in silk science and technology. Woodhead Publishing, pp 261-270

29. Jadi PK, Mandal BB (2019) Inhibitory role of silk cocoon extract on elastase, hyaluronidase and UV radiation-induced matrix metalloproteinases expression in human dermal fibroblast and keratinocytes. Photochem Photobiol Sci 18(5):1259-1274

30. Lewis RV (2006) Spider silk: ancient ideas for new biomaterials. Chem Rev 106:3762-3774

31. Heim M, Keerl D, Scheibel T (2009) Spider silk: from soluble protein to extraordinary fiber. Angewandte Chemie Int Edit 48:3584-3596

32. Eisoldt L, Smith A, Scheibel T (2011) Decoding the secrets of spider silk. Mat Today 14:80-86

33. Hu X et al (2007) Analysis of aqueous glue coating proteins on the silk fibers of the cob weaver, Latrodectus Hesperus. Biochemistry 46:3294-3303

34. Vollrath F et al (1990) Compounds in the droplets of the orb spider's viscid spiral. Nature 345:526 
35. Tokareva O, Jacobsen M, Buehler M, Wong J, Kaplan DL (2014) Structure-function-property-design interplay in biopolymers: spider silk. Acta Biomater 10:1612-1626

36. Hu X et al (2006) Molecular mechanisms of spider silk. Cell Mol Life Sci CMLS 63:1986-1999

37. Basu A (ed) (2015) Advances in understanding the properties of silk. In: Advances in silk science and technology. Woodhead Publishing, pp 3-16

38. Kundu B, Rajkhowa R, Kundu SC, Wang X (2013) Silk fibroin biomaterials for tissue regenerations. Adv Drug Deliv Rev 65:457-470

39. Giesa T, Arslan M, Pugno NM, Buehler MJ (2011) Nanoconfinement of spider silk fibrils begets superior strength, extensibility, and toughness. Nano Lett 11:5038-5046

40. Yucel T, Lovett ML, Kaplan DL (2014) Silk-based biomaterials for sustained drug delivery. J Controll Release 190:381-397

41. Mai-Ngam K, Boonkitpattarakul K, Jaipaew J, MaiNgam B (2011) Evaluation of the properties of silk fibroin films from the non-mulberry silkworm Samia cynthia ricini for biomaterial design. J Biomater Sci Polym Edit 22:2001-2022

42. Mieszawska AJ et al (2011) Clay enriched silk biomaterials for bone formation. Acta Biomater 7:3036-3041

43. Gupta P et al (2016) Mimicking form and function of native small diameter vascular conduits using mulberry and non-mulberry patterned silk films. ACS Appl Mater Interfac 8(25):15874-15888

44. Koeppel A, Holland C (2017) Progress and trends in artificial silk spinning: a systematic review. ACS Biomater Sci Eng 3:226-237

45. Lewis R (1996) Unraveling the weave of spider silk: one of nature's wondrous chemical structures is being dissected so that it can be used in human inventions. Bioscience 46:636-638. https://doi.org/10.2307/1312891

46. Boutry C, Blackledge TA (2010) Evolution of supercontraction in spider silk: structure-function relationship from tarantulas to orb-weavers. J Exp Biol 213:3505-3514

47. Liu Y, Shao Z, Vollrath F (2005) Relationships between supercontraction and mechanical properties of spider silk. Nat Mater 4:901

48. Widhe M, Johansson J, Hedhammar M, Rising A (2012) Current progress and limitations of spider silk for biomedical applications. Biopolymers 97:468-478

49. Singh H, Kumar NS (2010) On the breeding of bivoltine breeds of the silkworm, Bombyx mori L.(Lepidoptera: Bombycidae), tolerant to high temperature and high humidity conditions of the tropics. Psyche J Entomol 2010

50. Browne S, Zeugolis DI, Pandit A (2013) Collagen: finding a solution for the source. Tissue Eng Part A 19:1491-1494
51. Bettinger CJ et al (2007) Silk fibroin microfluidic devices. Adv Mater 19:2847-2850

52. Mandal BB, Kundu S (2008) A novel method for dissolution and stabilization of non-mulberry silk gland protein fibroin using anionic surfactant sodium dodecyl sulfate. Biotechnol Bioeng 99:1482-1489

53. Yamada H, Nakao H, Takasu Y, Tsubouchi K (2001) Preparation of undegraded native molecular fibroin solution from silkworm cocoons. Mater Sci Eng C 14:41-46

54. Ajisawa A (1998) Dissolution of silk fibroin with calcium chloride/ethanol aqueous solution. J Seric Sci Jpn 67:91-94

55. Asakura T, Yao J, Yamane T, Umemura K, Ulrich AS (2002) Heterogeneous structure of silk fibers from Bombyx M Ori Resolved by 13C Solid-State NMR spectroscopy. J Am Chem Soc 124:8794-8795

56. Asakura T, Yoshimizu H, Yoshizawa F (1988) NMR of silk fibroin. 9. Sequence and conformation analyses of the silk fibroins from Bombyx mori and Philosamia cynthia ricini by $15 \mathrm{~N}$ NMR spectroscopy. Macromolecules 21:2038-2041

57. Gupta P et al (2016) Mimicking form and function of native small diameter vascular conduits using mulberry and non-mulberry patterned silk films. ACS Appl Mater Interfaces 8:15874-15888

58. Moses JC, Nandi SK, Mandal BB (2018) Multifunctional cell instructive silk-bioactive glass composite reinforced scaffolds toward osteoinductive, proangiogenic, and resorbable bone grafts. Adv Healthc Mater 7:1701418

59. Gupta A, Mita K, Arunkumar KP, Nagaraju J (2015) Molecular architecture of silk fibroin of Indian golden silkmoth, Antheraea assama. Sci Rep 5:12706

60. Mandal BB, Kundu SC (2009) Osteogenic and adipogenic differentiation of rat bone marrow cells on nonmulberry and mulberry silk gland fibroin 3D scaffolds. Biomaterials 30:5019-5030

61. Mandal BB, Kundu SC (2009) Cell proliferation and migration in silk fibroin 3D scaffolds. Biomaterials 30:2956-2965

62. Gangrade A, Mandal BB (2019) An injectable carbon nanotube impregnated silk based multifunctional hydrogel for localized targeted and on demand anticancer drug delivery. ACS Biomater Sci Eng 5(5):2365-2381

63. Chouhan D, Lohe TU, Samudrala PK, Mandal BB (2018) In Situ forming injectable silk fibroin hydrogel promotes skin regeneration in full thickness burn wounds. Adv Healthc Mater 7:1801092

64. Kumar M, Gupta P, Bhattacharjee S, Nandi SK, Mandal BB (2018) Immunomodulatory injectable silk hydrogels maintaining functional islets and promoting antiinflammatory M2 macrophage polarization. Biomaterials 187:1-17 
65. Bhunia BK, Mandal BB (2018) Modulation of extracellular matrix by annulus fibrosus cells on tailored silk based angle-ply intervertebral disc construct. Mater Des 158:74-87

66. Chouhan D, Chakraborty B, Nandi SK, Mandal BB (2017) Role of non-mulberry silk fibroin in deposition and regulation of extracellular matrix towards accelerated wound healing. Acta Biomater 48:157-174

67. Chouhan D, Janani G, Chakraborty B, Nandi SK, Mandal BB (2018) Functionalized PVA-silk blended nanofibrous mats promote diabetic wound healing via regulation of extracellular matrix and tissue remodelling. J Tissue Eng Regen Med 12:e1559-e1570

68. Silva SS et al (2013) Silk hydrogels from non-mulberry and mulberry silkworm cocoons processed with ionic liquids. Acta Biomater 9:8972-8982

69. Srivastava CM, Purwar R, Gupta AP (2019) Enhanced potential of biomimetic, silver nanoparticles functionalized Antheraea mylitta (tasar) silk fibroin nanofibrous mats for skin tissue engineering. Int J Biol Macromol 130:437-453

70. Goujon N, Rajkhowa R, Wang X, Byrne N (2013) Effect of solvent on ionic liquid dissolved regenerated Antheraea assamensis silk fibroin. J Appl Polym Sci 128:4411-4416

71. Pereira RF et al (2018) Ionic liquid-assisted synthesis of mesoporous silk fibroin/silica hybrids for biomedical applications. ACS Omega 3:10811-10822

72. Stanton J et al (2018) Impact of ionic liquid type on the structure, morphology and properties of silkcellulose biocomposite materials. Int J Biol Macromol 108:333-341

73. Murphy AR, Kaplan DL (2009) Biomedical applications of chemically-modified silk fibroin. J Mater Chem 19:6443-6450

74. Acharya C, Hinz B, Kundu SC (2008) The effect of lactose-conjugated silk biomaterials on the development of fibrogenic fibroblasts. Biomaterials 29:4665-4675

75. Meinel L et al (2006) Silk based biomaterials to heal critical sized femur defects. Bone 39:922-931

76. Kim SH et al (2018) Precisely printable and biocompatible silk fibroin bioink for digital light processing 3D printing. Nat Commun 9:1620

77. Rnjak-Kovacina J, DesRochers TM, Burke KA, Kaplan DL (2015) The effect of sterilization on silk fibroin biomaterial properties. Macromol Biosci 15:861-874

78. Hofmann S, Stok KS, Kohler T, Meinel AJ, Müller R (2014) Effect of sterilization on structural and material properties of 3-D silk fibroin scaffolds. Acta Biomater 10:308-317

79. Rim N-G et al (2017) Predicting silk fiber mechanical properties through multiscale simulation and protein design. ACS Biomater Sci Eng 3:1542-1556

80. Tran DP, Lam VT, Tran TL, Nguyen TNS, Tran HTT (2018) In silico study of Bombyx mori fibroin enhancement by graphene in acidic environment. Phys Chem Chem Phys 20:19240-19249

81. Cheng Y et al (2015) Peptide-graphene interactions enhance the mechanical properties of silk fibroin. ACS Appl Mater Interfaces 7:21787-21796

82. López Barreiro D, Yeo J, Tarakanova A, Martin-Martinez FJ, Buehler MJ (2019) Multiscale modeling of silk and silk-based biomaterials-a review. Macromol Biosci 19:1800253

83. Zhu Z et al (2018) High-strength, durable all-silk fibroin hydrogels with versatile processability toward multifunctional applications. Adv Func Mater 28:1704757

84. Chung H, Kim TY, Lee SY (2012) Recent advances in production of recombinant spider silk proteins. Curr Opin Biotechnol 23:957-964

85. Chouhan D et al (2018) Recombinant spider silk functionalized silkworm silk matrices as potential bioactive wound dressings and skin grafts. ACS Appl Mater Interfaces 10:23560-23572

86. Nilebäck L et al (2017) Silk-silk interactions between silkworm fibroin and recombinant spider silk fusion proteins enable the construction of bioactive materials. ACS Appl Mater Interfaces 9:31634-31644

87. Wang $\mathrm{Y}$ et al (2008) In vivo degradation of threedimensional silk fibroin scaffolds. Biomaterials 29:3415-3428

88. Panilaitis B et al (2003) Macrophage responses to silk. Biomaterials 24:3079-3085

89. Numata K, Cebe P, Kaplan DL (2010) Mechanism of enzymatic degradation of beta-sheet crystals. Biomaterials 31:2926-2933. https://doi.org/10.1016/j.bioma terials.2009.12.026

90. Hu Y, Zhang Q, You R, Wang L, Li M (2012) The relationship between secondary structure and biodegradation behavior of silk fibroin scaffolds. Adv Mater Sci Eng 2012:185905. https://doi.org/10.1155/2012/185905

91. Rajkhowa R, Hu X, Tsuzuki T, Kaplan DL, Wang X (2012) Structure and biodegradation mechanism of milled Bombyx mori silk particles. Biomacromol 13:2503-2512

92. Wang $\mathrm{Y}$ et al (2008) In vivo degradation of threedimensional silk fibroin scaffolds. Biomaterials 29:3415-3428. https://doi.org/10.1016/j.biomateria 1s. 2008.05 .002

93. Takasu Y, Yamada H, Tsubouchi K (2002) Isolation of three main sericin components from the cocoon of the silkworm, Bombyx mori. Biosci Biotechnol Biochem 66:2715-2718

94. Yang G, Wu M, Yi H, Wang J (2016) Biosynthesis and characterization of a non-repetitive polypeptide derived from silk fibroin heavy chain. Mater Sci Eng C 59:278-285

95. Tanaka K, Mizuno S (2001) Homologues of fibroin L-chain and P25 of Bombyx mori are present in Dendrolimus spectabilis and Papilio xuthus but not 
detectable in Antheraea yamamai. Insect Biochem Mol Biol 31:665-677

96. Dutta S, Bharali R, Devi R, Devi D (2012) Purification and characterization of glue like sericin protein from a wild silkworm Antheraea assamensis helfer. Glob J Bio Sci Biotechnol (GJBB) 1:229-233

97. Ho M-P, Wang H, Lau K-T (2012) Effect of degumming time on silkworm silk fibre for biodegradable polymer composites. Appl Surf Sci 258:3948-3955

98. Tao W, Li M, Zhao C (2007) Structure and properties of regenerated Antheraea pernyi silk fibroin in aqueous solution. Int J Biol Macromol 40:472-478

99. Nayak S, Kundu SC (2016) Silk protein sericin: promising biopolymer for biological and biomedical applications. In: Biomaterials from nature for advanced devices and therapies. Wiley-Society for Biomaterials, pp 142-154

100. Kobayashi I, Kojima K, Sezutsu H, Uchino K, Tamura T (2009) Expression of the Japanese oak silkworm Antheraea yamamai fibroin gene in the domesticated silkworm Bombyx mori. Insect Sci 16:465-473

101. Zurovec $M$ et al (2016) Sericin composition in the silk of Antheraea yamamai. Biomacromolecules 17(5):1776-1787

102. Pal S, Kundu J, Talukdar S, Thomas T, Kundu SC (2013) An emerging functional natural silk biomaterial from the only domesticated non-mulberry silkworm Samia ricini. Macromol Biosci 13:1020-1035

103. Ahmad R, Kamra A, Hasnain SE (2004) Fibroin silk proteins from the nonmulberry silkworm Philosamia ricini are biochemically and immunochemically distinct from those of the mulberry silkworm Bombyx mori. DNA Cell Biol 23:149-154

104. Suzuki Y et al (2015) Structural determination of the tandem repeat Motif in Samia cynthia ricini Liquid silk by solution NMR. Macromolecules 48:6574-6579

105. Gaines WA IV, Marcotte WR Jr (2008) Identification and characterization of multiple Spidroin 1 genes encoding major ampullate silk proteins in Nephila clavipes. Insect Mol Biol 17:465-474

106. Choresh O, Bayarmagnai B, Lewis RV (2009) Spider web glue: two proteins expressed from opposite strands of the same DNA sequence. Biomacromol 10:2852-2856

107. dos Santos-Pinto JRA, Arcuri HA, Esteves FG, Palma MS, Lubec G (2018) Spider silk proteome provides insight into the structural characterization of Nephila clavipes flagelliform spidroin. Sci Rep 8:14674

108. Li X, Shi C-H, Tang C-L, Cai Y-M, Meng Q (2017) The correlation between the length of repetitive domain and mechanical properties of the recombinant flagelliform spidroin. Biol Open 6:333-339

109. Perry DJ, Bittencourt D, Siltberg-Liberles J, Rech EL, Lewis RV (2010) Piriform spider silk sequences reveal unique repetitive elements. Biomacromol 11:3000-3006
110. Gao Z et al (2013) Structural characterization of minor ampullate spidroin domains and their distinct roles in fibroin solubility and fiber formation. PLoS ONE 8:e56142

111. Lin Z, Huang W, Zhang J, Fan J-S, Yang D (2009) Solution structure of egg case silk protein and its implications for silk fiber formation. Proc Natl Acad Sci 106:8906-8911

112. Vasanthavada $\mathrm{K}$ et al (2007) Aciniform spidroin, a constituent of egg case sacs and wrapping silk fibers from the black widow spider Latrodectus hesperus. J Biol Chem 282:35088-35097

113. Sen K, Babu K (2004) Studies on Indian silk. I. Macrocharacterization and analysis of amino acid composition. J Appl Polym Sci 92:1080-1097

114. Reddy N, Yang Y (2010) Structure and properties of cocoons and silk fibers produced by Hyalophora cecropia. J Mater Sci 45:4414-4421

115. Zhang J et al (2015) Surface energy of silk fibroin and mechanical properties of silk cocoon composites. RSC Advances 5:1640-1647

116. Reddy N, Yang Y (2012) Investigation of the structure and properties of silk fibers produced by Actias lunas. J Polym Environ 20:659-664

117. Sezutsu H, Tamura T, Yukuhiro K (2008) Leucine-rich fibroin gene of the Japanese wild silkmoth, Rhodinia fugax (Lepidoptera: Saturniidae). Eur J Entomol 105:561

118. Plaza GR et al (2012) Relationship between microstructure and mechanical properties in spider silk fibers: identification of two regimes in the microstructural changes. Soft Matter 8:6015-6026

119. Pérez-Rigueiro J, Elices M, Llorca J, Viney C (2001) Tensile properties of Argiope trifasciata drag line silk obtained from the spider's web. J Appl Polym Sci 82:2245-2251

120. Swanson B, Blackledge T, Beltrán J, Hayashi C (2006) Variation in the material properties of spider dragline silk across species. Appl Phys A 82:213-218

121. Grubb DT, Jelinski LW (1997) Fiber morphology of spider silk: the effects of tensile deformation. Macromolecules 30:2860-2867

122. Tien LW, Gil ES, Park SH, Mandal BB, Kaplan DL (2012) Patterned silk film scaffolds for aligned lamellar bone tissue engineering. Macromol Biosci 12:1671-1679

123. Gil ES, Park SH, Marchant J, Omenetto F, Kaplan DL (2010) Response of human corneal fibroblasts on silk film surface patterns. Macromol Biosci 10:664-673

124. Luan X-Y et al (2006) Attachment and growth of human bone marrow derived mesenchymal stem cells on regenerated Antheraea pernyi silk fibroin films. Biomed Mater 1:181

125. Gupta P, Moses JC, Mandal BB (2018) Surface patterning and innate physicochemical attributes of silk films concomitantly govern vascular cell dynamics. ACS Biomater Sci Eng 5:933-949 
126. Yang $M$ et al (2014) Mineralization and biocompatibility of Antheraea pernyi (A. pernyi) silk sericin film for potential bone tissue engineering. Bio Med Mater Eng 24:815-824

127. Nishida A et al (2011) Sustained-release of protein from biodegradable sericin film, gel and sponge. Int J Pharm 407:44-52

128. Kumar JP, Bhardwaj N, Mandal BB (2016) Crosslinked silk sericin-gelatin $2 \mathrm{D}$ and $3 \mathrm{D}$ matrices for prospective tissue engineering applications. RSC Adv 6:105125-105136

129. Huemmerich D, Slotta U, Scheibel T (2006) Processing and modification of films made from recombinant spider silk proteins. Appl Phys A 82:219-222

130. Huang J, Wong C, George A, Kaplan DL (2007) The effect of genetically engineered spider silk-dentin matrix protein 1 chimeric protein on hydroxyapatite nucleation. Biomaterials 28:2358-2367

131. Bai J et al (2006) Regenerated spider silk as a new biomaterial for MEMS. Biomed Microdevice 8:317-323

132. Dao AT, Shimokata JI, Takeuchi K, Nakayama K, Taniike T (2018) Stabilization of recombinant spider silk in thermo-oxidative degradation: high-throughput screening for antioxidants. Polym Degrad Stabil 153:37-46

133. Mandal BB, Kundu SC (2008) Non-bioengineered silk fibroin protein 3D scaffolds for potential biotechnological and tissue engineering applications. Macromol Biosci 8:807-818

134. Mandal BB, Grinberg A, Gil ES, Panilaitis B, Kaplan DL (2012) High-strength silk protein scaffolds for bone repair. Proc Natl Acad Sci 109:7699-7704

135. Gupta P, Adhikary M, Kumar M, Bhardwaj N, Mandal BB (2016) Biomimetic, osteoconductive non-mulberry silk fiber reinforced tricomposite scaffolds for bone tissue engineering. ACS Appl Mater Interfaces 8:30797-30810

136. Bhardwaj $\mathrm{N}$ et al (2016) Potential of silk fibroin/chondrocyte constructs of muga silkworm Antheraea assamensis for cartilage tissue engineering. J Mater Chem B 4:3670-3684

137. Janani G, Nandi SK, Mandal BB (2018) Functional hepatocyte clusters on bioactive blend silk matrices towards generating bioartificial liver constructs. Acta Biomater 67:167-182

138. Kumar M, Nandi SK, Kaplan DL, Mandal BB (2017) Localized immunomodulatory silk macrocapsules for islet-like spheroid formation and sustained insulin production. ACS Biomat Sci Eng 3:2443-2456

139. Singh YP, Moses JC, Bhunia BK, Nandi SK, Mandal BB (2018) Hierarchically structured seamless silk scaffolds for osteochondral interface tissue engineering. J Mater Chem B 6:5671-5688

140. Singh YP, Adhikary M, Bhardwaj N, Bhunia BK, Mandal BB (2017) Silk fiber reinforcement modulates in vitro chondrogenesis in 3D composite scaffolds. Biomed Mater 12:045012

141. Sahu N et al (2015) Nonmulberry silk fibroin scaffold shows superior osteoconductivity than mulberry silk fibroin in calvarial bone regeneration. Adv Healthc Mater 4:1709-1721

142. Kaplan DL, Mandal BB; Tufts University (2015) Multilayered silk scaffolds for meniscus tissue engineering. United States patent US8986380B2, granted: March 24

143. Pritchard EM, Kaplan DL (2011) Silk fibroin biomaterials for controlled release drug delivery. Expert Opin Drug Deliver 8:797-811

144. Moses JC et al (2019) Synergistic effects of silicon/ zinc doped brushite and silk scaffolding in augmenting the osteogenic and angiogenic potential of composite biomimetic bone grafts. ACS Biomater Sci Eng 5(3):1462-1475

145. Lamboni L, Gauthier M, Yang G, Wang Q (2015) Silk sericin: a versatile material for tissue engineering and drug delivery. Biotechnol Adv 33:1855-1867

146. Liu $\mathrm{H}$ et al (2007) Modification of sericin-free silk fibers for ligament tissue engineering application. J Biomed Mater Res B Appl Biomater 82:129-138

147. Choudhury AJ et al (2016) Controlled antibioticreleasing Antheraea assama silk fibroin suture for infection prevention and fast wound healing. Surgery 159:539-547

148. Yang Y et al (2007) Development and evaluation of silk fibroin-based nerve grafts used for peripheral nerve regeneration. Biomaterials 28:5526-5535

149. Li G et al (2013) A 5-fluorouracil-loaded polydioxanone weft-knitted stent for the treatment of colorectal cancer. Biomaterials 34:9451-9461

150. Mandal BB, Kundu SC (2010) Biospinning by silkworms: silk fiber matrices for tissue engineering applications. Acta Biomater 6:360-371

151. Roloff F, Strauß S, Vogt PM, Bicker G, Radtke C (2014) Spider silk as guiding biomaterial for human model neurons. BioMed Res Int 2014:906819. https://doi. org/10.1155/2014/906819

152. Hennecke $\mathrm{K}$ et al (2013) Bundles of spider silk, braided into sutures, resist basic cyclic tests: potential use for flexor tendon repair. PLoS One 8:e61100

153. Doblhofer E, Heidebrecht A, Scheibel T (2015) To spin or not to spin: spider silk fibers and more. Appl Microbiol Biotechnol 99:9361-9380

154. Bhattacharjee P et al (2015) Nanofibrous nonmulberry silk/PVA scaffold for osteoinduction and osseointegration. Biopolymers 103:271-284

155. Reardon PJT, Konwarh R, Knowles JC, Mandal BB (2017) Mimicking hierarchical complexity of the osteochondral interface using electrospun silk-bioactive glass composites. ACS Appl Mater Interfaces 9:80008013. https://doi.org/10.1021/acsami.6b16590

156. He J, Cheng Y, Cui S (2013) Preparation and characterization of electrospun Antheraea pernyi silk fibroin 
nanofibers from aqueous solution. J Appl Polym Sci 128:1081-1088

157. Soffer L et al (2008) Silk-based electrospun tubular scaffolds for tissue-engineered vascular grafts. J Biomater Sci Polym Ed 19:653-664

158. Wittmer CR et al (2011) Multifunctionalized electrospun silk fibers promote axon regeneration in the central nervous system. Adv Func Mater 21:4232-4242

159. Ki CS, Gang EH, Um IC, Park YH (2007) Nanofibrous membrane of wool keratose/silk fibroin blend for heavy metal ion adsorption. J Membr Sci 302:20-26

160. Biazar E, Baradaran-Rafii A, Heidari-keshel S, Tavakolifard S (2015) Oriented nanofibrous silk as a natural scaffold for ocular epithelial regeneration. J Biomater Sci Polym Ed 26:1139-1151

161. Manchineella $S$ et al (2016) Pigmented silk nanofibrous composite for skeletal muscle tissue engineering. Adv Healthc Mater 5:1222-1232

162. Dinis TM et al (2014) Method to form a fiber/growth factor dual-gradient along electrospun silk for nerve regeneration. ACS Appl Mater Interfaces 6:16817-16826

163. Hang Y, Zhang Y, Jin Y, Shao H, Hu X (2012) Preparation of regenerated silk fibroin/silk sericin fibers by coaxial electrospinning. Int J Biol Macromol 51:980-986

164. Gilotra S, Chouhan D, Bhardwaj N, Nandi SK, Mandal BB (2018) Potential of silk sericin based nanofibrous mats for wound dressing applications. Mater Sci Eng C 90:420-432

165. Shehata $\mathrm{N}$ et al (2018) Piezoresponse, mechanical, and electrical characteristics of synthetic spider silk nanofibers. Nanomaterials 8:585

166. Bessa PC et al (2010) Silk fibroin microparticles as carriers for delivery of human recombinant BMPs. Physical characterization and drug release. J Tissue Eng Regen Med 4:349-355

167. Bhardwaj N, Rajkhowa R, Wang X, Devi D (2015) Milled non-mulberry silk fibroin microparticles as biomaterial for biomedical applications. Int J Biol Macromol 81:31-40

168. Zhang Y-Q et al (2004) Immobilization of L-asparaginase on the microparticles of the natural silk sericin protein and its characters. Biomaterials 25:3751-3759

169. Lammel A, Schwab M, Slotta U, Winter G, Scheibel T (2008) Processing conditions for the formation of spider silk microspheres. ChemSusChem 1:413-416

170. Lucke $\mathrm{M}$ et al (2018) Engineered hybrid spider silk particles as delivery system for peptide vaccines. Biomaterials 172:105-115

171. Chen J, Hu J, Zuo P, Shi J, Yang M (2018) Facile preparation of recombinant spider eggcase silk spheres via an HFIP-on-Oil approach. Int J Biol Macromol 116:1146-1152

172. Mehrotra S et al (2019) A comprehensive review on silk at nanoscale for regenerative medicine and allied applications. ACS Biomat Sci Eng 5(5):2054-2078
173. Cho KY et al (2003) Preparation of self-assembled silk sericin nanoparticles. Int J Biol Macromol 32:36-42

174. Kanoujia J, Singh M, Singh P, Saraf SA (2016) Novel genipin crosslinked atorvastatin loaded sericin nanoparticles for their enhanced antihyperlipidemic activity. Mater Sci Eng C 69:967-976

175. Hofer M, Winter G, Myschik J (2012) Recombinant spider silk particles for controlled delivery of protein drugs. Biomaterials 33:1554-1562

176. Zhang Y et al (2018) “Genetically Engineered" biofunctional triboelectric nanogenerators using recombinant spider silk. Adv Mater 30:1805722

177. Bhunia BK, Mandal BB (2019) Exploring gelation and physicochemical behavior of in situ bioresponsive silk hydrogels for disc degeneration therapy. ACS Biomater Sci Eng

178. Floren M, Migliaresi C, Motta A (2016) Processing techniques and applications of silk hydrogels in bioengineering. J Funct Biomater 7:26

179. Kumari S, Bargel H, Anby MU, Lafargue D, Scheibel $\mathrm{T}$ (2018) Recombinant spider silk hydrogels for sustained release of biologicals. ACS Biomater Sci Eng 4:1750-1759

180. Schacht K, Scheibel T (2011) Controlled hydrogel formation of a recombinant spider silk protein. Biomacromol 12:2488-2495

181. Ghosh S, Parker ST, Wang X, Kaplan DL, Lewis JA (2008) Direct-write assembly of microperiodic silk fibroin scaffolds for tissue engineering applications. Adv Func Mater 18:1883-1889

182. Jose RR, Brown JE, Polido KE, Omenetto FG, Kaplan DL (2015) Polyol-silk bioink formulations as two-part room-temperature curable materials for $3 \mathrm{D}$ printing. ACS Biomater Sci Eng 1:780-788

183. Chameettachal S, Midha S, Ghosh S (2016) Regulation of chondrogenesis and hypertrophy in silk fibroin-gelatin-based 3D bioprinted constructs. ACS Biomater Sci Eng 2:1450-1463

184. Zheng $\mathrm{Z}$ et al (2018) 3D Bioprinting of self-standing silk-based bioink. Adv Healthc Mater 7:1701026

185. Parker ST et al (2009) Biocompatible silk printed optical waveguides. Adv Mater 21:2411-2415

186. Chawla S, Midha S, Sharma A, Ghosh S (2018) Silkbased bioinks for 3D bioprinting. Adv Healthc Mater 7:1701204

187. Schacht $\mathrm{K}$ et al (2015) Biofabrication of cell-loaded 3D spider silk constructs. Angew Chem Int Ed 54:2816-2820

188. DeSimone E, Schacht K, Jungst T, Groll J, Scheibel T (2015) Biofabrication of 3D constructs: fabrication technologies and spider silk proteins as bioinks. Pure Appl Chem 87:737-749

189. DeSimone E, Schacht K, Pellert A, Scheibel T (2017) Recombinant spider silk-based bioinks. Biofabrication 9:044104 
190. Hamidi $Y$ et al (2018) Silk as a natural reinforcement: processing and properties of silk/epoxy composite laminates. Materials 11:2135

191. Perrone GS et al (2014) The use of silk-based devices for fracture fixation. Nat Commun 5:3385

192. Katori S, Kimura T (2002) Injection moulding of silk fiber reinforced biodegradable composites. WIT Transact Built Environ 59:97-105

193. Suryavanshi A, Khanna K, Sindhu K, Bellare J, Srivastava R (2019) Development of bone screw using novel biodegradable composite orthopedic biomaterial: From material design to in vitro biomechanical and in vivo biocompatibility evaluation. Biomed Mater 14(4):045020

194. Konwarh R, Gupta P, Mandal BB (2016) Silk-microfluidics for advanced biotechnological applications: a progressive review. Biotechnol Adv 34:845-858

195. Sparkes J, Holland C (2017) Analysis of the pressure requirements for silk spinning reveals a pultrusion dominated process. Nature Commun 8:594

196. Rising A, Johansson J (2015) Toward spinning artificial spider silk. Nat Chem Biol 11:309

197. Andersson M, Johansson J, Rising A (2016) Silk spinning in silkworms and spiders. Int J Mol Sci 17:1290

198. Wegst UG, Bai H, Saiz E, Tomsia AP, Ritchie RO (2015) Bioinspired structural materials. Nat Mater 14:23

199. Altman GH et al (2003) Silk-based biomaterials. Biomaterials 24:401-416

200. Bhunia BK, Kaplan DL, Mandal BB (2018) Silk-based multilayered angle-ply annulus fibrosus construct to recapitulate form and function of the intervertebral disc. Proc Natl Acad Sci 115:477-482

201. Vepari C, Kaplan DL (2007) Silk as a biomaterial. Prog Polym Sci 32:991-1007

202. Yeong W-Y, Chua C-K, Leong K-F, Chandrasekaran M (2004) Rapid prototyping in tissue engineering: challenges and potential. Trends Biotechnol 22:643-652

203. Tan K et al (2003) Scaffold development using selective laser sintering of polyetheretherketone-hydroxyapatite biocomposite blends. Biomaterials 24:3115-3123

204. Zein I, Hutmacher DW, Tan KC, Teoh SH (2002) Fused deposition modeling of novel scaffold architectures for tissue engineering applications. Biomaterials 23:1169-1185

205. Vozzi G, Previti A, De Rossi D, Ahluwalia A (2002) Microsyringe-based deposition of two-dimensional and three-dimensional polymer scaffolds with a welldefined geometry for application to tissue engineering. Tissue Eng 8:1089-1098

206. Mir TA, Nakamura M (2017) Three-dimensional bioprinting: toward the era of manufacturing human organs as spare parts for healthcare and medicine. Tissue Eng Part B Rev 23:245-256

207. Yeo I-S et al (2008) Collagen-based biomimetic nanofibrous scaffolds: preparation and characterization of collagen/silk fibroin bicomponent nanofibrous structures. Biomacromol 9:1106-1116

208. Reardon P, Konwarh R, Knowles J, Mandal B (2017) Mimicking hierarchical complexity of the osteochondral interface using electrospun silk-bioactive glass composites. ACS Appl Mater Interfaces 9:8000-8013

209. Roh D-H et al (2006) Wound healing effect of silk fibroin/alginate-blended sponge in full thickness skin defect of rat. J Mater Sci Mater Med 17:547-552

210. Chlapanidas $\mathrm{T}$ et al (2013) Formulation and characterization of silk fibroin films as a scaffold for adiposederived stem cells in skin tissue engineering. Int J Immunopathol Pharmacol 26:43-49

211. Chao PHG et al (2010) Silk hydrogel for cartilage tissue engineering. J Biomed Mater Res B Appl Biomater 95:84-90

212. Yodmuang S et al (2015) Silk microfiber-reinforced silk hydrogel composites for functional cartilage tissue repair. Acta Biomater 11:27-36

213. Ribeiro M et al (2015) Development of silk fibroin/ nanohydroxyapatite composite hydrogels for bone tissue engineering. Eur Polymer J 67:66-77

214. Sommer MR et al (2017) Silk fibroin scaffolds with inverse opal structure for bone tissue engineering. J Biomed Mater Res B Appl Biomater 105:2074-2084

215. Das $S$ et al (2015) Bioprintable, cell-laden silk fibroingelatin hydrogel supporting multilineage differentiation of stem cells for fabrication of three-dimensional tissue constructs. Acta Biomater 11:233-246

216. Rodriguez MJ et al (2017) Silk based bioinks for soft tissue reconstruction using 3-dimensional (3D) printing with in vitro and in vivo assessments. Biomaterials 117:105-115

217. Hong N, Yang GH, Lee J, Kim G (2018) 3D bioprinting and its in vivo applications. J Biomed Mater Res B Appl Biomater 106:444-459

218. Xiong S et al (2017) A gelatin-sulfonated silk composite scaffold based on 3D printing technology enhances skin regeneration by stimulating epidermal growth and dermal neovascularization. Sci Rep 7:4288

219. Compaan AM, Christensen K, Huang Y (2016) Inkjet bioprinting of 3D silk fibroin cellular constructs using sacrificial alginate. ACS Biomater Sci Eng 3:1519-1526

220. Li Z et al (2018) 3D-printed scaffolds with calcified layer for osteochondral tissue engineering. J Biosci Bioeng 126:389-396

221. Finkemeier CG (2002) Bone-grafting and bone-graft substitutes. JBJS 84:454-464

222. Yaszemski MJ, Payne RG, Hayes WC, Langer R, Mikos AG (1996) Evolution of bone transplantation: molecular, cellular and tissue strategies to engineer human bone. Biomaterials 17:175-185

223. Salgado AJ, Coutinho OP, Reis RL (2004) Bone tissue engineering: state of the art and future trends. Macromol Biosci 4:743-765 
224. Meinel L et al (2006) Osteogenesis by human mesenchymal stem cells cultured on silk biomaterials: comparison of adenovirus mediated gene transfer and protein delivery of BMP-2. Biomaterials 27:4993-5002

225. Zhao J et al (2009) Apatite-coated silk fibroin scaffolds to healing mandibular border defects in canines. Bone 45:517-527

226. Leukers B et al (2005) Hydroxyapatite scaffolds for bone tissue engineering made by $3 \mathrm{D}$ printing. J Mater Sci Mater Med 16:1121-1124

227. Liu L et al (2008) Preparation and characterization of nano-hydroxyapatite/silk fibroin porous scaffolds. J Biomater Sci Polym Ed 19:325-338

228. Wang $\mathrm{G}$ et al (2010) The use of silk fibroin/hydroxyapatite composite co-cultured with rabbit bone-marrow stromal cells in the healing of a segmental bone defect. J Bone Joint Surg Br 92:320-325

229. Kirker-Head C et al (2007) BMP-silk composite matrices heal critically sized femoral defects. Bone 41:247-255

230. Bhumiratana $S$ et al (2011) Nucleation and growth of mineralized bone matrix on silk-hydroxyapatite composite scaffolds. Biomaterials 32:2812-2820

231. Singh YP, Moses JC, Bhunia BK, Nandi SK, Mandal BB (2018) Hierarchically structured seamless silk scaffolds for osteochondral interface tissue engineering. J Mater Chem B 6:5671-5688

232. Bhardwaj N, Chouhan D, Mandal BB (2017) Tissue engineered skin and wound healing: current strategies and future directions. Curr Pharm Des 23:3455-3482

233. Boyce ST, Lalley AL (2018) Tissue engineering of skin and regenerative medicine for wound care. Burns Trauma 6:4

234. Abrigo M, McArthur SL, Kingshott P (2014) Electrospun nanofibers as dressings for chronic wound care: advances, challenges, and future prospects. Macromol Biosci 14:772-792

235. Vasconcelos A, Cavaco-Paulo A (2011) Wound dressings for a proteolytic-rich environment. Appl Microbiol Biotechnol 90:445-460

236. Mogoşanu GD, Grumezescu AM (2014) Natural and synthetic polymers for wounds and burns dressing. Int J Pharm 463:127-136

237. Chung C, Burdick JA (2008) Engineering cartilage tissue. Adv Drug Deliv Rev 60:243-262

238. Wang Y, Kim U-J, Blasioli DJ, Kim H-J, Kaplan DL (2005) In vitro cartilage tissue engineering with 3D porous aqueous-derived silk scaffolds and mesenchymal stem cells. Biomaterials 26:7082-7094

239. Makaya K, Terada S, Ohgo K, Asakura T (2009) Comparative study of silk fibroin porous scaffolds derived from salt/water and sucrose/hexafluoroisopropanol in cartilage formation. J Biosci Bioeng 108:68-75

240. Hofmann $S$ et al (2006) Cartilage-like tissue engineering using silk scaffolds and mesenchymal stem cells. Tissue Eng 12:2729-2738
241. Shangkai C et al (2007) Transplantation of allogeneic chondrocytes cultured in fibroin sponge and stirring chamber to promote cartilage regeneration. Tissue Eng 13:483-492

242. Singh YP, Bhardwaj N, Mandal BB (2016) Potential of agarose/silk fibroin blended hydrogel for in vitro cartilage tissue engineering. ACS Appl Mater Interfaces 8:21236-21249

243. Song H-HG, Rumma RT, Ozaki CK, Edelman ER, Chen CS (2018) Vascular tissue engineering: progress, challenges, and clinical promise. Cell Stem Cell 22:340-354

244. Unger R et al (2004) Endothelialization of a non-woven silk fibroin net for use in tissue engineering: growth and gene regulation of human endothelial cells. Biomaterials 25:5137-5146

245. Lovett $\mathrm{M}$ et al (2010) Tubular silk scaffolds for small diameter vascular grafts. Organogenesis 6:217-224

246. McClure MJ, Simpson DG, Bowlin GL (2012) Trilayered vascular grafts composed of polycaprolactone, elastin, collagen, and silk: optimization of graft properties. J Mech Behav Biomed Mater 10:48-61

247. Enomoto S et al (2010) Long-term patency of smalldiameter vascular graft made from fibroin, a silk-based biodegradable material. J Vasc Surg 51:155-164

248. Mehrotra S, Nandi SK, Mandal BB (2017) Stacked silkcell monolayers as a biomimetic three dimensional construct for cardiac tissue reconstruction. J Mater Chem B 5:6325-6338

249. Engler AJ, Sen S, Sweeney HL, Discher DE (2006) Matrix elasticity directs stem cell lineage specification. Cell 126:677-689

250. Patra C et al (2012) Silk protein fibroin from Antheraea mylitta for cardiac tissue engineering. Biomaterials 33:2673-2680

251. Stoppel WL, Hu D, Domian IJ, Kaplan DL, Black LD III (2015) Anisotropic silk biomaterials containing cardiac extracellular matrix for cardiac tissue engineering. Biomed Mater 10:034105

252. Allen JW, Hassanein T, Bhatia SN (2001) Advances in bioartificial liver devices. Hepatology 34:447-455

253. Yu Y et al (2012) Cell therapies for liver diseases. Liver Transpl 18:9-21

254. Sokal EM et al (2003) Hepatocyte transplantation in a 4-year-old girl with peroxisomal biogenesis disease: technique, safety, and metabolic follow-up1. Transplantation 76:735-738

255. Rimann M, Graf-Hausner U (2012) Synthetic 3D multicellular systems for drug development. Curr Opin Biotechnol 23:803-809

256. Miranda JP et al (2010) Extending Hepatocyte functionality for drug-testing applications using highviscosity alginate-encapsulated three-dimensional cultures in bioreactors. Tissue Eng Part C Methods 16:1223-1232 
257. Cirillo B, Morra M, Catapano G (2004) Adhesion and function of rat liver cells adherent to silk fibroin/collagen blend films. Int J Artif Org 27:60-68

258. She Z, Liu W, Feng Q (2010) Silk fibroin/chitosan/heparin scaffold: preparation, antithrombogenicity and culture with hepatocytes. Polym Int 59:55-61

259. Lv Q, Hu K, Feng Q, Cui F, Cao C (2007) Preparation and characterization of PLA/fibroin composite and culture of HepG2 (human hepatocellular liver carcinoma cell line) cells. Compos Sci Technol 67:3023-3030

260. Boldrin L et al (2007) Satellite cells delivered by micropatterned scaffolds: a new strategy for cell transplantation in muscle diseases. Tissue Eng 13:253-262

261. Sleep E et al (2017) Injectable biomimetic liquid crystalline scaffolds enhance muscle stem cell transplantation. Proc Natl Acad Sci 114:E7919-E7928

262. Sarrafian TL, Bodine SC, Murphy B, Grayson JK, Stover SM (2018) Extracellular matrix scaffolds for treatment of large volume muscle injuries: a review. Vet Surg 47:524-535

263. Zhang M, Guo B (2017) Electroactive 3D scaffolds based on silk fibroin and water-borne polyaniline for Skeletal muscle tissue engineering. Macromol Biosci 17:1700147

264. Shuang L, Quan L, Xiu-fa T, Yang F, Deng-qi H (2011) cytocompatibility of electro-spinning nano-fibrous scaffolds for skeletal muscle tissue engineering. J Clin Rehabil Tissue Eng Res 15:2171-2174

265. Yang G, Rothrauff BB, Tuan RS (2013) Tendon and ligament regeneration and repair: clinical relevance and developmental paradigm. Birth Defects Res Part C Embryo Today Rev 99:203-222

266. Liu H, Fan H, Toh SL, Goh JC (2008) A comparison of rabbit mesenchymal stem cells and anterior cruciate ligament fibroblasts responses on combined silk scaffolds. Biomaterials 29:1443-1453

267. Altman GH et al (2002) Silk matrix for tissue engineered anterior cruciate ligaments. Biomaterials 23:4131-4141

268. Sharifi-Aghdam M, Faridi-Majidi R, Derakhshan MA, Chegeni A, Azami M (2017) Preparation of collagen/ polyurethane/knitted silk as a composite scaffold for tendon tissue engineering. Proc Inst Mech Eng [H] 231:652-662

269. Chen JL et al (2010) Efficacy of hESC-MSCs in knitted silk-collagen scaffold for tendon tissue engineering and their roles. Biomaterials 31:9438-9451

270. Chen X et al (2014) Scleraxis-overexpressed human embryonic stem cell-derived mesenchymal stem cells for tendon tissue engineering with knitted silk-collagen scaffold. Tissue Eng Part A 20:1583-1592

271. Hu Y et al (2016) Application of silk-based tissue engineering scaffold for tendon/ligament regeneration. Zhejiang da xue xue bao Yi xue ban J Zhejiang Univ Med Sci 45:152-160
272. Billy G, Lemieux S, Chow M (2016) Changes in lumbar disk morphology associated with prolonged sitting assessed by magnetic resonance imaging. PMR 6(9):790-795. https://doi.org/10.1016/j. pmrj.2014.02.014

273. Maniadakis N, Gray A (2000) The economic burden of back pain in the UK. Pain 84:95-103

274. Daly C, Ghosh P, Jenkin G, Oehme D, Goldschlager T (2016) A review of animal models of intervertebral disc degeneration: pathophysiology, regeneration, and translation to the clinic. BioMed Res Int 2016:5952165. https://doi.org/10.1155/2016/5952165

275. Stergar J, Gradisnik L, Velnar T, Maver U (2019) Intervertebral disc tissue engineering: a brief review. Bosnian J Basic Med Sci 19(2):130

276. Park S-H et al (2011) Intervertebral disk tissue engineering using biphasic silk composite scaffolds. Tissue Eng Part A 18:447-458

277. Du L et al (2014) A novel integrated biphasic silk fibroin scaffold for intervertebral disc tissue engineering. Mater Lett 117:237-240

278. Mandal BB, Park S-H, Gil ES, Kaplan DL (2011) Multilayered silk scaffolds for meniscus tissue engineering. Biomaterials 32:639-651

279. Walker PS, Erkman MJ (1975) The role of the menisci in force transmission across the knee. Clin Orthop Relat Res 109:184-192

280. Grassi A, Zaffagnini S, Muccioli GMM, Benzi A, Marcacci M (2014) Clinical outcomes and complications of a collagen meniscus implant: a systematic review. Int Orthop 38:1945-1953

281. Hansen RT, Choi G, Bryk E, Vigorita VJ (2011) The human knee meniscus: a review with special focus on the collagen meniscal implant. J Long Term Eff Med Implants 21(4):321-337

282. Welsing RT et al (2008) Effect on tissue differentiation and articular cartilage degradation of a polymer meniscus implant: a 2-year follow-up study in dogs. Am J Sports Med 36:1978-1989

283. Lee $\mathrm{CH}$ et al (2014) Protein-releasing polymeric scaffolds induce fibrochondrocytic differentiation of endogenous cells for knee meniscus regeneration in sheep. Sci Transl Med 6:266ra171

284. Kobayashi M, Chang Y-S, Oka M (2005) A 2 year in vivo study of polyvinyl alcohol-hydrogel (PVA-H) artificial meniscus. Biomaterials 26:3243-3248

285. Mandal BB, Park S-H, Gil ES, Kaplan DL (2011) Stem cell-based meniscus tissue engineering. Tissue Eng Part A 17:2749-2761

286. Schmidt CE, Leach JB (2003) Neural tissue engineering: strategies for repair and regeneration. Annu Rev Biomed Eng 5:293-347

287. Liu X, Bai S, Zhao H (2014) Silk fibroin-based scaffold for neural tissue engineering. J Biomat Tissue Eng 4:1012-1018 
288. Subia B, Rao RR, Kundu SC (2015) Silk 3D matrices incorporating human neural progenitor cells for neural tissue engineering applications. Polym J 47:819

289. Wang $Y$ et al (2016) Electrospun, reinforcing networkcontaining, silk fibroin-based nerve guidance conduits for peripheral nerve repair. J Biomater Tissue Eng 6:53-60

290. Zhao Y-H et al (2018) Novel conductive polypyrrole/ silk fibroin scaffold for neural tissue repair. Neural Regen Res 13:1455

291. Gao M et al (2016) Electrospun silk fibroin/polycaprolactone biomimetic scaffold for peripheral nerve regeneration. J Biomater Tissue Eng 6:902-909

292. Kumar N, Joisher H, Ganguly A (2018) Polymeric Scaffolds for pancreatic tissue engineering: a review. Rev Diabet Stud RDS 14:334-353

293. Qiu Y, Park K (2001) Environment-sensitive hydrogels for drug delivery. Adv Drug Deliv Rev 53:321-339

294. Vaithilingam V, Tuch BE (2011) Islet transplantation and encapsulation: an update on recent developments. Rev Diabet Stud RDS 8:51

295. Davis NE et al (2012) Enhanced function of pancreatic islets co-encapsulated with ECM proteins and mesenchymal stromal cells in a silk hydrogel. Biomaterials 33:6691-6697

296. Hamilton DC et al (2017) A silk-based encapsulation platform for pancreatic islet transplantation improves islet function in vivo. J Tissue Eng Regen Med 11:887-895

297. Jastrzebska $\mathrm{K}$ et al (2015) Silk as an innovative biomaterial for cancer therapy. Rep Pract Oncol Radiother 20:87-98

298. Seib FP, Kaplan DL (2012) Doxorubicin-loaded silk films: drug-silk interactions and in vivo performance in human orthotopic breast cancer. Biomaterials 33:8442-8450

299. Chiu B et al (2014) Surgery combined with controlledrelease doxorubicin silk films as a treatment strategy in an orthotopic neuroblastoma mouse model. Br J Cancer 111:708

300. Seib FP, Pritchard EM, Kaplan DL (2013) Self-assembling doxorubicin silk hydrogels for the focal treatment of primary breast cancer. Adv Func Mater 23:58-65

301. Wu P et al (2013) Facile preparation of paclitaxel loaded silk fibroin nanoparticles for enhanced antitumor efficacy by locoregional drug delivery. ACS Appl Mater Interfaces 5:12638-12645

302. Xia X-X, Wang M, Lin Y, Xu Q, Kaplan DL (2014) Hydrophobic drug-triggered self-assembly of nanoparticles from silk-elastin-like protein polymers for drug delivery. Biomacromol 15:908-914

303. Cheema SK et al (2007) Silk fibroin mediated delivery of liposomal emodin to breast cancer cells. Int J Pharm 341:221-229

304. Gupta V, Aseh A, Ríos CN, Aggarwal BB, Mathur $A B$ (2009) Fabrication and characterization of silk fibroin-derived curcumin nanoparticles for cancer therapy. Int J Nanomed 4:115

305. Dondajewska E, Juzwa W, Mackiewicz A, DamsKozlowska H (2018) Heterotypic breast cancer model based on a silk fibroin scaffold to study the tumor microenvironment. Oncotarget 9:4935

306. Tan PH, Aung K, Toh S, Goh JC, Nathan S (2011) Three-dimensional porous silk tumor constructs in the approximation of in vivo osteosarcoma physiology. Biomaterials 32:6131-6137

307. Kundu B, Saha P, Datta K, Kundu SC (2013) A silk fibroin based hepatocarcinoma model and the assessment of the drug response in hyaluronan-binding protein 1 overexpressed HepG2 cells. Biomaterials 34:9462-9474

308. Talukdar S et al (2011) Engineered silk fibroin protein $3 \mathrm{D}$ matrices for in vitro tumor model. Biomaterials 32:2149-2159

309. Reagan MR et al (2012) Stem cell implants for cancer therapy: TRAIL-expressing mesenchymal stem cells target cancer cells in situ. J Breast Cancer 15:273-282

310. Sontheimer-Phelps A, Hassell BA, Ingber DE (2019) Modelling cancer in microfluidic human organs-onchips. Nat Rev Cancer 19(2):65-81

311. Cheng W, Klauke N, Sedgwick H, Smith GL, Cooper JM (2006) Metabolic monitoring of the electrically stimulated single heart cell within a microfluidic platform. Lab Chip 6:1424-1431

312. Alexander F, Eggert S, Wiest J (2018) Skin-on-a-chip: transepithelial electrical resistance and extracellular acidification measurements through an automated airliquid interface. Genes 9:114

313. Huh D et al (2010) Reconstituting organ-level lung functions on a chip. Science 328:1662-1668

314. Lee J, Kim S (2018) Kidney-on-a-Chip: a new technology for predicting drug efficacy, interactions, and druginduced nephrotoxicity. Curr Drug Metab 19:577-583

315. Günther A et al (2010) A microfluidic platform for probing small artery structure and function. Lab Chip 10:2341-2349

316. Huh D, Hamilton G, Ingber D, Program B (2011) From three-dimensional cell culture to organs-on-chips. Dongeun Trends Cell Biol 21:745-754

317. Zhao $S$ et al (2016) Bio-functionalized silk hydrogel microfluidic systems. Biomaterials 93:60-70

318. Tao $\mathrm{H}$ et al (2015) Inkjet printing of regenerated silk fibroin: From printable forms to printable functions. Adv Mater 27:4273-4279

319. Yin H, Ai S, Xu J, Shi W, Zhu L (2009) Amperometric biosensor based on immobilized acetylcholinesterase on gold nanoparticles and silk fibroin modified platinum electrode for detection of methyl paraoxon, carbofuran and phoxim. J Electroanal Chem 637:21-27

320. Burrs $\mathrm{S}$ et al (2015) A comparative study of graphenehydrogel hybrid bionanocomposites for biosensing. Analyst 140:1466-1476 
321. Tao $\mathrm{H}$ et al (2012) Silk-based conformal, adhesive, edible food sensors. Adv Mater 24:1067-1072

322. Parker ST et al (2009) Biocompatible silk printed optical waveguides. Adv Mater 21:2411-2415

323. Tao H, Kaplan DL, Omenetto FG (2012) Silk materials-a road to sustainable high technology. Adv Mater 24:2824-2837

324. Zhou $\mathrm{Z}$ et al (2017) The use of functionalized silk fibroin films as a platform for optical diffraction-based sensing applications. Adv Mater 29:1605471

325. Tao $\mathrm{H}$ et al (2010) Metamaterial silk composites at terahertz frequencies. Adv Mater 22:3527-3531

326. Xu L et al (2016) High-Q silk fibroin whispering gallery microresonator. Optic Exp 24:20825-20830

327. Khalid A et al (2015) Fluorescent nanodiamond silk fibroin spheres: advanced nanoscale bioimaging tool. ACS Biomater Sci Eng 1:1104-1113

328. Gao H et al (2017) Microwave assisted synthesis of luminescent carbonaceous nanoparticles from silk fibroin for bioimaging. Mater Sci Eng 80:616-623

329. Wu ZL et al (2013) One-pot hydrothermal synthesis of highly luminescent nitrogen-doped amphoteric carbon dots for bioimaging from Bombyx mori silk-natural proteins. J Mater Chem 1:2868-2873

330. Roy M et al (2014) Graphene oxide from silk cocoon: a novel magnetic fluorophore for multi-photon imaging. 3 Biotech 4:67-75

331. FAO (2011) Global food losses and food waste - Extent, causes and prevention, Rome. http://www.fao.org/3/ai2697e.pdf. Accessed 18 Aug 2019

332. Kumar J, Mandal B (2019) Inhibitory role of silk cocoon extract against elastase, hyaluronidase and UV radiation-induced matrix metalloproteinase expression in human dermal fibroblasts and keratinocytes. Photochem Photobiol Sci 18(5):1259-1274

333. Lawrence BD, Pan Z, Liu A, Kaplan DL, Rosenblatt MI (2012) Human corneal limbal epithelial cell response to varying silk film geometric topography in vitro. Acta Biomater 8:3732-3743

334. Lawrence BD et al (2010) Effect of hydration on silk film material properties. Macromol Biosci 10:393-403

335. Marelli B, Brenckle M, Kaplan DL, Omenetto FG (2016) Silk fibroin as edible coating for perishable food preservation. Sci Rep 6:25263

336. Pritchard EM et al (2014) Encapsulation of oil in silk fibroin biomaterials. J Appl Polym Sci 131(6). https:// doi.org/10.1002/app.39990

337. Valentini L, Bittolo Bon S, Pugno N (2018) Combining living microorganisms with regenerated silk provides nanofibril-based thin films with heat-responsive wrinkled states for smart food packaging. Nanomaterials $8: 518$

338. Baycin D, Altiok E, Ülkü S, Bayraktar O (2007) Adsorption of olive leaf (Olea europaea L.) antioxidants on silk fibroin. J Agric Food Chem 55:1227-1236
339. Joseph B, Raj SJ (2012) Therapeutic applications and properties of silk proteins from Bombyx mori. Front Life Sci 6:55-60

340. Rangi A, Jajpura L (2015) The biopolymer sericin: extraction and applications. J Text Sci Eng 5:1-5

341. Sasaki M, Yamada H, Kato N (2000) Consumption of silk protein, sericin elevates intestinal absorption of zinc, iron, magnesium and calcium in rats. Nutr Res 20:1505-1511

342. Kato $\mathrm{N}$ et al (1998) Silk protein, sericin, inhibits lipid peroxidation and tyrosinase activity. Biosci Biotechnol Biochem 62:145-147

343. Agyei D, Kasargod B, He L (2014) A scalable bioprocess for degradation of dairy proteins using immobilized cell-envelope proteinases. In: Chemeca 2014: processing excellence; powering our future. Engineers Australia, Barton, ACT, pp 790-803

344. Kurioka A, Yamazaki M (2002) Purification and identification of flavonoids from the yellow green cocoon shell (Sasamayu) of the silkworm, Bombyx mori. Biosci Biotechnol Biochem 66:1396-1399

345. Takechi T, Takamura H (2014) Development of bread supplemented with the silk protein sericin. Food Sci Technol Res 20:1021-1026

346. Seul G K (2018) Manufacturing method of baby food having silk protein. Korean patent, KR101882229(B1), granted: July 26

347. Ji SD; Kim KY; Kim NS; Kweon HY; Kang PD; Kim MJ; Ko YH; Kim AY; Rural Dev Administration (Rura-C) Univ Hallym Ind Academic Coop Found (Uyhm-C) (2017) Composition comprising silkworm having silk protein for preventing or treating Parkinson's disease. South Korean Patent, KR101793552B1, granted: November 3

348. Grayson ACR et al (2004) A BioMEMS review: MEMS technology for physiologically integrated devices. Proc IEEE 92:6-21

349. Ledet EH et al (2012) Implantable sensor technology: from research to clinical practice. JAAOS J Am Acad Orthop Surg 20:383-392

350. Hwang S-W et al (2012) A physically transient form of silicon electronics. Science 337:1640-1644

351. Kim D-H et al (2009) Silicon electronics on silk as a path to bioresorbable, implantable devices. Appl Phys Lett 95:133701

352. Hsieh C-Y et al (2013) Enhanced mobility of organic thin film transistors by water absorption of collagen hydrolysate gate dielectric. Appl Phys Lett 103:118_111

353. Irimia-Vladu M et al (2010) Edible electronics: biocompatible and biodegradable materials for organic fieldeffect transistors (Adv. Funct. Mater. 23/2010). Adv Funct Mater 20:4017

354. Bettinger CJ, Bao Z (2010) Organic thin-film transistors fabricated on resorbable biomaterial substrates. Adv Mater 22:651-655 
355. Tao $H$ et al (2014) Silk-based resorbable electronic devices for remotely controlled therapy and in vivo infection abatement. Proc Natl Acad Sci 111:17385-17389

356. Tang-Schomer MD et al (2014) Film-based implants for supporting neuron-electrode integrated interfaces for the brain. Adv Func Mater 24:1938-1948

357. Kim D-H et al (2010) Dissolvable films of silk fibroin for ultrathin conformal bio-integrated electronics. Nat Mater 9:511

358. Koh L-D et al (2015) Structures, mechanical properties and applications of silk fibroin materials. Prog Polym Sci 46:86-110

359. Yun YS et al (2013) Microporous carbon nanoplates from regenerated silk proteins for supercapacitors. Adv Mater 25:1993-1998

360. Wang CH, Hsieh CY, Hwang JC (2011) Flexible organic thin-film transistors with silk fibroin as the gate dielectric. Adv Mater 23:1630-1634

361. You X, Pak JJ (2014) Graphene-based field effect transistor enzymatic glucose biosensor using silk protein for enzyme immobilization and device substrate. Sens Actuator B Chem 202:1357-1365

362. Tao $\mathrm{H}$ et al (2012) Silk-based conformal, adhesive, edible food sensors. Adv Mater 24:1067-1072

363. Dattilo PP Jr, King MW, Cassill NL, Leung JC (2002) Medical textiles: application of an absorbable barbed bi-directional surgical suture. J Text Appar Technol Manag 2:1-5

364. Daniele M, Boyd D, Adams A, Ligler F (2015) Microfluidic strategies for design and assembly of microfbers and nanofbers with tissue engineering and regenerative medicine applications. Adv Healthcare Mater 4:11-28

365. Williams DF (1986) Definitions in biomaterials: proceedings of a consensus conference of the European society for biomaterials, vol 4, Chester, England, March 3-5, 1986. European Society for Biomaterials

366. Liu S et al (2013) Bilayered vascular grafts based on silk proteins. Acta Biomater 9:8991-9003

367. Wang Y, Blasioli DJ, Kim H-J, Kim HS, Kaplan DL (2006) Cartilage tissue engineering with silk scaffolds and human articular chondrocytes. Biomaterials 27:4434-4442

368. Wang M, Yu JH, Kaplan DL, Rutledge GC (2006) Production of submicron diameter silk fibers under benign processing conditions by two-fluid electrospinning. Macromolecules 39:1102-1107

369. Altman GH et al (2003) Silk-based biomaterials. Biomaterials 24:401-416

370. Wang X, Kluge JA, Leisk GG, Kaplan DL (2008) Sonication-induced gelation of silk fibroin for cell encapsulation. Biomaterials 29:1054-1064. https://doi. org/10.1016/j.biomaterials.2007.11.003

371. Hu X et al (2010) Biomaterials from ultrasonicationinduced silk fibroin-hyaluronic acid hydrogels. Biomacromol 11:3178-3188
372. Hardy JG, Scheibel TR (2010) Composite materials based on silk proteins. Prog Polym Sci 35:1093-1115

373. Vendrely C, Scheibel T (2007) Biotechnological production of spider-silk proteins enables new applications. Macromol Biosci 7:401-409

374. Gil ES, Panilaitis B, Bellas E, Kaplan DL (2013) Functionalized silk biomaterials for wound healing. Adv Healthc Mater 2:206-217

375. Xia Y, Gao G, Li Y (2009) Preparation and properties of nanometer titanium dioxide/silk fibroin blend membrane. J Biomed Mater Res Part B Appl Biomater Off J Soc Biomater Jpn Soc Biomater Aus Soc Biomater Korean Soc Biomater 90:653-658

376. Kanokpanont S, Damrongsakkul S, Ratanavaraporn J, Aramwit P (2013) Physico-chemical properties and efficacy of silk fibroin fabric coated with different waxes as wound dressing. Int J Biol Macromol 55:88-97

377. Kanokpanont S, Damrongsakkul S, Ratanavaraporn J, Aramwit P (2012) An innovative bi-layered wound dressing made of silk and gelatin for accelerated wound healing. Int J Pharm 436:141-153

378. Lee KH, Baek DH, Ki CS, Park YH (2007) Preparation and characterization of wet spun silk fibroin/poly (vinyl alcohol) blend filaments. Int J Biol Macromol 41:168-172

379. Gulrajani M, Gupta D, Periyasamy S, Muthu S (2008) Preparation and application of silver nanoparticles on silk for imparting antimicrobial properties. J Appl Polym Sci 108:614-623

380. Viju S, Thilagavathi G (2013) Characterization of tetracycline hydrochloride drug incorporated silk sutures. J Text Inst 104:289-294

381. Sultan MT et al (2019) Recirculating peritoneal dialysis system using urease-fixed silk fibroin membrane filter with spherical carbonaceous adsorbent. Mater Sci Eng, C 97:55-66

382. Ricci G et al (2004) Clinical effectiveness of a silk fabric in the treatment of atopic dermatitis. Br J Dermatol 150:127-131

383. Sha L-Z, Zhao H-F, Xiao G-N (2013) Photocatalytic degradation of formaldehyde by silk mask paper loading nanometer titanium dioxide. Fibers and Polymers 14:976-981

384. Sha L, Zhao H (2012) Preparation and properties of Nano-TiO 2 photo-catalytic silk respirator paper. Fibers Polym 13:1159-1164

385. Gold J (2005) Surface modification of biomaterials from an academic research perspective. Eur Cell Mater 10:2

386. Cassinelli C et al (2006) Physical-chemical and biological characterization of silk fibroin-coated porous membranes for medical applications. Int J Artif Organs 29:881

387. Lee K, Kong S, Park W, Ha W, Kwon IC (1998) Effect of surface properties on the antithrombogenicity of silk 
fibroin/S-carboxymethyl kerateine blend films. J Biomater Sci Polym Ed 9:905-914

388. Gogoi D et al (2011) Enhancement of hydrophobicity and tensile strength of muga silk fiber by radiofrequency Ar plasma discharge. Appl Surf Sci 258:126-135

389. Inbakumar S (2010) Effect of plasma treatment on surface of protein fabrics. J Phy Conf Series 208(1):012111

390. Chu PK, Chen J, Wang L, Huang N (2002) Plasma-surface modification of biomaterials. Mater Sci Eng R Rep 36:143-206

391. Kim KS, Ryu CM, Park CS, Sur GS, Park CE (2003) Investigation of crystallinity effects on the surface of oxygen plasma treated low density polyethylene using X-ray photoelectron spectroscopy. Polymer 44:6287-6295

392. Abbasi AR, Morsali A (2010) Formation of silver iodide nanoparticles on silk fiber by means of ultrasonic irradiation. Ultrason Sonochem 17:704-710

393. Suanpoot $P$ et al (2008) Surface analysis of hydrophobicity of Thai silk treated by SF6 plasma. Surf Coat Technol 202:5543-5549

394. Vepari CP, Kaplan DL (2006) Covalently immobilized enzyme gradients within three-dimensional porous scaffolds. Biotechnol Bioeng 93:1130-1137

395. Yamada H, Fuha Y, Yuri O, Obayashi M, Arashima T; Noevir Co Ltd; Seiren Co Ltd (1998) Promoter of collagen production, and skin preparation for external use for prevention from getting older including the same. Jpn Kokai Tokkyo Koho, JP3758794B2, granted: March 22

396. Ogawa A, Yamada H (2002) External preparation for skin. Jpn Kokai Tokkyo Koho, JP3280903B2, granted: May 13

397. Henne W, Hoppe U (1989) Light and sun screen agents. European Patent, EP0154303B1, granted: April 26

398. Sheng JY, Xu J, Zhuang Y, Sun DQ, Xing TL, Chen GQ (2013) Study on the application of sericin in cosmetics. Adv Mater Res (Trans Tech Publ) 796:416-423

399. Padamwar M, Daithankar A, Pisal S, Pawar A Evaluation of moisturizing efficiency of silk protein II: silk sericin. Sixty second World Cong of FIP, Nice (France)

400. Kirikawa M, Kasaharu T, Kishida K, Akiyama D (2000) Silk protein fine powder and its production. Jpn Kokai Tokkyo Koho, JP2000044598A, published: February 15

401. Miyashita T, Hakusan SKK (1999) Cosmetic. Jpn Kokai Tokkyo Koho, JPH11152206A, granted: June 8

402. Yamada H, Yamazuki K, Nozaki K (2009) Cosmetic. Jpn Kokai Tokkyo Koho, JP4310008B2, granted: August 5

403. Sakamoto K, Yamakishi K (2000) Detergent composition. Jpn Kokai Tokkyo Koho, JP2000073090A, granted: March 7

404. Yamada H, Yuri O (2004) Sericin-coated powder and cosmetic obtained by formulating the same powder. Jpn Kokai Tokkyo Koho, JP3494339B2, granted: February 9
405. Yoshioka M, Segawa A, Ueda A, Omi S (2010) Cosmetic formulated with filled fine microcapsule. Jpn Kokai Tokkyo Koho, JP4521792B2, granted: August 8

406. Yamada H, Yamasaki K, Zozaki K (2007) Nail cosmetics containing sericin. European Patent, EP1632214B1, granted: October 3

407. Hoppe U, Koerbaecher K, Roeckl M (1988) Cosmetic compositions containing sericin. Ger Offen, DE3233388C2, granted: June 16

408. Hata O (1987) Cosmetic compounded with liquid composition containing hydrolyzed sericin. Jpn Kokai Tokkyo Koho, JPS6236308A, granted: February 2

409. Engel W, Hoppe U (1987) Hair cosmetic medium. Ger Offen, DE3603595A1, granted: August 13

410. Pelit L, Ertaş FN, Eroğlu AE, Shahwan T, Tural H (2011) Biosorption of $\mathrm{Cu}$ (II) and $\mathrm{Pb}$ (II) ions from aqueous solution by natural spider silk. Biores Technol 102:8807-8813

411. Koley P, Sakurai M, Takei T, Aono M (2016) Facile fabrication of silk protein sericin-mediated hierarchical hydroxyapatite-based bio-hybrid architectures: excellent adsorption of toxic heavy metals and hazardous dye from wastewater. RSC Advances 6:86607-86616

412. Triped J, Sanongraj W, Oonkhanond B, Sanongraj S (2009) Synthesis of silk fibroin fiber for indoor air particulate removal. World Acad Sci Eng Technol 51:1-6

413. de Andrade JR, da Silva MGC, Gimenes ML, Vieira MGA (2018) Bioadsorption of trivalent and hexavalent chromium from aqueous solutions by sericin-alginate particles produced from Bombyx mori cocoons. Environ Sci Pollut Res 25:25967-25982

414. Gao X, Gou J, Zhang L, Duan S, Li C (2018) A silk fibroin based green nano-filter for air filtration. RSC Adv 8:8181-8189

415. Li Z et al (2018) Biomineralization-mimetic preparation of hybrid membranes with ultra-high loading of pristine metal-organic frameworks grown on silk nanofibers for hazard collection in water. J Mater Chem A 6:3402-3413

416. Ling $S$ et al (2017) Design and function of biomimetic multilayer water purification membranes. Sci Adv 3:e1601939

417. Koley P, Sakurai M, Aono M (2016) Controlled fabrication of silk protein sericin mediated hierarchical hybrid flowers and their excellent adsorption capability of heavy metal ions of $\mathrm{Pb}$ (II), $\mathrm{Cd}$ (II) and $\mathrm{Hg}$ (II). ACS Appl Mater Interfaces 8:2380-2392

418. Xiao S, Wang Z, Ma H, Yang H, Xu W (2014) Effective removal of dyes from aqueous solution using ultrafine silk fibroin powder. Adv Powder Technol 25:574-581

419. Gao A, Xie K, Song X, Zhang K, Hou A (2017) Removal of the heavy metal ions from aqueous solution using modified natural biomaterial membrane based on silk fibroin. Ecol Eng 99:343-348

420. Ajitha P et al (2017) Removal of toxic heavy metal lead (II) using chitosan oligosaccharide-graft-maleic 
anhydride/polyvinyl alcohol/silk fibroin composite. Int J Biol Macromol 104:1469-1482

421. Kwak HW, Lee KH (2018) Polyethylenimine-functionalized silk sericin beads for high-performance remediation of hexavalent chromium from aqueous solution. Chemosphere 207:507-516

422. Kwak HW, Hong Y, Lee ME, Jin H-J (2018) Sericinderived activated carbon-loaded alginate bead: an effective and recyclable natural polymer-based adsorbent for methylene blue removal. Int J Biol Macromol 120:906-914
423. Min K, Kim S, Kim S (2018) Silk protein nanofibers for highly efficient, eco-friendly, optically translucent, and multifunctional air filters. Sci Rep 8:9598

424. Patowary M, Pathak K, Ananthakrishnan R (2016) Robust superhydrophobic and oleophilic silk fibers for selective removal of oil from water surfaces. RSC Adv 6:73660-73667

425. Seal B, Otero T, Panitch A (2001) Polymeric biomaterials for tissue and organ regeneration. Mater Sci Eng R Rep 34:147-230

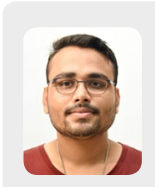

Ashutosh Bandyopadhyay is a Ph.D. scholar in Biosciences and Bioengineering Department, of Indian Institute of Technology Guwahati, under the supervision of Dr. Biman B. Mandal. He received his Bachelors in Technology from National Institute of Technology Raipur and Masters in Technology from Indian Institute of Technology (BHU), India. His research interests include 3D bioprinting, tissue engineering and biomaterials. His doctoral research is focussed on silk-based 3D bioprinting for fabrication of functional meniscus tissue engineering.

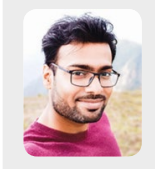

Suvro Kanti Chowdhury is a Junior Research Fellow in the Department of Biosciences and Bioengineering, IIT Guwahati, under the supervision of Prof. Biman B. Mandal. His research interests lie in utilising stem cells for various tissue engineering and regenerative medicine applications. At present, his focus is on various biomaterial-based muscle tissue engineering.

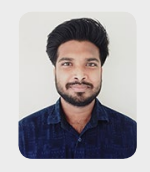

Souradeep Dey is a Ph.D. scholar in the Center for Nanotechnology, IIT Guwahati, under the supervision of Prof. Biman B. Mandal. His research interest lies in utilising 3D bioprinting and stem cells for tissue and organ fabrication. At present, his work is based on employing 3D bioprinting for corneal tissue engineering.

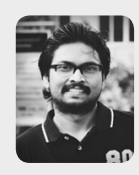

Joseph Christakiran Moses is a Ph.D. scholar in Biosciences and Bioengineering Department, IIT Guwahati, under the supervision of Prof. Biman B. Mandal. His research interests are developing 'cell instructive' resorbable, biomimetic composites and understanding bone cell biology. His doctoral thesis work is based on fabricating silk-bioceramic-based multifunctional composites for bone and osteochondral tissue engineering applications.

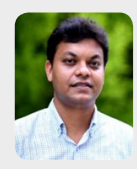

Biman B. Mandal is currently an Associate Professor in Department of Biosciences and Bioengineering at Indian Institute of Technology Guwahati, India. His research group focuses on using silk as a biomaterial for tissue engineering and regenerative medicine. His current research interests include 3D bioprinting of human tissues and organs, stem cell based regeneration, targeted anti-cancer drug delivery and development of $3 \mathrm{D}$ disease models for high-throughput drug screening applications. 